\title{
Kapitel 1: Sammeln
}

\section{Die Moskauer muzejščiki "auf den heißen Spuren der Ereignisse»}

Am Samstag, dem 29. Juni 1941, eine Woche nach dem überraschenden Angriff der Wehrmacht auf die Sowjetunion, veröffentlichte die Zeitung der Roten Armee »Roter Stern« auf ihrer Titelseite einen kurzen Artikel mit der Überschrift »Der Große Vaterländische Krieg des sowjetischen Volkes - Eine Ausstellung im Zentralmuseum der Roten Armee«. ${ }^{1}$

Wie war es den Kuratorinnen und Kuratoren des Armeemuseums gelungen, in nur wenigen Tagen eine Ausstellung zu einem Krieg aufzubauen, von dem zu diesem Zeitpunkt kaum jemand eine Vorstellung besaß?² Bei dem Artikel handelte es sich um eine Rezension der Dauerausstellung des Museums über die vergangenen Kriege des imperialen Russlands und der Sowjetunion. Er schloss mit der Ankündigung, in Kürze solle eine Ausstellung zu jenem Krieg eröffnen, der seit der Radioansprache des Volkskommissars für Äußeres Vjačeslav Molotov am 22. Juni 1941 die Bezeichnung "Großer Vaterländischer Krieg « trug. ${ }^{3}$ Der Rezensent hatte die politische Deutung eines deutschen Angriffs jedoch bereits erfasst und suggerierte seinen Leserinnen und Lesern, dass die Dauerausstellung des Museums nur militärische Invasionen eines alten und bekannten Feindes präsentiere:

»An der Wand hängt ein Plakat [...] >Der deutsche Militarismus will die russischen und ukrainischen Bauern und Arbeiter erwürgen < [...]. Hier ist ein Brief eines Schuldirektors: >Der Unterricht musste unterbrochen werden, da vor den Türen und

Ohne Autor: Velikaja otečestvennaja vojna sovetskogo naroda, Vystavka v central'nom muzee Krasnoj armii, in: Krasnaja Zvezda, 29. Juni 1941, S. 1.

2 Für die Kriegsereignisse ab Juni 1941 bis und mit der Schlacht um Moskau vgl. Braithwaite, Rodric: Moscow 1941, A City and its People at War, London 2006.

3 Am 23. Juni 1941 druckte die Zeitung »Pravda« die Radioansprache von V. Molotov. Auf der gleichen Seite befand sich ein Porträt Stalins und ein Kommentar mit dem Titel »Croßer Vaterländischer Krieg« des Redaktionsmitglieds Jaroslavskij. Vgl.: Brooks, Jeffrey: Thank you, Comrade Stalin!, S. 159. Diese Bezeichnung ist eine semantische Anknüpfung an den sogenannten »Vaterländischen Krieg« (Otečestvennaja vojna), den Russland 1812 siegreich gegen Napoleon führte. 
Fenstern der Schule das deutsche Strafkommando eine Gruppe von Arbeitern abführte.< Neben dem Brief - die Kopie des Befehls Nr. 2 des Leiters der deutschen Division in Kremenc: >Für jeden getöteten oder verwundeten deutschen Soldaten werden sofort die ersten 10 russischen Soldaten oder Zivilisten erschossen, die uns in die Hände fallen. «4

Diese narrative Verknüpfung des »Großen Vaterländischen Krieges« mit dem historischen Feind sollte den Schock über den unerwarteten Angriff des Dritten Reichs mindern, der bei der politischen Führung und den Menschen in der Sowjetunion Bestürzung und Panik auslöste. Der gegenwärtige Krieg wurde in die lange Reihe von militärischen Konflikten mit Deutschland gestellt, um Kontrolle und Siegesgewissheit zu demonstrieren. Der anonyme Autor des Artikels fasste seine Beschreibung der Ausstellung im Armeemuseum folgendermaßen zusammen: „Die gesammelten Objekte im Museum illustrieren den Kampf unseres Volkes mit den deutschen Barbaren im Verlauf der ganzen Geschichte der Russischen Staatlichkeit«. 5

Die geplante Ausstellungsarbeit wurde jedoch durch den Ausfall der vielen Mitarbeitenden, die sich spontan für den Militärdienst meldeten, verzögert. Viele muzejščiki schlossen sich den Moskauer Bürgerwehren an, die sich in den ersten Kriegstagen gebildet hatten, und fehlten dem Museum als spezialisierte Fachkräfte. Die Kuratorin des Staatlichen Historischen Museums (GIM) Marija Michailova Denisova (1887-1961) wunderte sich in ihrem Kriegstagebuch besorgt: "3. Juli 1941. Stalin ruft zur Organisation von Bürgerwehren auf. Warum versammelt man bereits jetzt Bürgerwehren? Ist unsere reguläre Armee etwa nicht genug? [...] 4. Juli 1941. Unsere ganze Museums-Intelligenz ist fast vollständig in die Bürgerwehren eingetreten. ${ }^{6}$

Obwohl die Moskauer Museen, wie alle anderen (Kultur-)Einrichtungen der Stadt, von den Mobilisierungen in die Armee oder in den Arbeitsdienst betroffen waren, konnte die von der Zeitung angekündigte Ausstellung über den »Großen Vaterländischen Krieg« im August 1941 im Armeemuseum eröffnen. Das Kuratorenteam zeigte Objekte über den Krieg der Novgoroder Armee gegen die schwedischen und die livländischen Ordenstruppen (1240-1242), zur Schlacht bei Tannenberg, über den Siebenjährigen Krieg, den Vaterländischen Krieg von 1812, den Ers-

6 GIM (Gosudarstvennij istoričeskij muzej). Astvacaturjan, $\dot{E} .:$ Iz »Dnevnika vojny« M.M. Denisovoj, in: Gosudarstvennij Istoričeskij Muzej (Hg.): Gosudarstvennij Istoričeskij Muzej v gody Velikoj Otečestvennoj vojny 1941-1945 gg, Sbornik vospominanij sotrudnikov muzeja, Moskva 1988, S. 73-97. 
ten Weltkrieg und, in einer gesonderten Abteilung, den Winterkrieg (1939-1940). ${ }^{7}$ Die letzten zwei Abteilungen der Ausstellung waren den gegenwärtigen Ereignissen des Deutsch-Sowjetischen Krieges gewidmet und stellten Objekte über militärische Aktionen der Marine, von sowjetischen Soldaten erbeutetes deutsches Kriegsgerät (Trophäen) sowie Dokumente über Kriegsverbrechen der Wehrmacht in den besetzten Gebieten aus. ${ }^{8}$

Mit der Ausstellung zum »Großen Vaterländischen Krieg«, die tatsächlich eine Präsentation über die historischen Konflikte Russlands mit Deutschland war, hatte das Armeemuseum die Instruktion des staatlichen Museumsinstitutes antizipiert und umgesetzt. ${ }^{9}$ Der Museologe und Institutsvorsteher Aleksej Dmitrievič Manevskij (1904-1949) verschickte am 15. Juli 1941 einen Brief an alle Museen, in dem er die neue politische Ausrichtung der Ausstellungen vorgab: »Im Besonderen muss die Ausstellung auf eine sehr lebendige Weise von den vielen Versuchen erzählen, als die deutschen Eindringlinge im Verlauf vieler Jahrhunderte das russische Volk versklaven wollten und [zeigen, A.H.] was dabei herausgekommen ist. «" ${ }^{10}$ Manevskij, der selber als Kurator im Museum der Russischen Revolution und im GIM am Roten Platz gearbeitet hatte, nannte seinen Kolleginnen und Kollegen Themen für eine entsprechende Schwerpunktsetzung in der musealen Inszenierung:

»Es muss anschaulich gezeigt werden, wie unter der Führung von Aleksandr Nevskij die russischen Truppen die historische russische Stadt Pskov von den deutschen Eindringlingen befreiten [...]. 1410 versuchten die deutschen Barone, das russische und das litauische Volk zu versklaven und erhielten eine grausame Lektion. Am 15. Juli 1410 fand die berühmte Schlacht [bei Tannenberg] zwischen den Deutschen Ritterorden und den vereinigten russischen, belarussischen und ukrainischen Streitkräften statt. Im 15. Jahrhundert versuchten die Deutschen Ritterorden erneut in die russische Erde einzufallen. Viele Male marschierten sie auf Pskov zu, doch jedes Mal erlitten sie eine Niederlage durch die russische Armee. «"

Die Kernaussage war die des immanenten Sieges. Dieses Vertrauen sollte in der Bevölkerung nicht mit der erfolgreichen Entwicklung der Sowjetunion begründet

7 Als »Winterkrieg« (Zimnaja vojna) wird der vom 30. November 1939 bis zum 13. März 1940 zwischen der Sowjetunion und Finnland ausgetragene Krieg bezeichnet.

8 Fatigarova, Natal'ja: Muzejnoe delo v RSFSR v gody Velikoj Otečestvennoj vojny, S. 194.

9 Narkompros (Narodnij kommissariat prosveščenija). Zur Geschichte des NIIKMR, siehe: Kudrjavceva, Elena: Obrazovanie i pervye gody suščestvovanija Instituta, in: Kulturologičeskij žurnal, 2012/2 (8): www.cr-journal.ru/files/file/07_2012_11_01_40_1342076500.pdf (Stand: 07.11.2016).

Manevskij, Aleksej: Ko vsem rabotnikam muzeev narkomprosa RSFSR (15.07.1941), in: NIIKMR (Hg.): Rabota politiko-prosvetitel'nych učreždenij v uslovijach voennogo vremeni, direktivnye i instruktivnye materialy dlja muzeev, Moskva 1943, S. 3-7. 
werden, sondern mit der militärischen Vergangenheit der Sowjetunion, in der die Deutschen immer von den Russen geschlagen wurden. Diese historischen Allegorien standen in Übereinstimmung mit der ersten Kriegsrede Stalins vom 3. Juli 1941 und mit der geschichtspolitischen Wende Mitte der 1930er Jahre, als von sämtlichen historischen Institutionen eine Hinwendung zur vorrevolutionären Geschichte verlangte wurde. ${ }^{12}$ Die muzejščiki konnten sich bei ihrer Ausstellungsvorbereitung aus diesem breiten Fundus an bereits bestehenden Topoi vergangener Kriege bedienen. ${ }^{13}$

Laut der russischen Historikerin Julija Kantor, die zu der staatlichen Museumspolitik während des Krieges forscht, sollte Manevskijs Befehl den Kulturinstitutionen eine Atempause verschaffen. Die "gewinnsichernden Themen der heroischen Vergangenheit« sollten die Museen bzw. ihr Publikum beschäftigen. Dies galt so lange, bis die ideologische Kehrtwende, die die Medien in Bezug auf Deutschland (das seit dem Molotov-Ribbentrop-Pakt als Verbündeter gegolten hatte) als erneuten Feind vollziehen mussten, theoretisch ausgearbeitet sei. ${ }^{14}$

Unabhängig von den möglichen politischen Hintergründen des Befehls scheint die Aktualisierung ihrer militärischen Kollektionen unter neuen Vorzeichen den muzejščiki Orientierung gegeben zu haben. Der Kurator des GIM Pavel Grigor'evič Ryndzjunskij (1909-1993) sah in dieser Ausstellungsarbeit eine Möglichkeit, zur geistigen Mobilisierung der Bevölkerung beizutragen. Er erinnert sich an:

»Die ersten Tage des Krieges ... Die Moskauer arbeiteten und lebten unter einer besonderen Einstellung: Wie soll ich mich in dieser neuen Situation zurechtfinden und, wichtiger, wie kann ich mich der landesweiten Sache [gemeint ist der Krieg, A.H.] anschließen? Für die Arbeiter des Historischen Museums war diese Frage anfänglich leicht zu beantworten. Das Museum bewahrte unzählige und unschätzbare Erinnerungsstücke von den jahrhundertealten Kämpfen unseres Volkes um

Das ZK veröffentlichte am 16. Mai 1934 gemeinsam mit dem Narkompros eine Erklärung über die Vermittlung der Ceschichte des Bürgerkrieges in den Schulen. Vgl.: Partizdat (Hg.): K izučeniju istorii, Moskva 1937, S. 10-20. Die Ausstellungsthemen über die historischen Siege standen als »Lehren der Ceschichte« in ideologischer und wörtlicher Übereinstimmung mit Stalins Rede, in der er historische Kriegshelden als Vorbilder für die Cegenwart genannt hatte. Vgl. Rundfunkrede am 3. Juli 1941, in: Stalin, Josef: Über den Großen Vaterländischen Krieg der Sowjetunion, 3. Auflage, Moskau 1946, S. 6-10.

13 Ein wichtiges Beispiel in diesem diskursiven Feld ist der Film von Sergej Ėjzenštejn »Aleksandr Nevskij « (1938), in dem die Schlacht auf dem Peipussee gegen den Deutschen Orden als antifaschistische Propaganda die Kriegsmentalität und die Verteidigungsbereitschaft der sowjetischen Bevölkerung stärken sollte. Vgl. Schenk, Frithjof Benjamin: Aleksandr Nevskij, Heiliger, Fürst, Nationalheld, Eine Erinnerungsfigur im russischen kulturellen Gedächtnis, 1263-2000, Köln/Weimar/Wien 2004, S. 266-373. Zur Wiederaufnahme des Films nach Ausbruch des Deutsch-Sowjetischen Krieges und Höhepunkt des Nevskij-Kultes: S. 381-404. 
die Freiheit und Verteidigung unserer Heimat. Jetzt werden diese Objekte und Dokumente mit besonderer Kraft mit den Museumsbesuchern >zu sprechen <eginnen. Das bedeutet, dass wir schnellstmöglich die Ausstellung zu den militärhistorischen Themen erneuern, ergänzen und verstärken müssen. Das ist und wird unsere Aufgabe sein. ${ }^{15}$

Auch das Armeemuseum befand sich mit seiner Sammlung in einer idealen Ausgangslage für die narrative Integration des aktuellen Krieges in die Militärgeschichte des Landes. Die Kritik führender Museologinnen und Museologen an der Dauerausstellung im Kontext des Ersten Allrussischen Museumskongresses 1930 hatte hier zu einer grundlegenden Neuausrichtung und Umstrukturierung des Museums geführt, die im Anschluss die Geschichte der Roten Armee umfassend darstellte. ${ }^{16}$ Anfang Juni 1941, kurz vor dem deutschen Überfall auf die Sowjetunion, hatte die renommierte Fachzeitschrift Istoričeskij Žurnal (Historisches Journal) die Dauerausstellung des Armeemuseums ausführlich rezensiert und die Präsentation der militärischen Bereitschaft des Landes, aus allen zukünftigen Kriegen ebenso siegreich hervorzugehen, ausdrücklich gelobt. ${ }^{17}$ Die Kuratorinnen und $\mathrm{Ku}-$ ratoren dieses Museums widmeten sich also bereits zehn Jahre vor Ausbruch des »Großen Vaterländischen Krieges« der militär-patriotischen Kultur und verfügten über die entsprechende Erfahrung, die Objekte des Krieges zu inszenieren.

Auch die jüngsten militärischen Ereignisse, wie die Besetzung Ostpolens durch die Rote Armee als Folge des geheimen Zusatzprotokolls des sogenannten »Deutsch-Sowjetischen Nichtangriffspaktes«, hatten Eingang in die Dauerausstellung des Armeemuseums gefunden. Im Saal »Die Rote Armee befreit die Völker in der westlichen Ukraine und im westlichen Belarus von dem Joch der polnischen Herren« inszenierten die muzejščiki ein Narrativ, demzufolge die ukrainischen und belarussischen Bevölkerungsgruppen Polens von einem »Terror- und künstlichen Kolonialregime« befreit und "wiedervereinigt « wurden. ${ }^{18}$ Ohne die deutsche Besatzung Westpolens zu erwähnen, stellten sie im Stil der Gräuelpropaganda polnisches Folterwerkzeug aus, erbeutete polnische Fahnen sowie Fotos und Dokumente, die die Freude der Bevölkerung über ihre Befreiung durch die Rote Armee und ihre Eingliederung in die Ukrainische respektive Belarussische SSR belegen toričeskij muzej (Hg.): Cosudarstvennyj istoričeskij muzej v gody velikoj otečestvennoj vojny 1941-1945, S. 33-39, hier S. 33. enno-muzejnoe stroitel'stvo, in: Sovetskij muzej, Nr. 6, 1932, S. 41-45. Pankov, I.: Dokumenty slavy i gerojstva, po zalam Central'nogo muzeja Krasnoj Armii, in: Istoričeskij Žurnal, Nr. 6, 1941, S. 146-155. Pankov, I.: Dokumenty slavy, S. 151. 
sollten. ${ }^{19}$ Dem Rezensenten Pankov zufolge zeigten die Exponate das "frohe und strahlende Leben der Arbeiterschaft in den westlichen Teilen der Ukraine und in Belarus unter der wärmenden Sonne der stalinschen Verfassung “. ${ }^{20}$ Stalins Verfassung der Union der Sozialistischen Sowjetrepubliken von 1936 wurde hier zur legitimierenden Instanz eines glücklichen sowjetischen Lebens in den ehemaligen polnischen Gebieten.

Die Beobachtung der führenden Rolle des Moskauer Armeemuseums bei der Darstellung des Deutsch-Sowjetischen Krieges zieht sich wie ein roter Faden durch die vorliegende Untersuchung. Diese Vorreiterrolle hatte einen zentralen Grund: Im Unterschied zu fast allen anderen Museen der Sowjetunion unterstand das Armeemuseum nicht dem Narkompros, sondern seit seiner Eröffnung im Jahr 1919 als zentrale Kulturabteilung dem Kommissariat für Verteidigung (NKO) bzw. der GlavPURKKA. ${ }^{21}$ Die institutionelle Anbindung an die militärpolitischen Entscheidungsträger im Krieg bot diverse Vorteile - wie beispielsweise den schnellen Informationsfluss und, als Kulturbeauftragte des NKO, den direkten Zugang zu der Roten Armee.

Im Sommer 1941 lag das Hauptaugenmerk des staatlichen Museumsinstitutes auf der Ausstellungsarbeit, die schnellstmöglich an den Krieg angepasst werden musste. In seiner ersten Instruktion an die Museen im Krieg forderte Manevskij die Dauerausstellungen umzubauen und die erfolgreichen historischen Kämpfe mit den deutschen Invasoren $\mathrm{zu}$ betonen. Er animierte die Kuratorinnen und $\mathrm{Ku}-$ ratoren, neue Ausstellungsmodelle und Vermittlungsformen anzuwenden: Die $m u-$ zejščiki sollten handliche "Wanderausstellungen« (peredvižnye vystavki) anfertigen, die sie temporär in städtischen Betrieben und öffentlichen Einrichtungen aufstellen und mit thematisch korrespondierenden Vorträgen begleiten sollten. Manevskij schlug beispielsweise vor, Wanderausstellungen in Form von Collagen und Plakaten über die Verteidigung Moskaus gegen feindliche Luftangriffe herzustellen. ${ }^{22}$

19 Vgl.: Saalfoto von einer Vitrine, die die erbeutete Fahne der 84. polnischen Infanterie und weitere Trophäen zeigt. In: Pankov, I.: Dokumenty slavy, S. 151.

20 Ebd. S. 151.

21 Die ClavPURKKA war für die politische Schulung und kulturelle Bildungsarbeit der Truppen zuständig. Am 25. Juni 1941 wurde zusätzlich das »Sowjetische Büro für militärpolitische Propaganda " geschaffen, das als Koordinierungsstelle zwischen Roter Armee und Partei vorgesehen war. Sein Vorsteher war Lev Mechlis, der zugleich der Chef der ClavPURKKA war. Zu den schwer durchschaubaren Zuständigkeiten innerhalb der Abteilungen der ClavPURRKA vgl. Morré, Jörg: Hinter den Kulissen des Nationalkomitees, Das Institut 99 in Moskau und die Deutschlandpolitik der UdSSR 1943-1946, München 2001, S. 28-34. Die Akten der ClavPURKKA befinden sich in dem Archiv des Verteidigungsministeriums in Podolsk (CAMO, RF), in das der Verfasserin im Januar 2016 einmaliger Zutritt und Einsicht in ausgewählte Quellen gegeben wurde. 
In diesen simplen, in der Regel zweidimensionalen Wanderausstellungen liegt der Ursprung des Gegenwartsbezugs der Sonderausstellungen, der für das Ausstellungswesen der sowjetischen Museen im Krieg charakteristisch werden sollte. Die Inklusion des Kriegsalltags in der Frontstadt erforderte eine Umstellung der Sammlungsarbeit. Manevskij beschrieb diese Neuausrichtung des Sammlungsprofils der Museen folgendermaßen:

»Die Museen müssen schnell und effizient auf alle aktuellen Ereignisse reagieren. Rechtzeitig müssen sie die entsprechende Ankündigung [oder A.H.] das Plakat aufhängen [...] Eine der wichtigsten Aufgaben des Museums ist die systematische Sammlungsarbeit von Objekten, die die heldenhafte Gegenwart unseres Volkes spiegeln. Das Sammeln von publizierten Plakaten, Losungen, Zeitungsausschnitten, Fotos, Karikaturen, Illustrationen usw. hat einen sehr großen Nutzen für das Museum. Es müssen einzelne Aufsätze der militärischen Spezialisten, Berichte und andere schriftliche Quellen, die den sieghaften Krieg spiegeln, gesammelt werden $[\ldots] . \ll^{23}$

Die Orientierung der Sammlungsprofile auf die zunächst zweidimensionalen Objekte der Gegenwart war eine grundlegende Neuausrichtung der Sammlungsarbeit und hatte Folgen für die Ausstellungsarbeit. Die historischen Museen waren seit der geschichtspolitischen Wende von 1934 damit beschäftigt gewesen, Sammlungen und Ausstellungen zur vorrevolutionären Geschichte, zur "präkapitalistischen Periode«, zur Geschichte des 16. bis 19. und zum Anfang des 20. Jahrhunderts zu erstellen. Konstantin Grigor'evič Levykin (1925-2015), der langjährige Direktor des GIM, betonte rückblickend, dass seine Vorgängerinnen und Vorgänger im GIM (im Gegensatz zu den muzejščiki des Armeemuseums) bei Kriegsausbruch 1941 keine praktische Erfahrung im Sammeln und Ausstellen von Objekten der Gegenwart gehabt hätten und dass der ausbrechende Krieg einen »radikalen Umbau« (korennaja perestrojka) der Museumsarbeit erfordert habe. ${ }^{24}$

Die museumspolitische Instruktion vom 15. Juli 1941 war zentral für die sowjetischen Kriegsausstellungen. Sie wird von der Forschung zitiert, um die richtungweisende Instanz des Narkompros zu belegen. ${ }^{25}$ Die Empirie zeigt jedoch, dass dieser Interpretation des staatlichen Museumsinstitutes als Vordenker und Lenker der Museumsarbeit im Krieg nur partiell zuzustimmen ist. In seinem Schreiben sprach der Museologe Manevskij zentrale Veränderungen in der Sammlungs-,

24 Levykin, Konstantin: Vvedenie, in: Gosudarstvennyj istoričeskij muzej (Hg.): Gosudarstvennyj istoričeskij muzej v gody velikoj otečestvennoj vojny 1941-1945, S. 3-7, hier S. 3; Levykin, Konstantin: Perestrojka raboty istoričeskich i istoriko-kraevedčeskich muzeev v gody velikoj otečestvennoj vojny, in: Voprosy istorii, Nr. 4, April 1985, S. 148-151, hier S. 148. 
Ausstellungs- und Vermittlungsarbeit an, die die Museen in ihrem Arbeitsalltag umsetzen sollten. Gleichzeitig zeigt sich jedoch eine im Verlauf des Krieges immer größer werdende Diskrepanz zwischen den Instruktionen und Vorgaben des Museumsinstitutes und der praktischen Arbeit der muzejščiki. Diese Leerstelle zwischen Anspruch und Wirklichkeit bestand auch auf einer lebensweltlichen Ebene. Die Museumsmitarbeiterinnen (nach Kriegsausbruch arbeiteten mehrheitlich Frauen in den Museen), wurden, wie alle Angestellten einer staatlichen Einrichtung, in den Dienst der »Fliegerabwehr« (Protivovozdušnaja oborona, PVO) gestellt. Sie mussten rund um die Uhr Schichtdienst leisten und Verwundete verarzten oder im Rahmen des Brandschutzes die Gebäude von Bomben befreien. Zusätzlich zu diesem Dienst bauten sie Verteidigungsanlagen, gruben Panzergräben und sicherten Gebäude mit Sandsäcken. ${ }^{26}$ Die Kriegsbedingungen in der Frontstadt Moskau ließen die Ausstellungsanleitungen der Behörde immer mehr zu einer abstrakten Norm werden. Die muzejščiki nutzten die entstandene Leerstelle und führten die praktische Umsetzung dieser Ansprüche in Eigenregie aus.

Während der erste Brief des Museumsinstitutes noch visionäre und innovative Elemente der Museumsarbeit beinhaltet hatte (Wanderausstellung mit Gegenwartsbezug), verloren die folgenden Instruktionen im Verlauf des Krieges diesen proaktiven Charakter. Im günstigsten Fall folgte die Behörde der Initiative der muzejščiki und legitimierte die neue Arbeitspraxis mit ihren Instruktionen als Norm. Häufig interferierten die Fachleute jedoch mit irrelevanten formellen Einschränkungen und Vorgaben und erschwerten damit längst etablierte Arbeitsabläufe. Dass diese Anweisungen die Umstände der Kriegsrealität nicht berücksichtigten und häufig nicht umgesetzt werden konnten, lag nicht zuletzt in der Evakuation der Behörde nach Kirow und der sich daraus ergebenden Distanz zu den Ereignissen an der Front begründet.

\section{„Bewahren«. Die Evakuationen der Museumssammlungen}

Die russische Forschung zur sowjetischen Museumsgeschichte im Krieg beschreibt die parteistaatliche Führung der Museumsarbeit im ersten Kriegshalbjahr als unkoordiniert. Sie wirft den Behörden vor, keine ausreichenden Maßnahmen ergriffen zu haben, um die Museen vor Zerstörung und Raub zu retten, da sie die Bedrohung nicht adäquat eingeschätzt hatten. ${ }^{27}$

Aufgrund des überraschenden Überfalls und des schnellen Vorrückens der deutschen Armee war die Evakuation der Museen in den westlichen Gebieten

26 Zaks, Anna: O rabote gosudarstvennogo istoričeskogo muzeja v 1941-1945, in: Nauka (Hg.): Sovetskaja kul'tura v gody velikoj otečestvennoj vojny, Moskva 1976, S. 129-141, hier S. 132.

27 Die Historikerin Julija Kantor lehnt den Begriff »Evakuation « in Bezug auf die Museumssammlung ab und spricht von »Ausladung« (razgruzka). Vgl. Kantor, Julija: Nevidimyj front, S. 9. 
der Ukraine, in Moldawien, im Baltikum und in Belarus unmöglich geworden. Diese Gebiete befanden sich bis zu drei Jahre lang unter deutscher Besatzung und erlitten z.T. unwiederbringliche Verluste. Die frontnahen Museen (beispielsweise in Smolensk, Novgorod, Pskov, Voronež, Orjol, Kursk, Sevastopol) konnten nur mit großen Schwierigkeiten und unter lebensgefährlichen Bedingungen evakuiert werden. ${ }^{28}$ Im Gegensatz zu Leningrad, wo die Museen über Evakuationspläne verfügten (ein feindlicher Angriff war hier als wahrscheinlich erachtet worden), mussten die Moskauer Museen diese Pläne angesichts der vorrückenden Front erst entwickeln. ${ }^{29}$

Die russische Historikerin und Museologin Marija Kaulen betont, dass große Teile der Sammlungen nur gerettet werden konnten, weil die Museumsmitarbeitenden in Eigeninitiative handelten und nicht auf die verspäteten Anweisungen der Behörden warteten. ${ }^{30}$ Dabei konnten die Gedenkmuseen (Memoral'nye muzei), die regionalwissenschaftlichen Museen sowie die historischen Museen am wenigsten von den improvisierten Evakuationsmaßnahmen profitieren, da ihre Objekte häufig sperrige Ausmaße hatten und die Behörden den Fokus ihrer Anstrengungen auf die Kunstmuseen bzw. die berühmteren Museen legten. ${ }^{31}$

Als am 21. Juli 1945 die deutschen Bombenangriffe auf Moskau begannen, wurden die staatlichen Evakuationsmaßnahmen beschleunigt. Die Sammlungen sollten entsprechend ihres Wertes in drei Kategorien eingeteilt werden - diese Anordnung verlangte nach Expertinnen und Experten, die aber häufig nicht vor Ort waren. Zusätzlich wurden die Vorbereitungen dadurch erschwert, dass die Museen

Die spätere Kuratorin des GIM, Nina Stolova, berichtet in ihren Erinnerungen von den Versuchen der Pskovsker MuseumsmitarbeiterInnen, die Sammlung vor den Wehrmachtverbänden zu retten und von ihrer Flucht aus dem Museum. Vgl. Stolova, Nina: Po gorjačim sledam vojny, in: Cosudarstvennyj istoričeskij muzej ( $\mathrm{Hg}$.): Cosudarstvennyj istoričeskij muzej v gody velikoj otečestvennoj vojny 1941-1945, S. 47-62. Insgesamt wurden von 41 Orten $66 \mathrm{Mu}$ seen des Narkompros evakuiert und an neun Orte im Hinterland (wie zum Beispiel Almaty, Armavir, Džambul, Erevan, Kirov, Kurgan, Penza, Sol'vyčegorsk, Taschkent, Uralsk, Fergan) gebracht. Vgl. Kaulen, Marija: Muzejnoe delo Rossii, Moskva 2010, S. 155.

29 Ebd.: S. 154-155. Zur Thematik der Evakuation, der Zerstörung der sowjetischen Museen und Kulturdenkmäler sowie der Raubkunst durch die deutsche Wehrmacht, die hier nicht explizit besprochen wird, vgl. Kuhr-Korolev, Corinna/Schmiegelt-Rietig, Ulrike/Zubkova, Elena: Raub und Rettung, Russische Museen im Zweiten Weltkrieg, Köln 2018.

»Alle Maßnahmen hätten nicht ohne die professionelle und wahrhaft heldenhafte Arbeit der Museumsmitarbeiter des Landes realisiert werden können. Sie waren es, die die Verstecke für die Museumskollektionen bewachten, die die Sammlungen aus den besetzten Cebieten in das tiefe Hinterland brachten, die die Sammlungen vor den Brandbomben retteten, die die Museumssammlungen und die privaten Sammlungen aus dem belagerten Leningrad retteten.« Kaulen, Marija: Muzejnoe delo Rossii, S. 153. 
häufig nicht über aktuelle Inventarlisten ihrer Sammlungen verfügten. ${ }^{32}$ Die Erinnerungen der GIM-muzejščiki berichten von Schwierigkeiten beim Verladen der oftmals großen und schweren Objekte und Kisten, die in der Regel von den in der Stadt zurückgebliebenen Frauen verladen wurden. ${ }^{33}$ Am 27. Juli 1941 verließ die »Karawane der Lastkähne« mit der »Staatlichen Sammlung Nr. 1 « unter deutschem Beschuss den südlichen Hafen von Moskau und transportierte die Angestellten mit ihren Familien. Gemeinsam mit Kisten voller Exponate aus dem GIM, dem Biologischen Museums, dem Ethnographischen Museum, dem Museum für östliche Kulturen, dem Museum der Revolution und den Beständen der Lenin-Bibliothek fuhren sie zuerst nach Chvalinsk, einer Kleinstadt an der Wolga, und in Anbetracht der vorrückenden deutschen Front mit der Eisenbahn weiter in die kasachische Stadt Kustanaj. Hier blieben sie, bis im Herbst 1944 als das siegreiche Ende des Krieges absehbar geworden war. ${ }^{34}$

Es ist zu vermuten, dass die Evakuationen der Sammlungen bei den muzejščiki zu einer gesteigerten Wertschätzung der Objekte geführt haben. Ihr Wert als Exponat und Original, der in der Vorkriegszeit zu einer `Statistenrolleく, zum Anschauungsmaterial für die politischen Ideen und historischen Prozesse reduziert worden war, stieg wieder an. Ein Museumsmitarbeiter des GIM erinnert sich an die Evakuation der Sammlung im Sommer 1941:

»Wenn die Objekte sprechen könnten, dann würden sie von ihrem schweren Weg erzählen. [...] Wie sollte das Porzellan-Service die lange Reise überstehen, die antiken Manuskripte, die persönlichen Cegenstände der Dekabristen, das wertvolle liturgische Cerät, die Sammlung von Orden und Ritterrüstungen, die Cewänder der Bojaren, die Duell-Pistolen?«35

Über die Abläufe der Evakuation des Armeemuseums ist vergleichsweise wenig bekannt. Diese Forschungslücke hängt vermutlich mit dem politischen Anspruch an das Museum und das Haus der Roten Armee zusammen: Diese Einrichtungen sollten zentrale Agitations- und Mobilisierungspunkte des »Großen Vaterländischen Krieges« sein, was eine Evakuation prinzipiell ausschloss. Offenbar wurden jedoch

32 Ebd. S. 155.

33 Zvereva, Nina: Kak GIM v uslovijach vojny sochranjal svoj sokrovišča, in: Gosudarstvennyj istoričeskij muzej (Hg.): Gosudarstvennyj istoričeskij muzej v gody velikoj otečestvennoj vojny 1941-1945, S. 24-32, hier S. 24.

34 Die Mitarbeiterin des GIM Marija Levinson-Nečaeva, die mit der »Staatlichen Sammlung Nr. 1. « bis nach Kasachstan fuhr, führte ein Tagebuch während der Evakuation, vgl. Razgonov, Sergej: Put' na Krasnuju ploščad', in: Sovetskij Muzej, Nr. 1, 1985, S. 22-26. Die Sammlungen der »Staatlichen Sammlung Nr. 2 « wurden in der Nikolaj-Kirche am Bersenevska-Ufer (Moskau) untergebracht, weitere Teile der Museumssammlungen wurden nach Perm und Omsk evakuiert. 
im Hintergrund zügig wichtige Entscheidungen über die Evakuation der militärischen Kultureinrichtungen der Roten Armee getroffen. Der Moskauer Leiter des Museumsarchives, A. Trofimov, wurde am 19. Juli 1941 zum Direktor des Hauses der Roten Armee in Kazan ernannt, und es wurde beschlossen, im Notfall das Museum in diese Stadt zu evakuieren. Diese Entscheidung ermöglichte es dem Museum, seine Sammlungsbestände sukzessiv in die Stadt an der Wolga zu transferieren, und als Mitte Oktober die überstürzten Fluchtbewegungen begannen, befanden sich die wertvollsten Bestände des Museums bereits in Sicherheit. ${ }^{36}$ Marija Nazarova, wissenschaftliche Mitarbeiterin des Armeemuseums, erinnerte sich an den »Tag der Evakuation«, als alle Mitarbeitenden rund um die Uhr arbeiten mussten und die Arbeitslast so groß war, dass die Fußballmannschaft vom Haus der Roten Armee zur Unterstützung geholt wurde. ${ }^{37}$ Von den wenigen, die nicht in die Armee oder die Bürgerwehren eingezogen wurden oder den Arbeitsplatz aufgegeben hatten, um aus der Stadt zu fliehen, begab sich die Mehrheit des Museumskollektivs und der Angestellten des Hauses der Roten Armee mit den Sammlungen nach Kazan. Das Museum schloss im Oktober 1941 seine Türen. ${ }^{38}$

Hinter den geschlossenen Museumstüren wurde die erste sogenannte »Expedition an die Front « geplant. Am 24. Dezember 1941 fuhren "Politische Offiziere» (Politruki) und wissenschaftliche Mitarbeitende in die von der Roten Armee befreiten Gebiete, um Kriegsrelikte zu sammeln. Die Ursprünge dieser Sammlungsarbeit an der Front lagen in den neuen Arbeitsmethoden des GIM begründet. Dieses Museum war das einzige der Moskauer Museen, das - mit Ausnahme von sechs Tagen im Oktober - im Herbst und Winter 1941 Ausstellungen konzipierte und Publikum empfing.

\section{Die `Antifaschistische Gruppenausstellunge}

Am 9. August 1941 forderte das Museumsinstitut sechs Moskauer Museen auf, gemeinsam eine Ausstellung zum Krieg zu konzipieren, die inhaltlich derjenigen des Armeemuseums entsprach. Sie sollte am 25. August 1941 unter dem Titel »Der Große Vaterländische Krieg des sowjetischen Volkes gegen den deutschen Faschismus« in den leergeräumten Sälen des GIM eröffnen. ${ }^{39}$ Die Gemeinschaftsausstellung, an

36 Pečen, N./Povesmo, P.: V gody surovych ispitanij, in: dies. (Hg.): 80 let na službe Otečestvu, Central'nij Muzej vooružennych sil, Moskva? 1999, S. 49-50.

37 Nazarova, Marija: Central'nyj muzej Krasnoj Armii v gody Velikoj Otečestvennoj vojny, Iz vospominanij Marii Konstantinovny Nazarovoj, in: Informacionno metodičeskij sbornik No. 5, Moskva 2000, S. 37-38.

38 Voennoe izdatel'stvo ministerstvo oborony SSSR (Hg.): CDKA imeni Frunze, Ordena trudovogo krasnogo znameni, Moskva 1978, S. 37

39 CARF [Staatliches Archiv der Russländischen Föderation], f. A-2306, op. 69, d. 2692, I. 45, zitiert nach: Kantor, Julija: Otraženie sobytij velikoj otečestvennoj vojny v muzejach RSFSR v 
der neben dem GIM auch das »Museum der Völker der UdSSR «, das »Biologische Museum«, das »Literaturmuseum«, das »Museum der Revolution« und das »Polytechnische Museum« teilnahmen, wurde von Manevskijs Museumsinstitut mit Materialien und Expertise unterstützt. Trotz vereinter Kräfte war die extrem knapp gesetzte Frist von 16 Tagen unter den Umständen in der Frontstadt (Mobilisierung des Personals, Evakuation, Dienst bei der militärischen Verteidigung) unmöglich einzuhalten. Die Eröffnung von zehn vollständig inszenierten Sälen einen knappen Monat später, am 17. September 1941, ist vor diesem Hintergrund beachtlich. Möglicherweise übte ein Befehl vom 2. September 1941, den der Volkskommissar für Bildung Vladimir Potëmkin persönlich erließ, zusätzlichen Druck auf die schnelle Fertigstellung der Ausstellung aus. In seinem Schreiben an alle Einrichtungen des Narkompros mahnte er, dass die »Mehrheit der Lese-Hütten (izba-čital'naja), Kulturhäuser, Bibliotheken und Museen ihre Arbeit noch nicht auf die Bedingungen des Krieges ausgerichtet [hätten, A.H.] und ihre Arbeit nicht den Aufgaben der Verteidigung des Landes unterstellt [hätten, A.H.]. ${ }^{40}$ Um diesen in den Augen des Kommissars unhaltbaren Missstand zu korrigieren, befahl Potëmkin, »dass alle Lesehütten, Kulturhäuser, Bibliotheken und Museen mindestens eine Ausstellung zum Großen Vaterländischen Krieg des sowjetischen Volkes gegen den deutschen Faschismus einrichten [sollten, A.H.]. ${ }^{41}$

Während sechs der zehn Museumssäle den historischen Kämpfen mit deutschen Invasoren gewidmet waren, stellten vier die aktuellen Ereignisse des Deutsch-Sowjetischen Krieges aus. ${ }^{42}$ Für die Mediävistin und Kuratorin des GIM, Marija Denisova, war die Verknüpfung der historischen Ereignisse mit der Gegenwart einleuchtend. Sie schrieb in ihr Kriegstagebuch:

1941-1945, in: Ivestija Ural'skovo federal'nogo universiteta, Bd. 142, No. 3, 2015, S. 8-22, hier S. 10, in: http://journals.urfu.ru/index.php/Izvestia2/article/view/1686 (Stand: 31.07. 2021).

40 Potèmkin, Vladimir: O rabote politiko-prosvetitel'nych učreždenij v voennoe vremja, iz prikaza narodnogo komissara prosveščenija RSFSR Nr. 656 ot 2 sentjabrja 1941 g, in: NIIKMR (Hg.): Rabota politiko-prosvetitel'nych učreždenij v uslovijach voennogo vremeni, direktivnye i instruktivnye materialy dlja muzeev, Moskva 1943, S. 8-9.

41 Ebd. S. 9.

42 Die zehn Säle trugen die Titel: 1. »Das sozialistische Vaterland in Gefahr«, 2. »Der heroische Kampf des russischen Volkes mit den deutschen Eroberern«, 3. »Der Sieg der Russischen Armee über die Streitkräfte Friedrichs II. und der Siebenjährige Krieg«, 4. »Die BrussilovOffensive, Verteidigung von Petrograd durch die Baltische Flotte 1917«, 5. »Die Zerschlagung der deutschen Besatzer in der Ukraine 1918«, 6. »Die Zerschlagung der Weißfinnen 1940«, 7. »Faschismus - Der ärgste Feind der Menschheit«, 8. »Der heldenhafte Kampf des sowjetischen Volkes mit dem deutschen Faschismus«, 9. »Die heldenhafte Verteidigung von Moskau, «10. »Die heldenhafte Arbeit des Hinterlandes«. GIM: OPI, f. 452, d. 27, I. 5. Zitiert nach: Lupalo, I.: Vklad muzeev istoričeskogo profilija v mobilizaciju duchovnych sil sovetskogo naroda na razgrom vraga v period Velikoj Otečestvennoj vojny 1941-1945 godov, in: Muzejnoe delo v SSSR, sb. Nauch. Tr., Moskva 1985, S. 117-146, hier S. 130. 
»2.-22. August 1941. Unser Museum entwickelt die Ausstellung >Die heroische Vergangenheit des Russischen Volkes . Die wichtigsten Beispiele aus der Ceschichte der Kämpfe mit den Deutschen [...]. All diese ruhmreichen Bilder der Vergangenheit; und heute müssen wir diese schwere Prüfung überleben. Sie nehmen uns eine Stadt nach der anderen. Das alte Novgorod und Pskov haben sie eingenommen, um Leningrad kämpfen sie wild, besonders die Matrosen. $^{43}$

Der Kuratorin dienten die historischen Kämpfe als Orientierung, an der sie ihre Gegenwart messen konnte. Der aktuelle Angriff der Wehrmacht war eine weitere Bedrohung in einer langen Reihe von ähnlichen, erfolgreich gewonnen Kämpfen. Ihr Tagebucheintrag zeigt ihre individuelle Identifizierung mit der Kriegsrhetorik. Sie verknüpfte die Tagesereignisse mit den historischen Kämpfen. Wenige Tage vor dem Tagebucheintrag, am 15. August 1941, hatte die Wehrmacht Novgorod eingenommen, und seit dem 9. Juli befand sich Pskov unter deutscher Besatzung. Zum Zeitpunkt der Niederschrift fanden heftige Kämpfe um Leningrad statt; drei Wochen später, am 8. September 1941, war der deutsche Belagerungsring um die Stadt an der Newa bereits geschlossen.

Die muzejščiki nannten die Gruppenausstellung »Antifaschistische Ausstellung" (antifašistskaja vystavka), ein Hinweis darauf, dass sowohl die Säle mit historischen Kämpfen als auch die der Gegenwart die Aussage des Kampfes gegen das Dritte Reich vermitteln sollten. ${ }^{44}$ Stellwände mit folgenden Titeln klärten das Publikum über die nationalsozialistische Ideologie und die Folgen des Faschismus auf: »Das Gesicht des deutschen Faschismus«, »Die Enthüllung der rassistischen Theorie im Faschismus«, »Faschismus - der Feind von Wissenschaft und Kultur«, »Die Plünderungen in den besetzten Gebieten«, »Die Vernichtung der nationalen Selbständigkeit und der Integrität der Völker und Staaten «. ${ }^{45}$ Diese theoretischen Elemente der Ausstellung sollten die Bevölkerung von den feindlichen Zielen der nationalsozialistischen Ideologie überzeugen. Dies war in den ersten Kriegsmonaten von größter Bedeutung, da das Dritte Reich seit dem Abschluss des Nichtangriffspaktes vom 23. August 1939 bis zum Überfall als Verbündeter der Sowjetunion gegolten hatte. ${ }^{46}$ Die Kuratorinnen und Kuratoren mussten nun, ohne über das notwendige

43 Astvacaturjan, Ė.: Iz »Dnevnika vojny« M. M. Denisovoj, S. 76.

44 Zaks, Anna: Kak my žili i rabotali v gody Velikoj Otečestvennoj vojny, in: Cosudarstvennyj istoričeskij muzej (Hg.): Cosudarstvennyj istoričeskij muzej v gody velikoj otečestvennoj vojny 1941-1945, S. 9-23, hier S. 9.

45 GARF, f. A-2306, op. 69, d. 2692, I. 49-50, zitiert nach Kantor, Julija: Otraženie sobytij, S. 11.

46 Gorjajewa, Tatjana: »Wenn morgen Krieg ist ...«, Zum Feindbild in der sowjetischen Propaganda 1941-1945, in: Eimermacher, Karl/Volpert, Astrid: Verführungen der Cewalt, München 2005, S. 427-468; Perepelicyn, Aleksandr V./Timofeeva, Natalja P.: Das Deutschen-Bild in der sowjetischen Militärpropaganda während des Großen Vaterländischen Krieges, in: Scherstjanoi, Elke (Hg.): Rotarmisten schreiben aus Deutschland, Briefe von der Front (1945) und historische Analysen, München 2004, S. 267-268. 
theoretische Material zu verfügen, eine ideologische Kehrtwende zum Antifaschismus vollziehen und für eine Anti-Hitler-Koalition werben. Die Unterstützung des Museumsinstitutes zu der Gemeinschaftsausstellung bestand in der Bereitstellung von Themen mit internationaler Dimension: „Die Eroberungskämpfe des deutschen Faschismus in Westeuropa«, »Der Kampf der Völker gegen den Faschismus in den besetzten Gebieten und in Deutschland selbst «, »Die solidarische Bewegung der Völker in England, den USA und anderen Ländern mit der UdSSR«. Die Stellwände, die die Abkommen der UdSSR mit Großbritannien, der polnischen Exilregierung und der Tschechoslowakei präsentierten, waren ein absolutes Novum, galten doch freundschaftliche Beziehungen, insbesondere zu den USA, vor dem Krieg als »konterrevolutionär « ${ }^{47}$ Hier fand erstmals eine Ausweitung der Darstellung des »Großen Vaterländischen Krieges« auf die internationalen Ereignisse des Zweiten Weltkrieges statt. Vormals zensierte Themen wurden nun zum Zweck der ideologischen 180-Grad-Wende, die den ehemaligen Freund zum Feind machen sollte, ausgestellt. Jene Darstellungen, die den Krieg an der Ostfront als Teil des Zweiten Weltkrieges kontextualisierten, wurden in den späteren Kriegsausstellungen nicht mehr gezeigt. Der obligatorische Zahlenzusatz »1941-1945 «, den man der Bezeichnung "Großer Vaterländischer Krieg« beigab, schloss alle Kriegsereignisse vor dem 21. Juni 1941, und damit die sowjetische Besatzung und Annexion der ostpolnischen Gebiete von 1939, kategorisch aus.

Gleichzeitig zwang der Druck, die unmittelbare Gegenwart auszustellen, die Kuratorinnen und Kuratoren dazu, ideologisches Neuland $\mathrm{zu}$ betreten. Die Ausstellungsinhalte über den Antisemitismus, der in den Kapiteln zur Rassenideologie der »Faschisten« gezeigt wurde, und über die Kriegsereignisse, die dem Deutsch-Sowjetischen Krieg vorausgegangen waren, belegen die Offenheit der ersten Kriegsdarstellungen, deren ideologische Regeln und Grenzen noch bestimmt werden mussten.

Die Moskauer muzejščiki scheinen Manevskijs Vorschlägen gefolgt zu sein, denn sie zeigten Objekte der Gegenwart. In einer kleinen Abteilung waren sogar die ersten Etappen der Kämpfe von Moskau ausgestellt. Jedoch war es den Kuratorinnen und Kuratoren verboten, Karten zu benutzen, die den Verlauf der Kriegsereignisse veranschaulichten, weil, so die Anweisung, das Hervorbringen einer "panischen Stimmung « zu vermeiden sei. Eine Einschränkung, die den muzejščiki missfiel, da sie ihrem Publikum so keine Vorstellung des Kriegsverlaufes vermitteln konnten, wie ein an der Gruppenausstellung beteiligte Kurator des Revolutionsmuseums rückblickend kritisierte. ${ }^{48}$

Hier zeigt sich der schmale Grat, auf dem die muzejščiki bei der Erfüllung des staatlichen Befehls balancieren mussten. Besonders in der Anfangsphase des Krie-

47 GARF, f. A-2306, op. 69, d. 2692, I. 49-50, zitiert nach Kantor, Julija: Nevidimyj front, S. 13.

48 Lupalo, I.: Vklad muzeev, S. 130. 
ges, als die Achsenmächte unbesiegbar schienen und den muzejščiki jegliche Erfahrung beim Sammeln und Ausstellen von Objekten der Gegenwart fehlte, liefen die Kuratorinnen und Kuratoren Gefahr, mit ihrer Darstellung des aktuellen Kriegsverlaufs bei der Bevölkerung Panik anstelle von Siegesgewissheit zu provozieren.

\section{Wie die Gegenwart zum Sammlungs- und Ausstellungsobjekt wurde}

Anfang Oktober, als die Wehrmacht immer näher auf Moskau vorrückte und sich die Luftangriffe auf die Stadt verstärkten, entwickelte ein Kurator des GIM eine kleine Sonderausstellung, die zur Grundlage des neuen Typus der >kommemorativen sowjetischen Kriegsausstellung wurde. Bei seinem Dienst in der Moskauer Fliegerabwehr (Zenitčiki) sammelte der erfahrene Museologe und wissenschaftliche Sekretär des GIM, Georgij Leonidovič Malickij (1886-1953), Materialien, die bei dem Training der zivilen Bevölkerung genutzt wurden, und fotografierte ihre Einsätze. ${ }^{49}$ Aus diesen Materialien erstellte er im Juni eine Ausstellung mit dem Titel "Die heroische Verteidigung von Moskau vor den Luftangriffen« (Geroičeskaja oborona Moskvy ot voszdušnych napadenij). ${ }^{50}$ Die Besucherinnen und Besucher, von denen viele selbst zum Dienst bei der Fliegerabwehr eingeteilt waren, interessierten sich besonders für die Ausrüstung der mobilisierten Zivilbevölkerung. ${ }^{51}$ Hier zeigt sich bereits die Resonanz, die die gegenwartsbezogenen Kriegsausstellungen bei ihrem Publikum hatten. Die Ausstellung war informativ und die museale Präsentation wertete zugleich das eigene Erleben auf und verlieh ihm damit Relevanz.

Der Kurator Malickij erstellte auf der Grundlage dieser Sammelpraxis eine Liste mit Objekten, die er für eine Ausstellung zu Themen zum »Großen Vaterländischen Krieg « als sinnvoll erachtete. ${ }^{52}$ Interessanterweise war es eben diese Liste, auf die sich weitere zentrale Instruktionen und Anleitungen zum Sammeln der Objekte des »Großen Vaterländischen Krieges« bezogen, die das staatliche Museumsinstitut im Verlauf des Krieges erließ. ${ }^{53}$ Diese Übernahme zeigt, wie das selbstmotivierte Handeln der muzejščiki Impulsgeber für das Museumsinstitutes sein konnte - und nicht andersherum.

Für die bekannte Museologin Anna Borisovna Zaks (1899-1996), die die »Antifaschistische Ausstellung« kuratiert hatte, war die Sonderausstellung zur Moskauer Fliegerabwehr der Beginn einer grundlegenden Neuausrichtung ihrer mu-

Zur Biografie und zu dem museologischen Erbe von Ceorgij Malickij vgl.: Sosimenko, I.: Osnovopoložniki otečestvennogo muzeevedenija: C. L. Malickij i ego pedagogičeskaja dejatel'nost', in: Voprosy museologii, Nr. 2, 2010, S. 46-53.

Zaks, Anna: O rabote, S. 133.

51 Zaks, Anna: Po gorjačim sledam, in: Sovetskij Muzej, Nr. 1, 1985, S. 27-32, hier S. 27.

52 Levykin, Konstantin: Vvedenie, S. 5. Sowie: Levykin, Konstantin: Perestrojka raboty, S. 150. 
sealen Arbeitsweise. ${ }^{54}$ Während die muzejščiki zuvor systematisch gesammelt und dabei nach spezifischen Objekten (sie nennt Uniformen, Ausrüstungen, Waffen, Orden, Medaillen, Plakate oder Briefmarken) gesucht hätten, um eine grundlegende Idee auszustellen, läge hier der Beginn einer neuen Perspektive: der thematisch ausgerichteten Suche. Hier waren die Objekte nicht im Vorfeld ideologisch festgelegt, sondern es stand die Darstellung des Ereignisses aus möglichst unterschiedlichen Perspektiven im Vordergrund. Ihr Arbeitskollege Georgij Malickij hatte beispielsweise nicht nur Gebrauchsanweisungen von militärischen Geräten gesammelt, sondern auch Dienstpläne, die zuvor als nicht ausstellungswürdige, bedeutungslose Arbeitsblätter gegolten hatten. ${ }^{55}$

Die Eröffnung der »Antifaschistischen Ausstellung« im September 1941 suggerierte eine Sicherheit, die in keiner Weise der Kriegsrealität entsprach. Die letzte Verteidigungslinie der Roten Armee vor Moskau befand sich in Auflösung. Am 15. Oktober 1941 ordnete Stalin die Evakuierung der wichtigsten Betriebe der Hauptstadt an. ${ }^{56}$ Panik hatte Moskau erfasst, und die Mehrheit der Museumsmitarbeitenden verließ mit ihren Familien die Stadt. ${ }^{57}$ Einige zogen es jedoch vor, aus persönlichen Gründen in Moskau auszuharren. Anna Zaks erinnert sich, dass sie und ihre Kolleginnen und Kollegen sich ihrem Beruf verpflichtet fühlten:

»Die schweren Oktobertage brachen an. [...] wie alle Moskauer gruben wir Panzerabwehrgräben. [...] Am 16. Oktober 1941 rief uns die Direktorin Anna Kaprova in ihr Büro. Sie sagte: > Heute um 15:00 Uhr müssen Sie evakuieren [...].< Noch heute beginnt mein Herz schneller zu schlagen, wenn ich diese Zeilen schreibe. Damals erstarrten wir buchstäblich. Als erste unterbrach die Abteilungsleiterin A.L. Vejnberg die Stille: >lch kann nicht gehen, solange meine Sammlungen der zweiten Ordnung nicht evakuiert sind. Das sind Kostbarkeiten von unschätzbarem Wert [gromadnaja cennost'] [...] k. Sie wurde von dem Abteilungsleiter N.I. Sobolev unterstützt und nach ihm von allen anderen: ১Wir gehen nicht<, sagten alle unbeirrt. Der Blick von Kaprova richtete sich voller Hoffnung auf mich. Irgendjemand musste den Befehl zur >sofortigen Evakuation< erfüllen. [Ich sagte: A.H.] >Aber auf

54 Zaks, Anna: Opyt sobiranija materialov po istorii velikoj otečestvennoj vojny gosudarstvennym istoričeskim muzeem v 1941-1945, in: Archeografičeskij ežegodnik za 1975, Moskva 1976, S. 149-158, hier S. 149-150.

55 Ebd.

56 Für die Kriegsereignisse ab Juni 1941 einschließlich der Schlacht um Moskau vgl. Braithwaite, Rodric: Moscow 1941.

57 Von den 177 Mitarbeiterinnen und Mitarbeitern, die vor dem Krieg im GIM arbeiteten, blieben bis zu ihrer individuellen Rückkehr im Februar 1942 nur 66 im Museum zurück. Vgl. Zaks, Anna: O rabote, S. 130-131. 
mir liegt die Verantwortung für die Sicherheit der Antifaschistischen Ausstellung. Solange ich nicht alle Objekte übergeben habe, kann ich nicht gehen. แ $^{58}$

Auch wenn sich hier eine gewisse (heroische) Selbstinszenierung in der retrospektiv geschriebenen Autobiografie zeigt, gab es triftige Gründe für die Museumsmitarbeitenden, trotz der drohenden feindlichen Einnahme in Moskau bleiben zu wollen. Eine Motivation war das Gefühl der Verantwortung, das Anna Zaks und ihre Mitstreiterinnen und Mitstreiter empfanden. Ihre Verbundenheit mit dem Museum zeigt sich in dem Erinnerungsalbum, dass sie collagenartig beklebte und mit Kommentaren versah. ${ }^{59}$ Eine Seite gestaltete sie mit den Umschlägen von vier an sie, bzw. an das Museum adressierten Briefen und einem Porträt von sich selbst. Neben das Foto klebte sie einen auf weißes Papier getippten Text: »Die Briefe kamen aus allen Ecken des Landes. Hier ist nur ein kleiner Teil. Sie waren wie >Vitamine $<$, die uns halfen, die Schwierigkeiten und die Trauer der Kriegszeit zu ertragen.«Ihre Selbstdarstellung als Empfängerin von Botschaften aus dem ganzen Land verstärkt den Eindruck von einer historisch bewussten Frau, die sich selbst als Zeitzeugin, Chronistin und Dokumentaristin sah. ${ }^{60}$

Viele der verbliebenen muzejščiki waren bereits ältere und alleinstehende Frauen. Sie waren sich der Lebensgefahr bewusst, die ein Verbleib in der Stadt bedeutete, aber die Vorstellung, alles Vertraute zurückzulassen und in einer unbekannten Stadt neu zu beginnen, schreckte sie ab. Die Evakuationsstädte im Hinterland lagen größtenteils in Sibirien oder Kasachstan, und einige hatten Angst, die Reise und das kalte Klima nicht zu überleben oder keine neue Arbeit vor Ort zu finden. ${ }^{61}$

Für die zurückbleibenden muzejščiki bot die Museumsarbeit Ablenkung und Erfüllung in der Panik, die trotz aller Gegenmaßnahmen des Geheimdienstes (Arreste etc.) Mitte Oktober die Hauptstadt erfasste. »Die Straßen von Moskau waren merkwürdig wiederbelebt«, erinnert sich Anna Zaks. »Niemand ging ruhig, alle rannten mit Koffern oder Rucksäcken in verschiedene Richtungen. Es war unmöglich, den

58 Zaks, Anna: Kak my žili i rabotali, S. 10.

59 Reproduktionen aus dem Erinnerungsalbum der Kuratorin des GIM Anna Zaks, in: Gosudarstvennyj istoričeskij muzej (Hg.): »Pobeda!«, k 70-letiju okončanija Velikoj Otečestvennoj vojny, Moskva 2015.

60 Die Sätze auf dem grünen Papier sind (adaptierte) Zitate aus zeitgenössischen Liedern und Gedichten. In der Mitte (oben): »Ždi menja i ja vernus' « (Wenn Du auf mich wartest, komme ich zurück). Unten links (handschriftlich): »Nam pis'ma verit' i žit' pomogajut« (Die Briefe lassen uns glauben und helfen beim Leben«). Dieses Zitat ist eine Anpassung des Refrains »Nam pesnja stroit' i žit' pomogajut « (Lieder bauen uns auf und helfen beim Leben) des populären Volksliedes »Legko na serdce ot pesni veseloj« von Lebedev-Kumač von 1934.

61 Vgl. Kriegstagebuch von Marija Denisova. Sie lehnte das Evakuationsangebot zwei Mal $a b$ und beschrieb die Ängste, die sie vor der Evakuation empfand, und ihren dringenden Wunsch, in Moskau zu bleiben, »auch wenn das den Tod bedeuten würde«. Astvacaturjan, E.: Iz »Dnevnika vojny« M. M. Denisovoj, S. 77ff. 
Bus oder die Tram zu benutzen. Wir, die wir im GIM saßen, gingen unseren Aufgaben nach und flohen so aus der panischen Stimmung. ${ }^{62}$ Da beinahe die ganze Führungsriege des GIM entweder evakuiert, mobilisiert oder von den Freiwilligenverbänden eingezogen worden war (auch die Direktorin des GIM, Anna Kaprova, wurde mit der zweiten Evakuationswelle aus Moskau gebracht), waren die muzejščiki sich selbst überlassen. Die meisten gimovcy, wie sich die Museumsmitarbeitenden des GIM bezeichnen, übernachteten nach der Ankündigung des Belagerungszustandes der Stadt im Museum und wohnten zum Teil mit ihren Familien in den Kellern des Gebäudes. ${ }^{63}$ Die Gemeinschaft und die berufliche Herausforderung schien ihnen in der bedrohlichen Zeit Kraft zu geben:

»Wir saßen am ovalen Tisch im inneren Korridor, gegenüber der Bibliothek. Hier gab es keine Fenster, und man konnte beruhigt das Licht anmachen, manchmal entschieden wir sogar, nicht in den Luftschutzbunker zu gehen. Normalerweise tranken wir hier Kaffee - Surrogat ohne Zucker und Milch. Wir versuchten einander aufzuheitern. Erzählten uns irgendwelche interessanten Begebenheiten aus unseren Leben, scherzten oder sagten das Schicksal des GIM mit Karten voraus. [...] Aber an diesem Tag [19. Oktober 1941 A.H.] scherzten wir nicht. Wir überlegten uns einen Plan für unsere zukünftige Arbeit. Und wir entschieden: Wir werden weiterhin Besucher in den Sälen empfangen, keiner von uns bleibt ohne Führungs- oder Beratungstätigkeit, wir werden gleichzeitig eine Dauerausstellung und eine Wanderausstellung [mit dem Namen A.H.] »Verteidigung von Moskau« erstellen. ${ }^{64}$

Hier zeigt sich erneut die Eigeninitiative der muzejščiki. Sie schrieben einen Ausstellungsplan mit einer Liste von zu sammelnden Objekten und konzipierten eine thematisch passende Vorlesungsreihe, die sie der nach Omsk evakuierten Direktorin schickten. ${ }^{65}$ Die muzejščiki begannen umgehend mit der Arbeit und erstellten ausgehend von dem Material der Nachrichtenagentur TASS eine chronologischthematische Fotoausstellung mit dem Titel »Die Verteidigung von Moskau, gestern und heute«. Wie geplant entstand parallel eine transportable Sonderausstellung aus sechs Pappschildern, die mit Fotos und Texten beklebt waren. Die Vermittlungspersonen, zu denen wegen der Stellenkürzungen nun auch die Kuratorinnen und Kuratoren gehörten, bekamen im Speisesaal des GIM eine Extraportion Suppe. Sie fuhren, die Schilder unter dem Arm, mit den Schlitten, die die Betriebe oder Militäreinheiten geschickt hatten. Häufiger noch suchten sie bei minus $30 \mathrm{Grad} \mathrm{zu}$ Fuß die Einheiten der Roten Armee auf, die Fabriken und Betriebe der Stadt und die Krankenhäuser, um Vorträge über die Kriegsereignisse zu halten. In der Regel

62 Zaks, Anna: Kak my žili i rabotali, S. 10.

63 Ebd. S. 10.

64 Ebd. S. 11.

65 Zaks, Anna: O rabote, S. 135. 
beendeten sie ihre Vorträge mit dem Auftrag an ihr Publikum, Erinnerungsstücke (pamjatniki) und Dokumente über den Krieg zu sammeln und sie dem GIM zu übergeben: »Wir kommen zu Ihnen und sammeln sie ein, um sie in den zukünftigen Ausstellungen des GIM zu zeigen. ${ }^{66}$

Der Kurator Malickij, der nach der Evakuation der Museumsdirektorin ihre Stelle interimistisch übernommen hatte, vermerkte folgende Episode in seinem Arbeitsbericht: Ein Kommissar der Roten Armee sagte zu den muzejščiki, die im Dezember 1941 mit Wanderausstellungen in die Moskauer Krankenhäusern kamen, um den Verwundeten Vorträge über den Krieg zu halten: »Die Arbeit, die Sie leisten, ist von großer Wichtigkeit, sie macht Sie zu Teilnehmern des Großen Vaterländischen Krieges. ${ }^{67}$ Eine Würdigung von respektierter Stelle, die das Selbstbild der muzejščiki als Dokumentaristinnen und Dokumentaristen des Krieges bestätigte.

Anna Zaks erinnerte sich, wie diese Arbeit jäh unterbrochen wurde, als am 29. Oktober 1941 die deutsche Luftwaffe Brandbomben in der Nähe des Roten Platzes abwarf und die Druckwellen große Teile des Museums zerstörten:

»Niemals werde ich den 29. Oktober vergessen. Ich hatte an diesem Tag Wachdienst. Die Luftangriffe waren noch nicht angekündigt worden. Aber sobald es dämmerte, flog neben dem Fenster des Direktorenbüros mit einem Pfeifen eine brennende Garbe vorbei und verschwand hinter der Kremlmauer. Die Fenster knallten auf, Glassplitter flogen auf den Tisch, die Verdunklung riss. Schnell machte ich das Licht aus. Das Geheul der Sirenen ertönte. Ich lief in den kleinen inneren Korridor, dort befand sich der Leiter der Wache, der bekannte Archäologe D.N. Eding. Er blieb ganz ruhig. Weder die Sirenen noch das Geräusch von zerbrechendem Glas oder mein aufgeregtes Aussehen störten ihn dabei, konzentriert zu beobachten, wie sein Kaffee aufkochte - er war der große Experte in dieser Sache. Wieder dröhnte es. Die dumpfen Schläge schienen in der Nähe zu sein. Erneutes Klirren. Diesmal schlug es die Fenster auf der Seite zum Roten Platz heraus [...] Das arme alte GIM zitterte. Nicht zufällig sind heute in seinem Fundament gefährliche Risse. ${ }^{68}$

Die Druckwellen der Bomben, die in dieser Nacht nur 800 Meter entfernt vom Roten Platz abgeworfen wurden, hatten die »Antifaschistische Ausstellung« vollständig zerstört. Als Marija Denisova am nächsten Morgen ins Museum kam, berichtete sie von der »totalen Niedergeschlagenheit« und von der Angst vor einer

66 Zaks, Anna: Po gorjačim sledam, S. 27-28.

67 Malickij, Georgij: Opyt raboty GIM v uslovijach Velikoj Otečestvennoj vojny, Otčet GIM za 1942 g. Zitiert nach: Zaks, istorii gosudarstvennogo istoričeskogo muzeja, 1941-1957 gg., in: Naučno-issledovatel'skij institut muzeevedenija (Hg.): Očerki istorii muzejnogo dela v Rossii, Ed. 3, Moskva 1961, S. 5-54, hier S. 9. 
endgültigen Schließung des Museums. ${ }^{69}$ Ihr Vorgesetzter Malickij beschrieb in seinem monatlichen Arbeitsbericht, wie das Museumskollektiv nach den Zerstörungen beschloss, die Reste der Ausstellung abzubauen und stattdessen die Ausstellung »Verteidigung von Moskau« aufzubauen:

»Die Druckwelle der am 29. Oktober in der Nähe des Museums abgeworfenen Bomben schlug die Scheiben und Rahmen der Fenster in den Ausstellungssälen heraus. Aber das Museum gibt nicht auf. Was auch immer passiert, zum 7. November - dem Tag der Oktoberrevolution - muss das Museum um jeden Preis wieder geöffnet sein. Kälte und Wind jagen durch die Säle des Museums, aber die hartnäckige Arbeit stellt sich ihnen entgegen. Die Schäden wurden beseitigt. « ${ }^{70}$

Im Gegensatz zu dieser Darstellung von heroischer Disziplin erinnert sich Anna Zaks, wie die Techniker und Handwerker der GIM protestierten, als sie von den Plänen der Ausstellungsabteilung hörten. Die Frist sei viel zu kurz, um die zerstörten Fenster und Rahmen zu reparieren und den obligatorischen Verdunklungsschutz wieder einzusetzen. Aber als die muzejščiki in Winterkleidung rund um die Uhr in den kalten und zugigen Sälen arbeiteten, habe »ihr Enthusiasmus auch die Hausmeister angesteckt «. ${ }^{71}$ Auch Marija Denisova beschreibt in ihrem Tagebuch die beruhigende Wirkung, die die Arbeit an der Ausstellung für sie gehabt habe: »Im Museum rissen wir uns zusammen und brachten die Ausstellung in Ordnung. Alle fühlten sich munterer (bodrej). ${ }^{72}$ Als Stalin am 7. November 1941 die Parade am Roten Platz abnahm, empfanden die muzejščiki eine große Zufriedenheit, dass sie rechtzeitig die passende Sonderausstellung auf die Beine gestellt hatten.

\section{Die Handlungsfreiräume der muzejščiki und die staatliche Museumspolitik}

Am 15. November 1941, vier Monate nach seinem letzten Brief an die Museen, verfasste der Institutsleiter Manevskij eine Instruktion mit dem Titel: »Über das Sammeln von Objekten zum Großen Vaterländischen Krieg «. ${ }^{73}$ In diesem Schreiben

69 Astvacaturjan, Ė.: Iz »Dnevnika vojny« M. M. Denisovoj, S. 78.

70 Malickij, Georgij: Očerki istorii muzejnogo dela v Rossii, Ed. 3, Moskva 1961, S. 7.

71 Zaks, Anna: Kak my žili i rabotali, S. 12.

72 Astvacaturjan, Ė.: Iz »Dnevnika vojny« M. M. Denisovoj, S. 78.

73 Manevskij, Aleksej: O sbore materialov velikoj otečestvennoj vojny, Direktoram muzeev, 15 nojabrja 1941, No. 170, in: NIIKMR (Hg.): Rabota politiko-prosvetitel'nych učreždenij v uslovijach voennogo vremeni, S. 14. Tatjana Timofejeva geht davon aus, dass Stalins Beschluss, in der Hauptstadt zu bleiben, seine Rede anlässlich der Revolutionsfeiertage am 6. und 7. November 1941, das Steckenbleiben der deutschen Angriffe vor Moskau und die Versorgung der Front mit neuen sowjetischen Truppen zu einer Verbesserung der militärischen Lage, der moralischen Stimmung in der Stadt allgemein und zu dem Erlass des Museumsinstutes geführt haben. Vgl. Timofejeva, Tatjana: Das historische Gedächtnis des Großen Vaterlän- 
tauchte erstmals das Argument auf, dass man »jetzt sammeln müsse, bevor es zu spät sei«:

»Die Mehrheit der Museen hat bis jetzt dem Sammeln von Objekten mit Bezug zum Großen Vaterländischen Krieg [...] nicht die gebührende Aufmerksamkeit gewidmet. Dabei ist den Museumsarbeitern wohl bekannt, dass viele sehr wertvolle Objekte aus dem Bürgerkrieg spurlos verschwunden sind, nur weil sie nicht rechtzeitig gesammelt wurden. $\ll^{74}$

Weder die muzejščiki des Armeemuseums noch die gimovcy konnten sich von der geäußerten Kritik angesprochen fühlen. Als eines der wenigen Museen hatten sie mit ihren Ausstellungen bereits eine Grundlage für die Sammlung von Objekten zum »Großen Vaterländischen Krieg« gelegt. Vielmehr scheint diese Instruktion des Museumsinstitutes eine Bestätigung ihrer Arbeitsweise gewesen zu sein, die sie mit der Ausstellung über die Verteidigung von Moskau fortsetzten. Rückblickend sah die GIM-Kuratorin Anna Zaks in dieser Ausstellung den Beginn einer neuen Methode, der sie den Titel »auf den heißen Spuren der Ereignisse« (po gorjačim sledam sobitij) gab. ${ }^{75}$ Diese Praxis beschrieb eine Sammlungstätigkeit, die den kriegerischen Ereignissen auf dem Fuß folgte, damit möglichst wenige Objekte verloren gingen. Diese Methode, die von dem drohenden Verlust der Exponate motiviert war, war die praktische Umsetzung von Manevskijs rhetorischem Argument, mit dem er vor einem Verpassen des richtigen Zeitpunktes warnte. Die Metapher der Suche nach Objekten mit Spuren »der heißen Ereignisse« etablierte sich bald im Museumsdiskurs. Noch 40 Jahre später beschrieben Kuratorinnen und Kuratoren mit diesen Worten die für den Krieg spezifische Arbeitsweise. ${ }^{76}$

Ende November 1941 verstärkten sich die deutschen Bombenangriffe auf Moskau. Marija Denisova notierte verzweifelt:

»22.-23. November 1941. Die Deutschen werfen sich in einen neuen Angriff, sie haben unsere Verteidigungslinien durchbrochen und Moskau von drei Seiten umkreist. Nachts starker Kanonendonner der Artillerie. Nein! Moskau wird nicht aufgegeben, unsere Truppen kämpfen verzweifelt [otčajanno]. [...] Mein liebes, mein geliebtes Moskau, ich verlasse dich nicht in diesen schrecklichen Stunden [...]. Im Angesicht des Todes ein verrückter Lebensdurst. «77

dischen Krieges und seine Gedenkorte, in: Hellbeck, Jochen/Vatlin, Alexander/Schmid, Lars Peter (Hg.): Russen und Deutsche in der Epoche der Katastrophen, Moskau 2012, S. 330-342. Manevskij, Aleksej: O sbore materialov velikoj otečestvennoj vojny, S. 14.

75 Zaks, Anna: Po gorjačim sledam, S. 27.

76 Levykin, Konstantin: Vvedenie, S. 5.

77 Astvacaturjan, Ė.: Iz »Dnevnika vojny« M. M. Denisovoj, S. 79. 
Wieder waren es persönliche und berufliche Gründe, die die muzejščiki von der Flucht abhielten. Als eine Abgeordnete des Städtischen Parteikomitees die Museumsmitarbeitenden eindringlich aufforderte, die Stadt zu verlassen, und dabei auf Lenin verwies, der während des Bürgerkrieges nur Betriebe mit verteidigungsrelevanter Funktion von den Evakuationen ausschloß, antworteten die Angestellten des GIM selbstbewusst: »Gerade wir alle, Propagandisten innerhalb und außerhalb der Partei, arbeiten für die Verteidigung, wir verstärken den Glauben an den Sieg und dabei sammeln wir Reliquien (relikvii) des Krieges [...] «. ${ }^{78}$ In diesem Zitat zeigen sich zwei Aspekte, die für die Untersuchung der agency der muzejščiki zentral sind: Die Museumsmitarbeitenden waren davon überzeugt, dass sie durch die Dokumentation und das Sammeln von Kriegsrelikten einen Beitrag zum Sieg leisteten. Dabei agierten sie keineswegs außerhalb staatlicher Strukturen oder abseits des offiziellen Kriegsdiskurses - im Gegenteil, sie verrichteten diese Arbeit als »Propagandisten für den Glauben an den Sieg« und als Sammlerinnen und Sammler von Relikten einer bewahrenswerten Zeit.

Anfang Dezember 1941 wurde die Situation in Moskau immer angespannter. Die Angestellten, die im GIM wohnten, wurden nachts vom Lärm der Panzer und der motorisierten Infanterie aufgeschreckt, die über den Roten Platz an die Front fuhren. Die Soldaten und Kommandeure, die am Museum vorbeiliefen, antworteten auf ihre drängenden Fragen: »Bald, bald werdet ihr es erfahren. «"9 Der Eintrag im Kriegstagebuch von Marija Denisova spiegelt die große Erleichterung wider, die die Gegenoffensive der Roten Armee unter den muzejščiki auslöste: »11. Dezember 1941. Welch ein Glück! Welch eine riesengroße Freude! Es hat sich herausgestellt, dass unsere Truppen bereits seit dem 6. Dezember zum Angriff übergegangen sind: Sie haben bereits eine ganze Reihe von Dörfern und Städten vor Moskau befreit. « ${ }^{80}$ Am 13. Dezember, als Presse und Radio die erfreulichen Nachrichten verbreiteten, schlossen die Museumsmitarbeitenden des GIM ihre Arbeiten an der Ausstellung »Die Verteidigung von Moskau«ab und nahmen die Ankündigung zum Anlass, ih-

78 Zaks, Anna: Kak my žili i rabotali, S. 13. Am 29. November 1941 schickte das Narkompros aus Kirov den Befehl, die erfahrensten und qualifiziertesten Mitarbeiterinnen und Mitarbeiter nach Omsk zu evakuieren. Die Museumsangestellten, die sich diesem Befehl offenbar nicht widersetzen konnten, machten sich zur Abfahrt bereit, jedoch wurde ihr Gepäck nicht rechtzeitig gebracht und sie verweigerten die Abreise erneut. Vgl.: Zaks, Anna: Kak my žili i rabotali, S. 13-14. Der Begriff »Reliquie« im sowjetischen musealen Kontext ist keine Innovation der Kriegsausstellungen. Bereits in den nach der Revolution von 1917 gegründeten »Revolutionsmuseen« wurde der Begriff von den Kuratorinnen und Kuratoren für die persönlichen Gegenstände der Revolutionäre gebraucht. VgI. Kivelitz, Christoph: Die Propagandaausstellung, S. 235-236.

79 Ebd. S. 13.

80 Astvacaturjan, E..: Iz »Dnevnika vojny« M. M. Denisovoj, S. 80. 
rer Sonderausstellung einen neuen Namen zu verleihen: »Die Zerschlagung der deutschen Truppen vor Moskau« (Razgrom nemeckich vojsk pod Moskvoj). ${ }^{81}$

Mit dieser Sonderausstellung knüpften sie direkt an die Semantik der anderen Medien der Hauptstadt an. Im Dezember 1941 war die `Zerschlagungsparoleく allgegenwärtig: Sie hing in großen Spruchbändern an den Fabriken, die Zeitungen druckten sie als Banner auf den oberen Rand ihrer Titelseiten und Frontreporter sowie Regisseure produzierten einen gleichnamigen Dokumentarfilm, der bald in allen Kinos der Stadt zu sehen war. ${ }^{82}$ Die muzejščiki erhöhten die Frequenz ihrer Vorlesungen, die sie sowohl vor militärischem als auch zivilem Publikum hielten. Während sie in den turbulenten Monaten Oktober-November "nur« 58 Vorträge halten konnten, erreichten sie im Dezember mit insgesamt 142 Vorträgen beinahe das Vorkriegsniveau (zum Vergleich: im Mai 1941 hielten sie 179 Vorträge). Auch die Besucherzahlen im GIM begannen wieder zu steigen. Während im November 1941 lediglich 774 Menschen die Ausstellungen besucht hatten, stieg die Zahl im Dezember bereits um das sechsfache, auf 4.831 Menschen. Jedoch stand dieser beachtliche Anstieg in keinem Verhältnis zum Vorkriegsniveau: Im Mai 1941 hatte das Museum 34.423 Menschen empfangen. ${ }^{83}$

Vor dem Hintergrund der aktiven Arbeit im Museum ist die Überraschung nachvollziehbar, die die muzejščiki empfanden, als das GIM am 19. Dezember 1941 folgenden Befehl des Museumsinstitutes erhielt: Sämtliche Stellen der wissenschaftlichen Mitarbeitenden sollten gestrichen und die Angestellten in die sibirische Stadt Omsk evakuiert werden. Nur ein Minimum des Personals sollte für die Bewachung des Gebäudes in Moskau zurückbleiben. ${ }^{84}$ Laut Anna Zaks bedeutete das die faktische Schließung des Museums. Die Hintergründe dieser Entscheidung blieben ihr jedoch ein Rätsel, und sie konnte nur Mutmaßungen anstellen:

81 Zaks, Anna: Po gorjačim sledam, S. 28.

82 Das Schlagwort »Razgrom « (Zerschlagung) war weder neu noch spezifisch für den medialen Diskurs über den »Großen Vaterländischen Krieg«. Im Gegenteil, in der Ausstellungsrezension des Armeemuseums vor Ausbruch des Deutsch-Sowjetischen Krieges wurde von der »Zerschlagung der Entente« im Kontext des Ersten Weltkrieges, von der »Zerschlagung Denikins und Wrangels« im Russischen Bürgerkrieg und von der »Zerschlagung Mannerheims« im Winterkrieg gesprochen, Vgl. Pankov, I.: Dokumenty slavy, S. 146-155.

83 Grišaev, Oleg: Gosudarstvennij istoričeskij muzej v gody velikoj otečestvennoj vojny, in: Vestnik VGU, Serija Gumanitarnye nauki, 2005, Nr. 1, S. 59-66, hier S. 63.

84 Anna Zaks schrieb in ihren Erinnerungen, dass der Befehl das GIM »wie ein Donner am klaren Himmel« traf. Vgl. Zaks, Anna: Kak my žili i rabotali, S. 14. Marija Denisova schrieb in ihr Kriegstagebuch: „Sie haben das Gehalt zum zweiten Mal nicht ausgezahlt. Es gehen Gerüchte um, das Museum nach Omsk zu bringen. Unerwartet treffen uns große Sorgen: Wir erhalten Nachrichten über Kürzungen und Streichungen. [...] Die großen Betriebe machen wieder auf und unser Museum wollen sie schließen?« Vgl. Astvacaturjan, $\dot{E} .:$ Iz »Dnevnika vojny« M. M. Denisovoj, S. 80. 
»Bis heute verstehe ich die Cründe dieses Befehls nicht. Wahrscheinlich hatte die schwierige finanzielle Situation zu der Kürzung der Mittel geführt. Eine bedeutende Rolle haben vielleicht auch die Berichte über die niedrigen Besucherzahlen im November 1941 gespielt, darüber, dass alle Moskauer Museen temporär geschlossen waren. Unter den Kriegsbedingungen waren die Beziehungen schlecht, auch das geringe Wissen, das die Abteilung von der Arbeit des GIM hatte, spielte eine Rolle. ${ }^{85}$

Nach ihrer Rückkehr ins Museum Mitte Januar 1942 konnte die Direktorin Anna Kaprova die Entscheidung rückgängig machen und alle Angestellten konnten weiterarbeiten. Diese Episode steht jedoch exemplarisch für das Verhältnis zwischen den Museen und ihrer übergeordneten Behörde. Ihre Vorstellungen von den Möglichkeiten der Museumsarbeit gingen in der Regel an den realen Handlungsspielräumen der Museen vorbei. Obwohl das Museum die Forderung des Museumsinstitutes nach einer ideologischen Erziehung der Moskauer Bevölkerung vorbildlich umgesetzt hatte, kam es beinahe zur Schließung.

Die Mehrheit der Museen außerhalb der Hauptstadt hatten mit weitaus schwierigeren Umständen zu kämpfen. Die Behörden überschätzten deren Arbeitsmöglichkeiten im Krieg maßlos und versagten gleichzeitig bei ihrer Unterstützung. Der Deutsch-Sowjetische Krieg brachte die Arbeit der Museen größtenteils zum Erliegen. Von den insgesamt 342 Museen, die zu Jahresbeginn 1941 dem Narkompros unterstanden (das entsprach ca. einem Drittel aller Museen in der ganzen Sowjetunion: 992) konnten ein Jahr nach Kriegsausbruch nur noch 121 weiterarbeiten, da sich viele im besetzten Gebiet befanden. ${ }^{86}$ Anstatt die Zustände in den besetzten und frontnahen Gebieten sowie im Hinterland $\mathrm{zu}$ berücksichtigen, warf der Volkskommissar für Bildung Potëmkin den Kultureinrichtungen vor, dass sie die »riesengroße politische Bedeutung ihrer Arbeit« nicht verstanden hätten und es sogar zu »unbegründeten Schließungen« einzelner Einrichtungen gekommen sei, die seine Behörde nicht akzeptieren würde. ${ }^{87}$

Die Museen, die weiterarbeiten konnten, bemühten sich, Potëmkins Befehl nach einer Ausstellung über den »Großen Vaterländischen Krieg« nachzukommen. Bald entstanden überall in der Sowjetunion Ausstellungen mit ähnlichen Titeln. Das Problem nicht vorhandener Exponate stellte sich den lokalen Museen, weit entfernt von der Front, in noch größerem Maßstab, weshalb sie auf das Material zurückgriffen, das ihnen das Museumsinstitut zur Verfügung stellte. So wurde die Ausstellung mit dem Titel »Die heldenhafte Vergangenheit des Russischen Volkes«

85 Zaks, Anna: Kak my žili i rabotali, S. 14.

86 Ebd. S. 156.

87 Potèmkin, Vladimir: O rabote politiko-prosvetitel'nych učreždenij v voennoe vremja, S. 8-9. 
(Geroičeskoe prošloe russkogo naroda) in den regionalwissenschaftlichen Museen in Astrachan, Sachalin, Igarka, Dmitrov und anderen Städten gezeigt. ${ }^{88}$ Während diese Museen tendenziell die gleichen historischen Narrative vom wiederkehrenden deutschen Eroberer als besiegbaren Feind ausstellten und ihre regionale Kriegserfahrung dabei scheinbar unberücksichtigt ließen, dürfen dennoch nicht voreilig generalisierende Aussagen über gleichgeschaltete Museen im Krieg getroffen werden. Bei genauerer Betrachtung zeigt sich nämlich, dass die Museen ihre Ausstellungen zum »Großen Vaterländischen Krieg« nach Möglichkeit durchaus individuell prägten. ${ }^{89}$

Diese Diskrepanz zwischen den behördlichen Vorstellungen und der Lebenswelt der muzejščiki wurde 1961 formuliert, als die Geschichte des Museumswesens im Krieg von sowjetischer Seite erstmals aufgearbeitet wurde. Die Kritik lautete, dass die Direktiven des Narkompros »die Schwierigkeiten, vor denen die Museen [...] standen, absolut nicht berücksichtigt hätten [...] und die Museen vor viel zu große Aufgaben gestellt hätten ${ }^{90}$

\section{»Sammeln, bevor es zu spät ist!“}

Die Grundlage für die Sonderausstellungen waren die Kollektionen zum »Großen Vaterländischen Krieg«, die die Museen im Verlauf des Krieges anlegten. Nach dem Sieg über das Dritte Reich verfügte das Moskauer Armeemuseum über die umfangreichste Sammlung zum Krieg. Die Eingänge von Objekten zum »Grossen Vaterländischen Krieg« sind seit Dezember 1941 dokumentiert. Jedoch hatten offenbar auch hier einzelne Angestellte gleich nach Kriegsausbruch mit dem Bewahren von zukünftigen Ausstellungsobjekten begonnen. Das Inventarbuch des Museums verzeichnet bereits »Ende Juli 1941« den Sammlungseingang eines von der sowjetischen Fliegerabwehr abgeschossenen deutschen Flugzeuges. ${ }^{91}$ Die nach Kazan evakuierten muzejščiki erhielten schon Ende Dezember 1941 von ihren Moskauer

88 Fatigarova, Natal'ja: Muzejnoe delo, S. 195.

89 Als weiteres Beispiel bietet sich das »Staatliche Museum Tatarstan« in Kazan an. Hier sammelten die Museumsmitarbeiterinnen und Museumsmitarbeiter nach Ausbruch des Krieges ebenfalls Objekte mit starkem regionalem Bezug. Die örtliche Gesellschaft »Tatarischer Künstler« (Tatchudožnik) produzierte sogenannte »Satirefenster« (Okna satiry), die das Museum ausstellte und die bis heute in der Museumssammlung und in ganz Russland als einmalige Kollektion gelten. Vgl. D’jaknov, Vladimir: Vospominanija o vystavkach voennych let, in: Muzejnoe delo v SSR, Moskva 1976, S. 177-183.

90 Simkin, Mendel': Sovetskie muzei v period Velikoj Otečestvennoj vojny, in: Trudy Naučno-issledovatel'skogo instituta muzeevedenija, Ed. 2, Moskva 1961, S. 207, zitiert nach: Fatigarova, Natal'ja: Muzejnoe delo v RSFSR v gody Velikoj Otečestvennoj vojny, S. 194.

91 Afanac'ev, Vladimir.: Ekspedicii na Front, in Koroleva, L. A. (Hg.): Muzejnij front Velikoj Otečestvennoij, Moskva 2014, S. 320-326, hier S. 320. 
Kolleginnen und Kollegen folgende Materialien direkt von der Front: »Plakate, einen deutschen Granatwerfer, ein deutsches Radio, eine deutsche Kreuzhacke mit Lederbezug, fünf deutsche Stahlhelme, den Ranzen eines deutschen Soldaten, fünf Fahnen ohne Stange, 27 mit [Stange A.H.], eine Kanone und einen Schlitten der Partisanen sowie verschiedene Mappen mit Zeitungen. ${ }^{92}$

Am 9. Dezember 1941 rapportierte der oberste Ausbildungsoffizier des Museums und Politkommissar Pëtr Loginov seinem Vorgesetzten in der GlavPURKKA die »Arbeitsperspektiven des Museums«. Er nannte an erster Stelle die Suche nach militärischen »Trophäen « wie Fotos, Dokumente und Agitationsplakate. ${ }^{93}$ Auch die Dringlichkeit der wissenschaftlichen Erschließung zukünftiger Exponate wurde im Bericht genannt. Als chronologisches Verzeichnis der verschiedenen Materialien zu den Kriegsereignissen sollte eine Kartei dienen. Hier zeigt sich erneut der Anspruch der muzejščiki, die Kriegsereignisse möglichst umfassend zu dokumentieren und zu archivieren. Der Arbeitsbericht endet mit Anträgen an die GlavPURKKA: Loginov bat um politische Unterstützung für seine Angestellten, um bei den kämpfenden Einheiten an der Front nach zukünftigen Ausstellungsexponaten zu suchen. ${ }^{94}$ Als Offizier verfügte der Kurator Loginov über eine militärische Ausbildung und den Rang eines Politkommissars. Diese politischen Offiziere (Politruki) waren verantwortlich für die ideologische Betreuung der Roten Armee. ${ }^{95}$ Loginov hatte also eine Vorstellung vom politischen Bewusstsein der Rotarmistinnen und Rotarmisten und ihrer Kooperationsbereitschaft mit (zivilen) Museumsangestellten. Offenbar erschien ihm ein erfolgreiches Objektesammeln der muzejščiki bei der Roten Armee ohne die offizielle Unterstützung der höchsten politischen Armeeverwaltung als unrealistisch. Mit dieser Maßnahme wollte er sich absichern, da er wohl ahnte, dass den muzejščiki ohne Erlaubnis von höherer Stelle keine Materialien ausgehändigt werden würden.

Am 24. Dezember 1941 schickte das Armeemuseum zwölf »Politarbeiter« (Politrabotniki) der Moskauer Militärakademie in Paaren zu den Einheiten der Armeen an verschiedene Frontabschnitte, um Objekte für die Ausstellung »Die Zerschlagung der deutschen Okkupanten vor Moskau« zu sammeln. ${ }^{96}$

92 Pavjutkina, Irina: >Dorogi vojny< vedut čerez muzej, in: Krasnaja Zvezda, 22. Juni 2011, http:// old.redstar.ru/2011/06/22_06/5_03.html (Stand: 31.07.2021).

93 CAMO RF [Zentralarchiv des Verteidigungsministeriums der Russländischen Föderation], f. 32, op. 11302, d. 9, I. 214-216.

94 Ebd. I. 216

95 Kalnins, Bruno: Agitprop, S. 61.

96 CMVS [Zentralmuseum der Vereinigten Streitkräfte der Russländischen Föderation, hier wurde auf die »Fond-Ebene« (f.) verzichtet] op. 3, d. 20/3, I. 1. Hinter diesem Befahl stand vermutlich eine Anweisung der GlavPURRKA. Es ist anzunehmen, dass nicht der nominelle Chef der Politischen Hauptverwaltung Lev Mechlis diesen Befehl angeordnet hatte, sondern A. Ščerbakov, der gemäß Jörg Morré der »entscheidende Mann« innerhalb der Behörde war, die er 
Die GlavPURKKA war die mächtigste administrative Verbündete der Militärmuseen beim Sammeln »auf den heißen Spuren der Ereignisse«. Diese Behörde verschaffte den muzejščiki Zugang zu den Verbänden der Roten Armee und damit auch zu den gewünschten Objekten. Die Personalstruktur der Museen verlangte in der Regel, dass leitende Stellen mit ranghohen Militärangehörigen besetzt wurden. Diese nutzten ihre Stellung, um bei der Behörde Druck auszuüben und die gewünschte Unterstützung zu erreichen. Im Dezember 1941 schrieb Jan Francevič Kuske (1897-1956), Oberst und Direktor des Historischen Artilleriemuseums in Leningrad der GlavPURKKA einen ausführlichen Bericht. ${ }^{97}$ Unter dem Titel »Das Sammeln der Erinnerungsstücke (pamjatniki) des [Großen] Vaterländischen Krieges!« appellierte Kuske an die politische Behörde der Roten Armee. Er betonte das Verantwortungsbewusstsein der muzejščiki, die erkannt hätten, dass der gegenwärtige Krieg »beispiellos in der Geschichte der Menschheit« sei. Dieser Krieg habe die geistige Elite vor die »allergrößte Aufgabe« gestellt: die museale Verewigung dieser Ereignisse. ${ }^{98}$

In seiner Rhetorik, mit der Direktor Kuske versuchte, die mächtige politische Instanz für die Relevanz des Sammelns von Kriegsrelikten zu sensibilisieren, tauchte das Argument des Museologen Manevskij über das »Sammeln, bevor es zu spät ist « wieder auf. Kuske schrieb:

»Es muss daran erinnert werden: Was jetzt nicht gesammelt und gesichert wird, wird im großen Maße für die Ceschichte und die Nachkommen verloren sein [..., ] dann wird die Mehrheit der gesammelten Erinnerungsstücke bereits ihre vollständige historische Bedeutung und ihr Interesse verloren haben, weil sie ihrer Bedeutung für das Cedächtnis [memorial'nogo značenie] beraubt sind, da sie nicht mehr mit den konkreten Fakten, Daten, Ereignissen, Orten und Menschen korrelieren. ${ }^{99}$

Hier zeigt sich das Quellenverständnis der muzejščiki im Allgemeinen und Kuskes Argumentation im Konkreten. Er erklärte sein Verständnis von den zu sammelnden »Erinnerungsstücken« als Gegenstände, die mit bestimmten historischen Ereignissen, Orten und Personen verbunden sein müssten. Diese Priorität der eindeutigen Provenienz des historischen Materials als unerlässliche Voraussetzung

im Juni 1942 übernahm. VgI. Morré, Jörg: Hinter den Kulissen, S. 29. A. Ščerbakov war der Vorsitzende des Sowjetischen Informationsbüros und initiierte im Dezember 1941 eine medial breit angelegte Kampagne zur Kriegsberichterstattung.

97 CAMO RF, f. 32, op. 11302, d. 96, I. 16a-18. Hier werden die Anstrengungen der Museumsarbeitenden beim Sammeln von Kriegsrelikten erstmals aktenkundig. Das hat die Forschung dazu verleitet, den Museumsdirektor Jan Kuske als Initiator einer systematischen und professionellen Suche zu bezeichnen. Vgl. Kantor, Julija: Otraženie sobytij, S. 12-13.

Ebd. 
für die erfolgreiche Erziehung und Bildung im Museum war das Argument, um die Behörden zur Unterstützung der Sammelarbeit zu bewegen. Rhetorisch geschickt antizipierte Kuske die vermutete Entgegnung der Behörde, dass nach dem gewonnenen Krieg noch genug Zeit zum Sammeln der Objekte sei, und entkräftete diese, indem er sagte:

»Es hat sich gezeigt, dass es `danach<nur noch möglich ist, Gegenstände und Denkmäler von allgemeinem Charakter zu sammeln [...]. Als Resultat davon haben wir diese beklagenswerte Situation, dass wir zu der ruhmvollen und siegreichen Ceschichte der Oktoberrevolution [...] fast keine echten, aktuellen Erinnerungsstücke haben: [...] Wo ist die von Ruhm durchwehte Fahne der Roten Garde? [...] Wo sind die Denkmäler und Erinnerungsstücke, die von den Helden von Chassan, von Chalchin-Gol und der Weiß-Finnischen Kampagne [dem Winterkrieg] erzählen? [...] Liegt es vielleicht daran, dass unsere Militärmuseen die größten Ereignisse unserer Zeit nur im Allgemeinen zeigen? [...] Die wichtigsten und grundlegenden Objekte sind fast ausschließlich Fotos, selbstgemalte Schemata, meterlange Zitate, Auszüge, Anmerkungen und Erklärungen, Fotos von ganzen Zeitungsspalten, Texte von Reden, Erlasse und Entscheidungen usw. usw. Diese Materialien sind darüber hinaus sehr häufig unsachgemäß ausgewählt, schlecht ausgeführt, geschmacklos gestaltet und ohne irgendein System inszeniert, alle Wände und Stellwände des Museums sind mit Blättern überzogen [zalistovany]. « ${ }^{100}$

Kuske benutzte seine Expertise als Kurator und konfrontierte die GlavPURKKA mit den Folgen der bisher unzulänglichen Museumsarbeit. Er bezeichnete die Oktoberrevolution und die militärischen Konflikte der Sowjetunion in der Mandschurei (1938-1939) und im Winterkrieg als Episoden einer erinnerungswürdigen Geschichte, die jedoch wegen fehlender Objekte auf eine unbefriedigende Ausstellung von Flachwaren reduziert werden müsste. Die militärhistorischen Erfolge stünden in keinem Verhältnis zu ihrer potentiellen propagandistischen Verwertung. Darüber hinaus seien sie derart schlecht inszeniert, dass der Museumsdirektor die Erfüllung des musealen Erziehungsauftrages anzweifelte und einen direkten Bezug zum »schlechten Ausbildungsstand « der Roten Armee herstellte:

»[...] ob es deswegen bei unseren Einheiten der Roten Armee zu einer äußerst schlechten Ausbildung der Soldaten und Kommandeure [...] gekommen ist? Cenau deswegen, weil es bei der Armee überhaupt keine materielle historische Basis für eine anschauliche militärpolitische Propaganda und Popularisierung gibt,

100 Ebd. I. 16-16ob. [oborona= Rückseite]. Zu den sowjetisch-japanischen Kämpfen am ChalchinCol-Fluss und am Chassan-See (beides in der heutigen Mongolei) zwischen Mai-September 1939 und zum Winterkrieg mit Finnland vom 30. November 1939 bis Mitte März 140, vgl. Reese, Roger: The Soviet Military Experience, A History of the Soviet Army, 1917-1991, London/New York 2000, S. 94-100. 
kann der Sinn für Militärgeschichte nicht eingeimpft werden [...]. Ich habe einmal einen Vortragenden nach der Versammlung gefragt, was konkret seine Einheit berühmt macht und er hat mir offen geantwortet, sWer zum Teufel soll das wissen?«101

Kuske kritisierte sein eigenes Fach und machte die Museen für die schlechte politische Bildung der Roten Armee mitverantwortlich. Der als Selbstkritik gerahmte Brief steckte voller Vorwürfe gegenüber der GlavPURKKA, die für die politische Bildung der Soldatinnen und Soldaten verantwortlich war. Die politische Unkenntnis der Kommandeure wörtlich zu zitieren, erscheint, insbesondere zu Kriegsausbruch, als das militärische Versagen der Armee gerade offenkundig geworden war, bemerkenswert. Der Leningrader Museumsdirektor beließ es jedoch nicht bei dieser Stellungnahme, sondern beschrieb die Sammlungsarbeit der vorrevolutionären Militärhistoriker und Museumsarbeiter als idealtypisches Vorbild. Wie dieses Vorgehen der vorrevolutionären muzejščiki Orientierung für die gegenwärtigen Aufgaben geben sollte, machte Kuske an drei Punkten deutlich: Erstens nannte er die erfolgreiche Arbeit der »Trophäen-Kommission«, die während des Ersten Weltkrieges nicht nur eine große Anzahl an Objekten gesammelt, sondern diese darüber hinaus wissenschaftlich für den musealen Nutzen aufgearbeitet habe. Dem stellt er die »Trophäen-Kommission« des »Großen Vaterländischen Krieges« gegenüber, die bislang nur für die Armee arbeite und zerschossenes Kriegsgerät sammle, um es zur Wiederverwendung zu reparieren. Zweitens sei die Sammlungsarbeit bereits unter Peter dem Großen von der Regierung unterstützt worden, was zu reichhaltigen Museumssammlungen geführt habe. Drittens sei bedauernswerterweise die Tradition der sogenannten »Heeresmuseen« (polkovych muzeev) durch die Revolution zerstört worden. Museumsdirektor Kuske empfahl, diese Tradition wiederaufzunehmen und jeder Einheit der Roten Armee ein eigenes Museum zuzuordnen, um das eintreffende Material ordnen und ausstellen zu können. Mit diesem Plädoyer für die vorrevolutionäre Museumspraktik war für Kuske die Dringlichkeit, augenblicklich mit der staatlichen Organisation der militärhistorischen und musealen Sammelarbeit zu beginnen, "ganz und gar einleuchtend «. ${ }^{102}$

\section{"Expeditionen« in die befreiten Gebiete und an die Front}

Die Arbeit der muzejščiki als Dokumentierende des gegenwärtigen Krieges fiel mit der Arbeit der sogenannten »Außerordentlichen Staatlichen Kommission für die Festellung und Untersuchung der Gräueltaten der deutsch-faschistischen Aggressoren« (Črezvyčajnaja gosudarstvennaja komissija po ustanovleniju i rassledovaniju zlode- 
janij nemecko-fašistskich zachvatčikov, kurz: ČGK) zusammen. ${ }^{103}$ Wissenschaftlerinnen und Wissenschaftler der "Akademie der Wissenschaften " fuhren in Kommissionen ab Januar 1942 in die erst kürzlich befreiten Gebiete, um die von der Wehrmacht verursachten Schäden an Personen und Materialien zu erfassen. Besonders für muzejščiki der nichtmilitärischen Museen boten die Kommissionen Gelegenheiten, in die befreiten Gebiete mitzureisen und an potentielle Museumsexponate zu gelangen. Fünf wissenschaftliche Mitarbeitende des GIM begleiteten die Kommission, als diese im Februar 1942 in die 60 Kilometer südlich von Moskau gelegene Stadt Istra fuhren. Auch die Kuratorin Anna Zaks war bei der ersten gemeinsamen Erkundungsfahrt dabei:

»Die erste Reise, die bereits Mitte Januar 1942 stattfand, ging in die Umgebung der Stadt Istra, um die berühmte Auferstehungskirche zu begutachten. [...] Bei minus $30 \mathrm{Grad}$ fuhren wir in einem offenen Lastwagen. Ich erinnere noch jedes Detail dieser Reise. Die Grenze zur Besatzung ließ sich zweifelsfrei bestimmen: Hinter ihr begann die >Wüstenzone $<$ - kein Wald, keine Wohnhäuser, nur die Kamine standen noch und hin und wieder die Skelette der Steinhäuser. Zur Kirche gingen wir auf einem genau festgelegten Weg: Wir hatten einen strengen Befehl erhalten, nirgendwo abzubiegen, nichts auf dem Weg anzufassen, auch wenn wir im Schnee Exponate für das Museum sehen würden. Und tatsächlich, irgendwo hatte sich ein Schild >Achtung, Minen! [ [deutsch im Original] erhalten. Die Besatzer hatten es bei ihrer hektischen Flucht nicht geschafft, die Warnungen zu entfernen. Erschüttert standen wir vor der zerstörten Kirche. [...] Wir bestimmten den Zustand des Denkmals detailliert. [...] Danach zeichneten wir die Berichte über das Besatzungsregime und über die Partisanenbewegung auf. Hier haben wir die ersten Erinnerungsstücke erhalten - Ausweise der Partisanen, Teile ihrer Ausrüstung, Trophäen. ${ }^{104}$

Deutsche Wehrmachtstruppen hatten die Stadt Istra vom 26. November bis zum 10. Dezember 1941 besetzt und schwere Schäden hinterlassen. Die Fahrt im Februar 1942 muss traumatisch gewesen sein - zum ersten Mal sahen die Zivilistinnen und Zivilisten das Ausmaß der Zerstörung mit eigenen Augen. Anna Zaks erinnert sich, dass ihr erst auf dieser Fahrt bewusst wurde, dass die Zerstörung der Kulturdenkmäler nur ein Nebeneffekt der eigentlichen deutschen Absicht des Vernichtungskrieges war. ${ }^{105}$ In ihren Erinnerungen wird unmittelbar spürbar, wie gefährlich sich die Situation angefühlt haben muss. Das Gebiet war noch nicht von

103 Zur Bedeutung der ČCK für die sowjetische Kriegserfahrungsgeneration siehe zuletzt: Hellbeck, Jochen: The Antifascist Pact, Forging a First Experience of Nazi Occupation in the Wartime Soviet Union, in: The Slavonic and East European Review, Vol. Nr. 1, 2018, S. 117-143.

104 Zaks, Anna: Kak my žili i rabotali, S. 15.

105 Zaks, Anna: Opyt sobiranija materialov, S. 150. 
Minen geräumt, und die Kommission musste sich an die strengen Vorgaben halten, die die bereits weiter westlich kämpfende Rote Armee hinterlassen hatte. Die Aufgabe bestand in der Sammlung von Informationen und der fotografischen Erfassung der Schäden - zu dem Zweck hatten sie speziell angefertigte Formulare dabei. Damit war der eigentliche Arbeitsauftrag erfüllt. Anna Zaks erinnert sich jedoch, dass innerhalb der Gruppe das Bedürfnis bestand, ihre Tätigkeit auszuweiten und neben den Denkmälern auch die Schäden in der Stadt zu erfassen. $\mathrm{Zu}$ diesem Zweck suchten sie die lokalen Parteiorganisationen auf und ließen sich Dokumentationsmaterial aushändigen. In Istra zeichneten die muzejščiki erstmals Augenzeugenberichte auf. Die Kuratorin betonte, dass sie bei der Befragung der Bevölkerung auf ein repräsentatives Spektrum achteten und die Berichte von Menschen mit verschiedenen sozialen und kulturellen Hintergründen aufzeichneten. Dieser quellenkritische Ansatz ist bemerkenswert. Neben der Aufzeichnung von Berichten ausgezeichneter Helden bestand unter den muzejščiki offenbar das Bewusstsein für die zukünftige Aussagekraft der Erzählungen »einfacher Menschen«. Diese Methode der Augenzeugeninterviews lässt sich als oral history avant la lettre beschreiben.

Für die muzejščiki schien der Aspekt der zeitlichen Nähe zwischen Erlebnis und Aufzeichnung zentral gewesen zu sein. Dieses methodische Bewusstsein ist bezeichnend für ihre Arbeit als dokumentierende Zeitzeuginnen und Zeitzeugen. Die Interviews wurden zum festen Bestandteil der Sammelmethode »auf den heißen Spuren der Ereignisse«. Ein Jahr später, nach der Kriegswende von Stalingrad, griff der Leiter des Museumsinstitutes Manevskij diese Praxis auf und schrieb sie als Arbeitsmethode der sowjetischen Museen fest. ${ }^{106} 1940$ hatte Manevskij noch in der Fachzeitschrift "Sowjetisches Museum« das Sammeln von Unikaten als negatives Charakteristikum der »vergangenen Museen« (prečnie muzej) beschrieben. Unter dem Eindruck der innovativen Sammelarbeit der muzejščiki bezeichnete er 1943 das thematische Sammeln als Grundlage der Ausstellungstätigkeit der Museen im Krieg. ${ }^{107}$

Auch das Moskauer Armeemuseum nutzte das Argument der gesteigerten Relevanz der Museumsarbeit im Krieg, um die bereits vorhandene Unterstützung der GlavPURKKA bei ihrer Sammlungsarbeit auszubauen. In seinem Schreiben vom Juli 1942 griff der Museumsdirektor die Rhetorik Kuskes auf. ${ }^{108} \mathrm{Zu}$ Beginn betonte

NIIKMR (Hg.): A. D. Manevskij, Osnovnye voprosy muzejno-kraevedčeskogo dela, posobie dlja rabotnikov muzeev, Moskva 1943, S. 12. Auch die russische museologische Forschung hat auf diese Kehrtwende hingewiesen, vgl. Poljakov, Taras: Mifologija muzejnogo proektirovanija, S. 60-63. nevskij, Aleksej; Osnovnoe zveno muzejnoe rabote, in: Sovetskij Muzej, 1940 Nr. 2, S. 1-5. 
er die Dringlichkeit der erzieherischen Aufgabe des Museums, darauf folgte eine selbstkritische Beschreibung der eigenen unzureichenden Arbeit, um anschließend die Behörde zu Zugeständnissen zu bewegen. Dieser Brief zeigt, wie der Krieg Raum für neue Arbeitsweisen schuf. Die selbstermächtigten Museumsdirektoren monierten Missstände, um innovative Veränderungen zu provozieren. Die Ausstellungsarbeit weise einen »dilettantischen Charakter« auf und sei in ihrem Wesen »vernachlässigt« worden.

In dieser Rhetorik zeigt sich möglicherweise die "crisis of representation", die der russische Museumshistoriker Dmitry Baranov im Ausstellungswesen der 1930er Jahre identifizierte. Die Vorgabe, >Ausstellungen von Ideen zu konzipieren, die das marxistisch-leninistische Ideal und den zukünftigen Kommunismus im Sinne des Sozialistischen Realismus darstellten, hatte zu Ausstellungen voller künstlich geschaffener Objekte (z.B. Modelle, Figurinen) und zweidimensionaler Exponate (Slogans, Zitate, Pläne, Fotografien und Zahlentabellen) geführt. Laut Baranov waren sie wirkungslos, da die Diskrepanz zwischen der Wirklichkeit und ihrer Repräsentation in den Ausstellungen schlicht zu groß war. ${ }^{109}$

Im Krieg hatte das Museumsinstitut erkannt, dass die Gegenwart permanent neues Material von historischem und musealem Wert produzierte, welches jedoch aufgrund der nicht existierenden staatlichen Organisation einer systematischen Sammelarbeit "verschwinde und verloren ging «. ${ }^{110}$ Das Armeemuseum brachte sich in Stellung und nutzte seine Beziehungen, um sich als zentrale Sammlungsinstitution der materiellen Kriegserinnerung zu profilieren. Die Museumsdirektoren wandten sich an Aleksandr Ščerbakov, der als Leiter des Sovinform-Büros bereits seit Kriegsausbruch die zentrale Verbreitung der Propaganda über den Krieg überwachte und der seit dem Frühjahr 1942 zum Leiter der GlavPURKKA befördert worden war. Diesem mächtigen Chefideologen, der mehrmals pro Woche mit Stalin die mediale Informationstrategien diskutierte, leiteten sie im August 1942 eine leicht

109 Baranov, Dmitry: Archaizing Culture, S. 77. Diese Diskrepanz, bzw. das Fehlen von Alltagsobjekten, wurde auch von der internationalen Presse in dem sowjetischen Pavillon an der Weltausstellung 1937 in Paris festgestellt. Vgl.: Swift, Anthony: Soviet Socialism on Display, in: Czech, Hans-Jörg/Doll, Nikola: Kunst und Propaganda im Streit der Nationen 1930-1945, Dresden 2007, S. 185-186.

110 CAMO RF, f. 32, op. 11302, d. 95, I. 477-478. Um diese Missstände zu beheben, schlugen die Autoren fünf Maßnahmen vor, die in erster Linie zu einem Macht- und Bedeutungszuwachs des Museums führen sollten. In ihrer Wahrnehmung ermächtigten der Krieg und die sich daraus ergebenden Exponate die muzejščiki zu selbstbewussten Forderungen. Da sie aufgrund der neuen Objekte mehr Ausstellungsfläche benötigten, forderten sie eine institutionelle Loslösung von dem Haus der Roten Armee und den Bau eines neuen Gebäudes. Dieses neue Museum sollte in der Folge das Zentrum der ganzen militärhistorischen Museumsarbeit werden, dem alle anderen Museen als Filialen untergeordnet werden sollten. 
angepasste Form des Briefes weiter. ${ }^{111}$ Darin wurde die Unterstützung der musealen Erziehungsarbeit als »staatliche Aufgabe« bezeichnet, der bislang »viel zu wenig Beachtung " geschenkt worden sei. Ščerbakov wurde aufgefordert, die Suche, die Auswahl und die Verteilung des Materials zu organisieren. Konkret sollte er die Armee- und Fronteinheiten proaktiv dazu verpflichten, dem Moskauer Armeemuseum Objekte zu schicken und gleichzeitig den Direktor mit der Befugnis ausstatten, Exponate bei den Einheiten an der Front zu sammeln. ${ }^{112}$

Diese Maßnahmen, die jedoch erst nach dem Sieg bei Stalingrad im Frühjahr 1943 umgesetzt wurden, verbesserten die Arbeitsbedingungen der Sammlerinnen und Sammler grundlegend. Davor fand die Sammelarbeit unter ausgesprochen gefährlichen und mühsamen Bedingungen statt. Die Erinnerungen der Museumsführerin und Mitarbeiterin des Armeemuseums Marija Nazarova geben Einblicke in ihre Erfahrungswelt, als sie im Frühling und November 1942 zu den kämpfenden Einheiten der Roten Armee an die Front geschickt wurde:

»Ab dem Frühjahr 1942 begannen die Museumsmitarbeiter regelmäßig an die Front zu reisen. [...] Einmal transportierte ich eine Ausstellung in dem Auto eines Generals, es stellte sich heraus, dass er der Leiter der Politabteilung der Westfront war. Ich erinnere diese Fahrt als Unterrichtsstunde, die mir der General gab. Als wir durch die Region Možaisk fuhren, fragte ich ihn: >Wohin fahren wir? Die Antwort war: >Mädchen, solche Fragen stellen Sie in Zukunft nicht mehr.<

Im November 1942 fuhr ich mit dem stellvertretenden Direktor des Museums P.N. Loginov zu den Einheiten der Don-Front. Wir fuhren in beheizten Eisenbahnwaggons [tepluška] und in unbeheizten Güterwaggons bis zum Ende der Gleise und dann weiter mit irgendwelchen Autos. Es gab viele Schwierigkeiten. Niemand hatte uns eingeladen und niemand wartete auf uns. Wir mussten uns zu dem nützlichen Material überall selber durchschlagen. Waren die Kommandeure bereits vor uns bei den Einheiten gewesen? Wir sortierten die Neuigkeiten aus den Flugblättern von der Front. Unsere Aufgabe war es, die Kämpfer zu finden, über die man in den Zeitungen schrieb. Falls sie verstorben waren, mussten wir ihre Waffen, Dokumente und persönlichen Gegenstände finden. Es war leichter, Material über den Feind zu finden, Trophäen, Briefe gab es in großer Zahl. Aber von den Unsrigen?

In den Politabteilungen der 24. und 26. Armee gab man uns ungefähre Koordinaten, wo wir unbedingt hinfahren sollten. Wir fuhren in die Richtung der Einheiten und Regimente, die sich in ständiger Bewegung befanden und den Kessel schlossen. Bei den Einheiten erhielten wir Flugblätter, die von den Soldaten-Helden berichteten. Aber es war schwierig, [ihre A.H.] Waffen zu bekommen. Die Lebenden 
wollten sich nicht von ihnen trennen, denn die Waffen und Ausrüstungen der getöteten Helden wurden den anderen häufig zur Ermunterung gegeben. [...] Unter großen Schwierigkeiten gelang es uns, die Parteibücher, die Komsomolzenausweise und die Auszeichnungen der Verstorbenen zu bekommen. Das alles gab es vor Ort - aber Informationen darüber waren äußerst selten. Und die Kamera von P.N. Loginov war eingefroren. Wir konnten nie mit unseren Leuten sprechen, da Angriffe stattfanden. Deswegen waren die Bezeichnungen auf den gesammelten Materialien sehr dürftig. Wir hatten genug Materialien gesammelt, aber es gab keine Transportmittel. Das Laden und Umladen von einem Auto auf ein anderes wurde immer schwieriger, häufig waren die Fahrer in Eile und wollten uns nicht mitnehmen. Es wurde entschieden, uns zu der Kačalinskaja-Station zu bringen, in der Nähe gab es einen Flugplatz und P.N. Loginov konnte vereinbaren, dass die Materialien und ich mit dem Flugzeug mitfliegen sollten, das auch die verwundeten Soldaten nach Moskau brachte. ${ }^{113}$

Die Erinnerungen von Marija Nazarova zeigen die Schwierigkeiten, die sich bei der Sammelarbeit an der Front stellten. Eine Dienstreise von Zivilistinnen und Zivilisten an die Front war per se ein risikoreiches Unterfangen. Insbesondere in den ersten zwei Kriegsjahren, die vielfach von Niederlagen der Roten Armee geprägt waren, müssen diese Expeditionen chaotisch und lebensgefährlich gewesen sein. Offenbar war die Begleitung eines Politoffiziers ein Schutz, von dem die muzejščiki abhängig waren. Gleichzeitig stellte diese Begleitung die einzige Möglichkeit dar, zu den Einheiten der kämpfenden Armee zu gelangen. Vor Ort waren sie auf die Kooperation der politischen Offiziere angewiesen. Dem Kurator Pëtr Loginov zufolge sei das Sammeln und Dokumentieren in den Kampfpausen zwischen den Operationen besonders erfolgreich gewesen. ${ }^{114}$ Es ist anzunehmen, dass die Politoffiziere ihren Untergebenen die Bedeutung ihres Kriegserlebnisses für die Menschen an der Heimatfront erläuterten und sie aufforderten, den muzejščiki Objekte (zum Beispiel im Kampf erbeutete Waffen oder persönliche Gegenstände gefallener Kameraden) zu überreichen, damit diese sie im Museum ausstellen konnten. Es hing vom Zufall und den Möglichkeiten vor Ort ab, ob und wie die Moskauer muzejščiki die Frontabschnitte erreichten. Die anfangs noch unzureichende Koordination mit den militärpolitischen Behörden zeigt sich auch daran, dass sie erst an der Front und nur in Glücksfällen die Flugblätter mit den nötigen Informationen zu den Kämpfen und den Helden erhielten. Auch waren die Militärs häufig nicht über

113 Nazarova, Marija: Central'nyj muzej Krasnoj Armii v gody Velikoj Otečestvennoj vojny, Iz vospominanij Marii Konstantinovny Nazarovoj, in: Informacionno metodičeskij sbornik No. 5 , Moskva 2000, S. 37-38.

114 Loginov, Pëtr: Po sledam vojny, in: Sovetskaja Rossija (Hg.): Muzejnoe delo v SSSR, 1976, S. 181183, hier S. 181. 
die Ankunft bzw. den Auftrag der muzejščiki informiert und es gab keine Abstimmung mit anderen Politkommissaren, die ebenfalls politisch brisantes Material für andere Zwecke sammeln sollten. Es konnte passieren, dass der Sammelwunsch der zivilen Städter bei den Soldatinnen und Soldaten Unverständnis hervorrief und es zu Interessenskonflikten kam. Den Rotarmistinnen und Rotarmisten schienen deutsche Briefe, die sie in der Regel nicht lesen konnten, gleichgültig gewesen zu sein, aber die Abgabe von Waffen konnte Widerstand provozieren. Hier kollidierten der kommemorative Anspruch des Museums mit demjenigen der Armee, für deren Angehörige die Waffe gefallener Kameraden häufig Andenken und Talisman waren. Doch der Anspruch der muzejščiki die Kriegserfahrung der Frontsoldatinnen und Frontsoldaten für die Menschen im Hinterland zu dokumentieren, ihr Versprechen ihren Kampf im Falle ihres Todes zu erinnern, konnte sie zur Kooperation bewegen. Nicht selten löste ihre Anwesenheit an der Front ein großes Mitteilungsbedürfnis und Dankbarkeit bei ihnen aus. Anhaltspunkte für die Sammlerinnen und Sammler waren die Berichte der Frontkorrespondenten und die Flugblätter, die mit Berichten über Heldentaten zum Kampf motivieren sollten. Hier wurden die Namen der Kämpfer genannt, zu denen die muzeǰšiki Erinnerungsstücke finden mussten. Dieser theoretische Auftrag traf auf die chaotische und sich ständig verändernde Lage an der Front. Die muzejščiki erhielten ungefähre Ortsangaben, deren Koordinaten sich in den meisten Fällen bei ihrem Eintreffen schon wieder verändert hatten. Marija Nazarova berichtete, dass es ihnen unter großer Mühe gelungen sei, persönliche Erinnerungsstücke wie Partei- und Komsomolzenausweise zu erhalten, diese aber häufig nicht mehr mit der Todesursache bzw. der Heldentat der Eigentümer in Verbindung gebracht werden konnten. Die Provenienzangaben auf den zukünftigen Exponaten fielen deswegen sehr knapp aus. Der Auftrag, kontextgebundene Objekte zu finden, die eine möglichst detaillierte Beschreibung ihrer Provenienz aufwiesen, war häufig unmöglich zu erfüllen.

\section{"Die Geschwindigkeit des Lebens ist so schnell wie nie« - Wer soll was sammeln?}

Ein Jahr nach dem Überfall der Wehrmacht auf die Sowjetunion, als sich die Sammelarbeit nach der Methode »auf den heißen Spuren der Ereignisse« bereits etabliert hatte, verschickte das Museumsinstitut eine systematische Anleitung, die erstmals von staatlicher Seite bestimmte, welche Objekte die Museen zu sammeln hatten. Das Schreiben »Über die Suche von materiellen und dokumentierenden Materialien des Großen Vaterländischen Krieges« beruhte auf der provisorischen Sammlungsliste des GIM-Kurators Georgij Malickij vom September $1941 .{ }^{115} \mathrm{Zu}$ Be-

115 Manevskij, Aleksej/Krjažin, Ivan: O sbore veščestvennych i dokumental'nych materialov velikoj otečestvennoj vojny, in: NIIKMR (Hg.): Rabota politiko-prosvetitel'nych učreždenij v uslo- 
ginn erinnerten die Experten an die Verantwortung, welche die Museumsangestellten trugen: »Wir stehen vor der ehrenvollen Aufgabe (početnaja zadača), Objekte und Dokumente über den Großen Vaterländischen Krieg für die Nachwelt zu sammeln und zu sichern «. ${ }^{116}$ Anschließend wurden fünf Kategorien genannt, nach denen die Museumsmitarbeitenden in Abstimmung mit dem Volkskommissariat für Verteidigung und dem Volkskommissariat für innere Angelegenheiten (NKVD) suchen sollten:

»1. Objekte: Erinnerungsstücke der Helden der Armee, der Partisanenbewegung und des Hinterlandes; Waffen, die nicht mehr im Kampf gebraucht werden, Fahnen, Bruchstücke von Granaten, Bestandteile der Ausrüstungen, Auszeichnungen und Ähnliches; Trophäen und faschistisches Folterwerkzeug.

2. Dokumente: Berichte, Protokolle, Ankündigungen, Aufzeichnungen, Erinnerungen, Briefe, Aufzeichnungen der Aussagen von Augenzeugen und Ähnliches; Werbung, Flugblätter, Befehle, Aufrufe, Erklärungen usw.; Ausschnitte aus den örtlichen Zeitungen, Zeitschriften, Wandzeitungen (von der Front, der Partisanenbewegung und dem Hinterland), Beschreibungen der Erinnerungsorte. [...]

3. Fotografien und Reproduktionen: Verschiedene Episoden von der Front und aus dem Hinterland, Porträts der herausragenden Frontsoldaten, Partisanen, Helden der Arbeit und aller ausgezeichneten Menschen unseres Landes; deutsche Cräueltaten, beschädigte und zerstörte Denkmäler und Kultureinrichtungen, Erinnerungsorte und Cebäude.

4. Graphische Materialien: Skizzen (zu Themen der Front und des Hinterlandes), Plakate, Karikaturen.

5. Kunstwerke und Skulpturen des Großen Vaterländischen Krieges. ${ }^{117}$

Diese wissenschaftlichen und professionellen Ratschläge waren für die Sammlerinnen und Sammler wegweisend. Insbesondere das »Handbuch zum Sammeln von Materialien des Großen Vaterländischen Kriegs«, das der bekannte und populäre Archäologe und Historiker Nikolaj Michailovič Korobkov (1897-1947) Ende 1942 im Auftrag des Museumsinstitutes veröffentlichte, fand bei den muzejščiki regen internen Gebrauch. ${ }^{118}$ Korobkov, der heute in der Geschichte des Museumsinstitutes als erster Direktor mit einer geisteswissenschaftlichen Ausbildung und einem

vijach voennogo vremeni, S. 14-16. Die Kuratorin des GIM, Anna Zaks, die im engen Kontakt zu den Behörden stand und später selbst beim Museumsinstitut ein ähnliches Schreiben herausgeben sollte, erinnert sich, dass die Crundlage dieser Anleitung die Liste ihres Kollegen Georgij Malickij gewesen sei, die dieser bei der ersten Sonderausstellung zur Moskauer Fliegerabwehr im September 1941 verfasst hatte. Vgl. Zaks, Anna: Kak my žili i rabotali, S. 19. Manevskij, Aleksej/Krjažin, Ivan: O sbore veščestvennych i dokumental'nych materialov, S. 15.

117 Ebd. S. 15.

118 NIIKMR (Hg.): Prof. N.M. Korobkov, Rukovodstvo, Moskva 1942. 
Interesse für Kulturgeschichte verehrt wird, übernahm 1942 die Leitung der historischen Abteilung. ${ }^{119}$ Sein kleines, 27 Seiten langes Handbuch gewährt aus der Retrospektive einen faszinierenden Einblick in das Selbstverständnis des Historikers im Krieg. Für die Museumsmitarbeitenden waren Korobkovs konkrete, detaillierte Hilfestellungen zu Fragen des "was wird wo und wie gesammelt« eine große Unterstützung. Gleich im ersten Satz benannte er die prägende doppelte Verantwortlichkeit seines Berufstandes: „Es ist unsere Pflicht, Zeugen und Teilnehmer im größten aller Kriege zu sein, den Russland je geführt hat. « ${ }^{120}$ Treffender hätte Korobkov die Selbstwahrnehmung der von einem historischen Bewusstsein geleiteten Akteure nicht beschreiben können. Menschen werden erst dann zu Zeuginnen und Zeugen, wenn sie von dem Erlebten berichten. Diese berufliche Dimension der Museumsmitarbeitenden als Vermittlerinnen und Vermittler war untrennbar mit ihrer Teilhabe am Krieg verflochten. Diese Gleichzeitigkeit von Erlebnis und musealer Darstellung desselben ist der entscheidende Hintergrund für den kommemorativen Charakter der Ausstellungen im Krieg.

Es ist anzunehmen, dass sich Korobkov den Respekt und die Glaubwürdigkeit auch damit verdient hatte, dass er als einer der wenigen unbequeme Wahrheiten thematisierte. In seinen einführenden Worten widersprach er Stalin, der im Mai 1942 bereits das baldige Ende des Krieges angekündigt hatte, und warnte vor der immer noch bestehenden Gefahr einer Niederlage aufgrund der militärischen Reserven der Wehrmacht. ${ }^{121}$ Gleichzeitig ließ er keinen Zweifel am finalen Sieg der Sowjetunion und begründete diese Zuversicht mit den Anstrengungen, die die sowjetische Bevölkerung für die Verteidigung leiste. Dabei lobte er explizit die Frauen, die »als Soldaten an der Seite der Männer « in der Roten Armee kämpften. ${ }^{122}$ Nach dieser persönlichen Einschätzung der politischen Situation beschrieb Korobkov die Auswirkung des gegenwärtigen Krieges aus der Perspektive eines Historikers und Erinnerungsforschers:

»Die Geschwindigkeit des Lebens ist so hoch wie noch nie. Die Dinge, Ereignisse und Eindrücke verändern sich schnell und werden von neuen verdrängt, sie werden historisch. Das brennende >Heute< wird zum >Gestern<, es verliert seine Strahlkraft; es verblasst ununterbrochen und viel wird vergessen.

119 Für eine kurze Biografie von Nikolaj Korobkov vgl.: Kudrjavceva, Elena: Obrazovanie i pervye gody suščestvovanija Instituta, S. 10-11. Ebd. nicht ausreichend thematisiert wurde, vgl. Krylova, Anna: Soviet Women in Combat, A History of Violence on the Eastern Front, Cambridge 2010. 
Die Erinnerung ist der allerunzuverlässigste Speicher der Geschichte. Derjenige, der später über zurückliegende Ereignisse schreibt oder berichtet [...], kann sie nur in Teilen wiederherstellen, es bleiben Lücken, häufig kommt es zu Verzerrungen und immer zu einer subjektiven Brechung. Selbstverständlich war und werden die Erinnerungen, insbesondere die der Zeitgenossen immer wichtig sein [...], doch noch wichtiger ist das Dokument, das dem Lebenslauf direkt entspringt [...] und ein Bruchstück der Wirklichkeit spiegelt. Es wird natürlich unmöglich sein, die [ganze A.H.] Wirklichkeit aus wenigen Fragmenten von Dokumenten vollständig und fehlerfrei wiederherzustellen, aber bei der Erziehung der Massen kann die beinahe fotografische, beinahe spiegelhafte Abbildung des Lebens eine Beziehung zu den Ereignissen herstellen, die diese Dokumente hervorgebracht haben. $\ll^{123}$

Aus der Perspektive des Historikers war die Beschleunigung der Zeit die direkteste Folge des Krieges. Das Ineinanderfließen von Gegenwart und Vergangenheit überforderte laut Korobkov die Erinnerungskapazitäten der Menschen und führte unweigerlich ins Vergessen. Genau wie der Leningrader Museumsdirektor Jan Kuske und die Moskauer Kuratorin Anna Zaks warb er nachdrücklich für eine möglichst zeitnahe Sammlung, damit die Aussagekraft der Relikte nicht verloren ginge. Je mehr Zeit zwischen dem Ereignis und seiner Deutung verstrich, umso »verzerrter und subjektiver« die Interpretation. Hinter der Warnung vor dem Vergessen steckte möglicherweise ein professionelles Streben nach größtmöglicher Objektivität der Quelleninterpretation, um diese zukünftig vor politisch-ideologischen Verfälschungen zu schützen. Korobkov schreibt:

»Die Bewahrung der Materialien für die zukünftige Ceschichte des Krieges wird zu einer der wichtigsten Aufgaben unserer Historiker [...]. Cenauso wichtig muss die Aufgabe des Sammelns von materiellen Erinnerungsstücken des Krieges gewichtet werden, sie sind, wenn man das so sagen kann, lebendige Illustrationen [živye illjustracii] zu den Fakten und Ereignissen. ${ }^{124}$

Im Gegensatz zu der ex post rekonstruierten Geschichte schienen die Objekte der Gegenwart belebt, sie waren »heiß « und mussten gesichert werden, bevor ihre »brennenden « Aussagen serkalteten und sausgelöscht werden würden. Korobkov schien euphorisiert. Im Vergleich zu dem Stillstand der »Großen Säuberungen« hatte der Krieg den vom Terror der Vorkriegsjahre erstarrten Wissenschaftlerinnen und Wissenschaftlern kleine Handlungsfreiräume zurückgegeben. Die sich ständig verändernde Gegenwart verlangte nach Expertinnen und Experten, die sich um ihre Dokumentation und Bewahrung der Zeitgeschichte bemühten. Begeistert 
vom Quellenreichtum zeichnete Korobkov ein Sammlungsprofil, das größtmögliche Diversität und Vollständigkeit verlangte:

»Alles wird interessant und gebraucht werden, alles: Die Berichte über geologische Forschungen, die Dokumentationen über die von Deutschen zerstörten archäologischen Denkmäler, die Quittungen von Bäckereien und Mensen, Unterrichtspläne von Hochschulen und die Programme von Museen und Theatern, Gerichtsakten und notarielle Beschlüsse, Auskünfte über die Kinderheime und Kindergärten sowie die Ergebnisse der Saat- und Erntekampagnen. Die Bücher des Standesamtes und die Arbeitsberichte der Betriebe und Fabriken der unterschiedlichsten Industrien, der Briefwechsel der Behörden und von Privatpersonen und so weiter und so weiter. ${ }^{125}$

In der Wahrnehmung des Archäologen hatte der Krieg wie ein Zeitenbruch alles interessant und erinnerungswürdig gemacht. Sein innovativer, ja pionierhafter Ansatz einer Alltagsgeschichte avant la lettre, die die Gesamtheit der sowjetischen Gesellschaft im Krieg einzufangen versuchte, musste jedoch eine Idealvorstellung bleiben, nicht zuletzt deshalb, weil verschiedene mächtige Institutionen um die Relikte des Krieges konkurrierten. Dem Historiker Korobkov war der Streit zwischen dem Kommissariat für Aufklärung (Narkompros), dem Kommissariat für Innere Angelegenheiten (NKVD) und der Historikerkommission an der Akademie der Wissenschaften um das Vorrecht, Kriegsdokumente zu sammeln, bekannt. ${ }^{126}$ Entgegen seiner idealistischen Vorstellung wies er die Museen in seiner detaillierten Sammlungsliste an, sich auf die materiellen und künstlerischen Objekte zu konzentrieren, um dem Geheimdienst das exklusive Sammlungsrecht auf alle Dokumente nicht streitig zu machen. ${ }^{127}$

Diese Einschränkung stand auch im Widerspruch zu dem zuvor zitierten Brief Manevskijs vom 18. Juni 1942, in dem er den Museen explizit empfahl, Dokumente, Protokolle, Befehle usw. zu sammeln. Die russische Museologin Natal'ja Fatigarova, stellte jedoch fest, dass die Museen diese Empfehlung nicht immer befolgt hätten, da »ihre Sammlungen mit Objekten und Kunstwerken zum Krieg ohne die schriftlichen Quellen in erheblichem Maß wertlos geworden wären «. ${ }^{128}$ Die muzejščiki hatten schon vor dieser Anweisung dokumentierendes Material gesammelt und schienen das, ihrem Anspruch nach kontextgebundenen Objekten folgend, weiterhin und unabhängig von staatlichen Vorschriften zu tun. Dabei waren die thema-

Ebd.

Für den angespannten Briefwechsel zwischen Sergej Kruglov (NKVD) und Vladimir Potemkin (Narkompros) und der Beschwerde des Letzteren beim ZK der KP vgl. Kaulen, Marija: Nevydimi front, S. 17. 
tischen Sammelanweisungen Korobkovs eine Orientierung. Trotz der Freiheit, die der Auftrag, alles zum Krieg zu sammeln, vermeintlich suggerierte, engte die Deutung der Objekte als Relikte eines siegreichen Kampfes die Auswahl ein. Korobkovs sogenanntes »Thematisches Schema für das Sammeln und die erste Klassifikation der Materialien« gab die ideologische Einordnung der Objekte vor. Die Materialien waren also nicht deutungsoffen, sondern wurden bereits beim Akt des Sammelns in die eine oder andere thematische Kategorie eingeordnet. Mit über vierzig Kategorien versuchte Korobkov das Chaos des Krieges einzufangen. Dabei sollte eine chronologische Einteilung der Ereignisse, die möglichst alle Regionen des Krieges abdeckte, die Gegenwart anhand der gesammelter Kriegsrelikte (be-)greifbar machen.

Im Sinne der These eines Anspruches der Alltagsgeschichte konkretisiert Korobkov die Kategorie »Trophäe«. Gemeinhin wird der Begriff von dem altgriechischen Wort tropaion abgeleitet und bezeichnet Symbole des Sieges über den Feind und die Praxis, den Ort des Sieges mit den Waffen des Feindes zu kennzeichnen. ${ }^{129}$ Im Kontext des »Großen Vaterländischen Krieges« wurde der Begriff auf alle Objekte ausgeweitet, die Wehrmachtssoldaten gehört hatten: in erster Linie deutsche Waffen, Fahnen und Auszeichnungen sowie zerstörtes militärisches Gerät und Uniformen. Korobkov zählte jedoch auch persönliche Dinge dazu, die den Gefangenen abgenommen wurden oder die auf dem Schlachtfeld zurückgeblieben waren. Als Beispiel nannte er Gegenstände, die die Deutschen auf ihrem Eroberungsfeldzug geraubt hatten. ${ }^{130}$ Diese Exponate verband die Tatsache, dass sie im Kontext des militärischen Sieges in die Hände der Sowjets gelangt waren.

Eine gänzlich neue Kategorie der Sammlungsanweisungen bildeten die sogenannten »Erinnerungsorte« (pamjatnye mesta). Als solche wurden Orte bezeichnet, die entweder Zeugen heroischer Ereignisse (Kämpfe, Heldentaten, Partisanenquartiere) gewesen waren oder die, im Gegenteil, Orte mit leidvollen Assoziationen waren. Hier nannte Korobkov Orte, an denen die Deutschen Exekutionen und Gräueltaten verübt hatten, außerdem Massengräber und Kulturdenkmäler, die von der deutschen Armee zerstört worden waren. ${ }^{131}$

Auch wenn offenbar Ansätze bestanden, das Kriegserlebnis nicht nur in seiner heldenhaften, sondern ebenso in seiner tragischen Dimension zu fassen, bestanden beim Sammeln der Objekte Grenzen, die nur in Einzelfällen überschritten wurden. Kein Brief, keine methodische Anleitung erwähnte jene Objekte, die mit der Befreiung des sowjetischen Territoriums offenbar wurden: Relikte, die an den Holocaust, an die sowjetischen Kriegsgefangenen bzw. Zwangsarbeiterinnen und

129 Schivelbusch, Wolfgang, Die Kultur der Niederlage, Der amerikanische Süden 1865, Frankreich 1871, Deutschland 1918, Berlin 2001, S. 17.

130 NIIKMR (Hg.): Prof. N.M. Korobkov, Rukovodstvo, Moskva 1942, S. 9.

131 Ebd. S. 10. 
Zwangsarbeiter oder an die Kollaboration sowjetischer Militärs und der Zivilbevölkerung mit den Achsenmächten erinnerten. ${ }^{132}$ Gleichzeitig ist kein Dokument bekannt, das das Sammeln solcher Objekte explizit verboten hätte. Die Zensur scheint in den Köpfen verankert gewesen zu sein, denn die muzejščiki waren diesen potentiellen Exponaten an der Front und in den befreiten Gebieten begegnet. Eine Ausnahme dieser Leerstellen der Erinnerungsbildung bilden möglicherweise die Zeitzeugeninterviews, die die muzejščiki mit Überlebenden der befreiten Gebiete geführt haben. ${ }^{133}$

Die Sammelarbeit der muzejščiki wurde schließlich durch den Befehl des Verteidigungskommissars vom März 1943 erleichtert, in dem er alle Einheiten der Roten Armee verpflichtete, »die wertvollsten Reliquien und Erinnerungsstücke zum Großen Vaterländischen Krieg zu sammeln«, um sie an die Sammlerinnen und Sammler hinter der Front weiterzugeben. ${ }^{134}$ Das Museumsinstitut folgte der Rhetorik der Anweisung und bezeichnete das Sammeln der Relikte des »Großen Vaterländischen Krieges « als »heilige Pflicht « (svjaščennaja objazannost') der Museen. ${ }^{135}$

Julija Kantor sieht in dieser Verordnung »Algorithmen der >Auslöschung« (algoritm sstiranijas) und den Beginn einer Reduzierung der vielfältigen Kriegserfahrung auf ein einziges heroisches Narrativ. ${ }^{136}$ Insbesondere vor dem Hintergrund der ge-

Eine interessante Ausnahme stellt das Museum für Militärmedizin in St. Petersburg (Voenno-medicinskij muzej) dar, das am 12. November 1942 in Moskau gegründet wurde. In seinem Auftrag sammelten Ärztinnen und Ärzte, Fotografinnen und Fotografen, Kinoregisseure sowie Künstler und Künstlerinnen Relikte der medizinischen Einheiten, die die Rote Armee in die befreiten Konzentrationslager (zum Beispiel Auschwitz-Birkenau) begleiteten. Dabei gelangten Objekte und Materialien in die Museumssammlungen, die später bei den Nürnberger Prozessen von der Anklage präsentiert wurden, in: Kantor, Julija: Formirovanie "prostranstva pamjati« o velikoj otečestvennoj vojne v1941-1945 gg, muzejnij aspekt, in: Edukacja humanistycna, Nr. 2, 33, 2015, S. 17-32, hier S. 28-29.

Die Aufzeichnungen, die sich in den Sammlungen der Museen befinden, wurden von der Verfasserin nicht eingesehen. Julija Kantor weist darauf hin, dass die Interviews erst nach der Kontrolle durch die örtlichen Parteiorgane publiziert oder ausgestellt werden durften. Darüber hinaus geht sie davon aus, dass die Aussagen der Zeitzeugen stark von einem vorbereiteten Text beeinflusst wurden. Vgl. Kantor, Julija: Nevidimyj front, S. 24-25.

NA VIMAIViVS [Wissenschaftliches Archiv des militärhistorischen Museums für Artillerie, Ingenieurwesen und Kommunikation] f. 3r., op. 1., d. 71., I. 18, zitiert nach Kantor, Julija: Nevidimyj front, S. 15. Manevskij, Aleksej: Osnovnye voprosy, S. 11.

Kantor, Julija: Nevidimyj front, S. 25. Kantor bezieht sich insbesondere auf das Empfehlungsschreiben von M.F. Komarova, in dem diese schrieb: »Der Vaterländische Krieg hat uns eine große Anzahl von Erinnerungsstücken an die Heldentaten des sowjetischen Volkes an der Front und im Hinterland hinterlassen und hinterlässt sie uns weiterhin. Und die Aufgabe der Museen und der Museumsarbeiter ist es, diese Erinnerungsstücke aufzuspüren, auszustellen und sie so zu formen, dass sie mit einer Stimme über die heroischen Seiten im Leben des russischen Volkes sprechen. «Vgl.: Komarova, M.F.: O rabote muzeev v dni Velikoj Otečestvennoj 
schilderten Eigeninitiative und den verspäteten bzw. inadäquaten Interventionen des Museumsinstitutes ist auch diese Instruktion in erster Linie als Ausdruck einer Wunschvorstellung von einer Norm zu lesen. Eine allgemeine Übertragung auf die museale Praxis ist nicht möglich und bedarf der empirischen Überprüfung anhand von Fallstudien.

Während der Kontakt zu Einheiten der Armee von den Direktoren der militärischen Museen selbst hergestellt werden konnte, war der Zugang zu den Partisaneneinheiten schwieriger. Der Dienstweg ging hier über den »Zentralstab der Partisanenbewegung « (Central'nij štab partizanskogo dviženija, CŠPD), der wiederum die Vorgesetzten der entsprechenden Einheiten instruieren mussten, damit diese die muzejščiki mit Objekten versorgten. Am 12. Oktober 1943 befahl der Anführer des Weststabes der Partisanenbewegung dem Vorsteher einer Einheit im Smolensker Gebiet, den Moskauer Armeemuseumsdirektor Vladimir Fedjanin innerhalb seiner Brigade alle Materialien sammeln zu lassen, die er brauchte:

»An den Vorsteher des Stabes Kapitän Cenosse Akimočkina

Gewähren Sie dem Oberst Genossen Fedjanin, V. I. - Direktor des Museums der Roten Armee -, Objekte, Fotos, Zeichnungen, Dokumente und Waffen zu sammeln. Die genannten Materialien sind unerlässlich für [die Ausstellung A.H.] des Museums des Vaterländischen Krieges über die Smolensker Partisanen.

Leiter des Weststabes der Partisanenbewegung Oberst A. Prochorov. « ${ }^{137}$

Mit dieser Bescheinigung reisten der Museumsdirektor Vladimir Fedjanin und die erfahrene Sammlerin Marija Nazarova im Oktober 1943 in das Smolensker Gebiet. Dieser waldreiche Landstrich war im Deutsch-Sowjetischen Krieg strategisch ausgesprochen wichtig, da hier zentrale Straßen- und Eisenbahnverbindungen nach Moskau führten und die Region an die besetzte belarussische Sowjetrepublik grenzte. Im Rücken der Heeresgruppe Mitte verübten hier zahlreiche Partisaneneinheiten Anschläge auf die deutschen Versorgungs- und Kommunikationswege. ${ }^{138}$

vojny, informacionnoe pis'mo Nr. 2, Moskva 1943, S. 4, zitiert nach Kantor, Julija: Nevidimyj front, S. 25.

137 CMVS, Dokumental'nyj fond, V. 98.

138 Zu der Partisanenbrigade Sergej Lazo vgl. Grenkevich, Leonid: The Soviet Partisan Movement 1941-1944, A Critical Historiographical Analysis, London 1999, 208; 165 (Karte). 
Abbildung 1: Marija Nazarova (dritte von links) und Direktor Oberst Vladimir Fedjanin (vierter von links) des Moskauer Armeemuseums bei der 5. Vorgovsker Partisanenbrigade, benannt nach Sergej Lazo, Smolensker Gebiet, Oktober 1943, Fotografin/Fotograf unbekannt @ C CMVS.

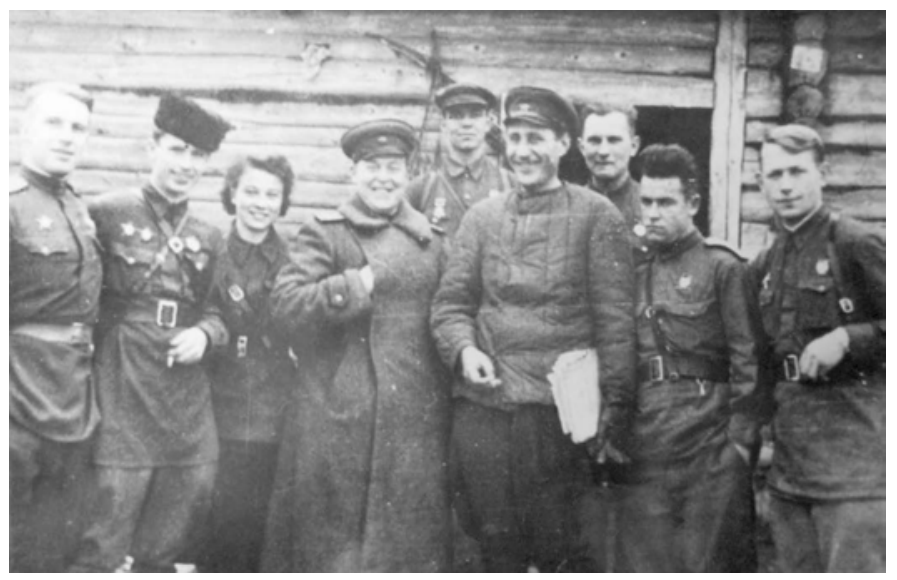

Auf dem Gruppenfoto (Abb. 1), das nach getaner Arbeit vor dem Eingang eines Holzhauses aufgenommen wurde, ist der Brigadekommandeur Kezikov unschwer an seiner papacha (kaukasische Kopfbedeckung aus Schafsfell) und seinen sternförmigen Orden auf der Brust zu erkennen. ${ }^{139}$ Er steht in lockerer Haltung mit Zigarette in der Hand neben der Museumsführerin Marija Nazarova. Neben ihr, in >Napoleon-/Stalin-Pose (die rechte Hand im Mantelrevers) und Offizierskappe, steht der Museumsdirektor Vladimir Fedjanin im Zentrum des Fotos. Rechts von ihm, ebenfalls mit Offizierskappe, steht in einer gesteppten Wattejacke Kozubeskij, das Mitglied der Brigade, das die Materialien übergeben hat. Die Übergabe scheint für beide Seiten zufriedenstellend verlaufen zu sein - diesen Eindruck vermitteln zumindest die lachenden Gesichter des Brigadekommandeurs, der muzejščiki und von Kozubeskij, der unter seinem linken Arm einen Stapel Dokumente hält. Bei diesen Dokumenten, die Nazarova und Fedjanin übergeben wurden, könnte es sich um Aufzeichnungen, Partisanen-Zeitschriften, Flugblätter oder Ähnliches handeln. Die muzejščiki konnten den Partisaninnen und Partisanen mit ihrem aufrichtigen Interesse an ihren Kriegserlebnissen das Gefühl von Anerkennung und Wertschätzung vermittelten. Sie versprachen ihnen, die gesammelten Materialien 
in ihren Ausstellungen zu präsentieren und daheim über ihren Kampf zu berichten.

\section{Die sheiligste Reliquier des Krieges}

Den Höhepunkt in der Sammlungsarbeit des Armeemuseums stellt die »Fahne des Sieges « (Znamja Pobedy) dar, die kurz vor Kriegsende auf dem Deutschen Reichstag gehisst wurde. Bis heute ist die Provenienz dieser Divisionsfahne wissenschaftlich umstritten und nicht vollständig aufgeklärt. ${ }^{140}$ Zusätzliche Verwirrung stiftet das wahrscheinlich berühmteste Foto des Krieges von Evgenij Anan'evič Chaldej (19171997), das drei Rotarmisten beim Hissen einer Fahne auf dem Reichstag zeigt. ${ }^{141}$ Die »Fahne des Sieges«, bis heute das zentrale Exponat des Moskauer Museums, ist weder die Fahne auf Chaldejs Foto, noch ist sie die einzige oder erste Fahne, die auf dem Reichstag gehisst wurde. Als gesichert gilt jedoch, dass sie eine der neun offiziellen Divisionsfahnen ist, die für das Hissen auf dem eroberten Reichstag bestimmt waren. Sie trägt auf der Rückseite die Nummer fünf und ist wahrscheinlich die Einzige, die nicht bei den andauernden Kämpfen zerstört wurde, weil sie auf der östlichen, geschützteren Seite des Reichstags hing. ${ }^{142}$ Ebenso ungeklärt ist die Frage, ob die Fahne, nachdem sie im Juni nach Moskau gebracht wurde, bei der Siegesparade am 24. Juni 1945 auf dem Roten Platz getragen wurde. Der Historiker und langjährige Kurator des Armeemuseums Arkadij Dement'ev, dessen Archivrecherchen 2008 die Verfälschungen in der Geschichte der gehissten Flagge auf dem Reichstag aufgedeckt hatten, kommt zu dem Schluss, dass die Fahne bei der Generalprobe benutzt wurde, anschließend jedoch entschieden wurde, sie nicht bei der Siegesparade zu präsentieren, sondern sie zum Schutz und zur Aufbewahrung dem Direktor des Armeemuseums zu übergeben. ${ }^{143}$

Rückblickend bezeichnet das Armeemuseum die Kriegszeit als die produktivsten und ertragreichsten Jahre seiner Geschichte. Am Ende des Krieges hatten die muzejščiki über ihre verschiedenen einflussreichen Kanäle beinahe 99.000 Exponate zum »Großen Vaterländischen Krieg « gesammelt. ${ }^{144}$ Im Vergleich trugen die Mitarbeitenden des GIM, das Mitte 1944 seine Sammlungs- und Ausstellungsarbeit

140 Die Diskussionen drehen sich hauptsächlich um die Frage, wer zu welchem Zeitpunkt welche Fahne auf dem Berliner Reichstag gehisst hat. Vgl. Platoff, Anne: Of Tablecloths and Soviet Relics, A Study of the Banner of Victory (Znamia Pobedy), in: A journal of Vexillology, Jahrgang 20, 2013, S. 55-83.

Shneer, David: Through Soviet Jewish Eyes, Photography, War and the Holocaust, New Brunswick 2011.

142 Dement'ev, Arkadij: Znamja pobedy, glavnaja relikvija velikoj otečestvennoj vojny v svete istoričeskich issledovanij, Moskva 2015.

143 Ebd. S. 37-38.

144 Ohne Autor: Istorija CMVS, in: www.cmaf.ru/history/ (Stand: 31.07.2021). 
wieder auf die Vorkriegsgeschichte der Sowjetunion ausrichten musste, »nur « rund 12.000 Objekte zur Sammlung »Großer Vaterländischer Krieg « zusammen. ${ }^{145}$ Dieser Vorsprung, der maßgeblich durch die institutionelle Anbindung des Museums an das Kommissariat für Verteidigung entstanden war, machte das Armeemuseum zur unionsweiten Deutungsinstanz über die museale Darstellung der Geschichte des »Großen Vaterländischen Krieges«.

Mit der Verleihung der Medaille »Für die Verteidigung von Moskau« an $20 \mathrm{Mi}$ tarbeiterinnen und Mitarbeiter des GIM im Januar 1945 wurde die innovative und unkonventionelle Sammlungs- und Ausstellungsarbeit der muzejščiki von höchster Stelle legitimiert und ausgezeichnet. ${ }^{146}$ Die Methode des Sammelns "auf den heißen Spuren der Ereignisse«, die hier ihren Ursprung hatte, verbreitete sich als Vorbild in den Moskauer Museen und wurde zum Indikator einer Wende in der sowjetischen Museologie. ${ }^{147}$ In der Nachkriegszeit organisierte das GIM sogenannte "historische Alltagsexpeditionen« [istoriko-bytovye èkspedicii], bei der die Erfahrungen der Kriegssammelpraxis einflossen. ${ }^{148}$ Zehn Jahre nach Kriegsende beschloss das Museumsinstitut des Narkompros, das sowjetische Museumswesen als theoretische Disziplin zu etablieren und die Arbeitsmethoden seiner Häuser zu verein-

Zwischen dem 1. Juli 1941 und dem 1. Juli 1944 erwarb das GIM 12.309 Objekte für die Sammlung »Großer Vaterländischer Krieg«. Vgl. Zaks, Anna: Iz istorii gosudarstvennogo istoričeskogo muzeja, S. 11.

Zusätzlich wurden die Namen der Direktorin des GIM Anna Kaprova und 19 ihrer Mitarbeiterinnen und Mitarbeiter am 9. Januar 1945 in das »Ehrenbuch der Republik« eingetragen. Vgl. Zaks, Anna: Iz istorii gosudarstvennogo istoričeskogo muzeja, 1941-1957 gg., in: Naučnoissledovatel'skij institut muzeevedenija (Hg.): Očerki istorii muzejnogo dela v Rossii, Ed. 3, Moskva 1961, S. 5-54, hier S. 13. Die Medaille wurde an Zivilisten und Militärs verliehen, die mindestens einen Monat zwischen dem 19. Oktober 1941 und dem 25. Januar 1942 aktiv an der Verteidigung Moskaus teilgenommen hatten.

Pëtr Loginov, der Kurator der Sonderausstellung »Die Zerschlagung der deutschen Truppen vor Moskau«, beschrieb die Sammelarbeit des Armeemuseums als »sammeln von Reliquien auf den heißen Spuren der Ereignisse«, in: Loginov, Pëtr: Po sledam vojny, S. 181. Auch das Museum der Revolution wandte während des Krieges diese Technik an, vgl. Lupalo, I.: Po sledam vojny, Sobiranie materialov Muzeem revoljucii SSSR, in: Archeografičeskij ežegodnik za 1975, Moskva 1976, S. 159-162. Auch die Angestellten des »Museums der Verteidigung von Leningrad « wandten diese Methode an. Die Kuratorin Marina Tichomirova erinnert sich: »Die Ausstellung > Die heldenhafte Verteidigung von Leningrad ‘ wurde auf den frischen Spuren der Ereignisse (po svežim sledam sobitij) erstellt. Man kann sagen in einem Atemzug, auf einem hohem geistigen Niveau. Sie integrierte Originaldokumente, lebendige (živye) Materialien, Trophäen, deren Bedeutung riesig war in diesen Zeiten. Sie vereinigte wahrhafte historische Claubwürdigkeit mit einer starken emotionalen Wirkung. Wer sie gesehen hat, der wird sie nie vergessen.«In: Tichomirova, Marina: Pamjatniki, Ljudi, Sobytija, S. 77-78, zitiert aus: Fatigarova, Natal'ja: Muzejnoe delo v RSFSR, S. 196.

148 Diese Expeditionen wurden zwischen 1949 und 1957 durchgeführt. Vgl. Zaks, Anna: Iz istorii gosudarstvennogo istoričeskogo muzeja, S. 16. 
heitlichen. In dem Grundlagenband zur sowjetischen Museologie war das unmittelbare Sammeln von Objekten der Gegenwart, die Methode der Moskauer muzejšči$k i$, als fester Bestandteil der Arbeit historischer Museen festgeschrieben. ${ }^{149}$ Damit wurde das Museumsexponat in Bezug auf seine Originalität und Einmaligkeit aufgewertet. Die Wirkung seiner Materialität und vermeintlichen Aura begann eine neue Rolle zu spielen. Dieses Verständnis stand im Gegensatz zu den Ausstellungen, die ab Mitte der 1930er Jahre die Geschichte Russlands über Kopien, Dubletten und Reproduktionen ausgestellt hatten.

Die muzejščiki sprachen den Relikten des »Großen Vaterländischen Krieges« einen großen Wert zu. Sie gingen davon aus, dass diese Exponate die dargestellten Ereignisse aus sich selbst heraus spiegelten, weil sie dem Ereignis direkt entnommen worden waren. Diese Aura wird den Objekten bis in die heutige Zeit zugeschrieben. Die Museumskollektionen aus dem Krieg, die die spätstalinistischen Säuberungen überdauerten, gelten heute als "goldene Sammlungen« (zolotye fondy) und werden mit besonderer Rücksicht behandelt.

149 Gardanov, V.: Sobiratel'skaja rabota muzeev, in: Naučno-issledovatel'skij institut muzeevedenija (Hg.): Osnovy sovetskogo muzeevedenija, Moskva 1955, S. 39-91. Auch der Museologe Taras Poljakov bestätigt diese Lesart, nach der die von den muzejščiki im Krieg entwickelten Arbeitsmethoden die spätstalinistischen Säuberungen überdauerten und Eingang in den grundlegenden Sammelband der sowjetischen Museologie fanden. Vgl. Poljakov, Taras: Mifologija muzejnogo proektirovanija, S. 65. Zum Anspruch und Stellenwert des Sammelbandes in der sowjetischen Museologie vgl. Šulepova, Ėleonora (Hg.): Muzeevedčeskaja mysl' v rossii, S. 771. 


\section{Die belarussische Historikerkommission dokumentiert die Besatzungserfahrung}

Nach der gewonnenen Schlacht um Moskau im Winter 1941/42 drang die sowjetische Armee bis zur Grenze der belarussischen Sowjetrepublik vor und erkämpfte nordöstlich von Witebsk eine Frontlücke. Hier, am »Tor von Suraž« (Suražskaja brama), beginnt die Geschichte des »Staatlichen belarussischen Museums zur Geschichte des Großen Vaterländischen Krieges«. Eine Kommission von Historikern sollte diesen Zugang $\mathrm{zu}$ den Gebieten der Partisaneneinheiten nutzen, um Dokumente und Materialien zu sammeln. Pantelejmon Ponomarenko (Belarussisch: Panzeljajmon Panamarënka), Vorsitzender des Zentralkomitees der Kommunistischen Partei von Belarus (ZK KP(b) B), der wegen der deutschen Einnahme der Hauptstadt am 28. Juni 1941 evakuiert worden war, hatte die Kommission ein knappes Jahr später in Moskau gegründet. ${ }^{150}$ Diese belarussische >Länder-Kommission` entstand im Kontext der >Zentralen Historikerkommission an der Moskauer Akademie der Wissenschaften. Im Dezember 1941, als die Rote Armee erstmals eine Gegenoffensive startete, hatte der Historiker Isaak Izrailevič Minc (1896-1956) im Auftrag des Parteisekretärs für Agitation und Propaganda die »Kommission zur Geschichte des Großen Vaterländischen Krieges« (Komissija po istorii Velikoj Otečestvennoj vojny) gegründet. Angebunden an die Akademie der Wissenschaften sammelte er mit einem Stab von 20 Mitarbeitenden Dokumente zur Geschichte des Krieges, um auf dieser Grundlage eine tägliche Chronik des Kriegsgeschehens zu verfassen. Die Kommission hatte mit der Dokumentation der Verteidigung von Moskau begonnen. Bald jedoch wurden zusätzliche Zweigstellen in anderen Städten eingerichtet, die als Unterkommissionen Materialien $\mathrm{zu}$ anderen Kämpfen in der Union archivierten. ${ }^{151}$

Jochen Hellbeck, der die Protokolle der Stalingrad-Kommission ausgewertet hat, sieht hier Parallelen zu vorangegangenen Historikerkommissionen in der Sowjetunion. ${ }^{152}$ Minc' Ansatz zur Dokumentation des »Großen Vaterländischen Krieges« stehe in der Tradition der revolutionären und avantgardistischen Dokumen-

Grundlegend für den deutschen Überfall, die deutsche Besatzung und die Folgen für Belarus vgl. Gerlach, Christian: Kalkulierte Morde, Die deutsche Wirtschafts- und Vernichtungspolitik in Weißrussland 1941-1944, Hamburg 1999, hier: Die Kampfhandlungen in Weißrussland, S. 128-134, sowie: Chiari, Bernhard: Alltag hinter der Front: Besatzung, Kollaboration und Widerstand in Weißrussland 1941-1944, Düsseldorf, 1998. Zur Gründung der Kommission siehe: NARB [Nationalarchiv der Republik Belarus], f. 4p. op. 3, d. 1236, I. 2-4.

151 Zur Cründung und Tätigkeit der Kommission während des Krieges vgl. Žuravlev, Sergej (Hg.): Vklad učenych-istorikov v sochranenie istoričeskoj pamjati o vojne, Moskva/St. Peterburg 2015, S. 50-130. Für die Erinnerungen von I. Minc an die Gründung und Arbeit der Kommission vgl. Minc, Isaak I.: Iz pamjati vyplyli vospominanija, Moskva 2007. 
tationen des Bürgerkrieges, die mit ihrer Darstellung der Gegenwart einen Beitrag zur Errichtung der neuen Gesellschaft leisten wollten und als Vorgänger der Kommissionen der 1940er Jahre betrachtet werden müssten. Bereits in den 1920er Jahren hatten sich Historikerinnen und Historiker den Ansatz, dessen Besonderheit in der Modellierung und Anpassung der Quellen für eine bessere Erziehung des Neuen Menschen bestand, angeeignet und umfassende historische Erinnerungsprojekte realisiert. Unter der Leitung des Schriftstellers Maxim Gorki und der Mitarbeit des Historikers Isaak Minc wurde beispielsweise 1931 die »Geschichte des Bürgerkrieges« geschrieben, die in ihrem Anspruch nach einer Schilderung der heldenhaften Menschen als direktes Vorbild für die Arbeit der Kommissionsmitglieder im »Großen Vaterländischen Krieg « gesehen werden kann. ${ }^{153}$

Das ZK der belarussischen Partei in Moskau hatte ranghohe Politiker aus den eigenen Reihen als Mitglieder ihrer Kommission bestimmt. Die Leitung des achtköpfigen Stabes war dem 37-jährigen Timofej Gorbunov (Belarussisch: Cimafej Garbunoŭ) übertragen worden, der seit April 1941 als Sekretär des Zentralkomitees für Propaganda der belarussischen Partei fungierte. Gorbunov, der mit 22 Jahren in die Partei eingetreten war, hatte nach seinem Geschichtsstudium die belarussische Parteizeitung »Zvjazda« geleitet und als Korrespondent in Minsk, Kiew, Jaroslawl und Odessa für die »Pravda« geschrieben. ${ }^{154}$ Mit Vladimir Malin (Belarussisch: Uladzimir Malin), dem späteren Privatsekretär Stalins, und Ivan Krupenja, dem stellvertretenden Leiter des Partisanenstabes, hatte die Kommission zwei weitere ZK-Mitglieder, die dank ihrer Funktionen über beste Beziehungen zur obersten Machtetage und zum Militär verfügten. ${ }^{155}$ Das einzige weibliche Mitglied der Gruppe war Evdokia Uralova (Belarussisch: Eŭdakija Uralava), die als Juristin und Angestellte des Kommissariats für Aufklärung bei der Kommission arbeitete. ${ }^{156}$ Das jüngste Mitglied der Gruppe war der 29-jährige Sergej Prityckij (Belarussisch: Sjargej Prytycki), der bereits Erfahrung mit der Arbeit im Untergrund hatte: In den 1930er Jahren arbeitete er als Sekretär der damals illegalen belarussischen Partei in Polen. Aufgrund eines gescheiterten Attentates auf einen polnischen Agenten wurde Prityckij verhaftet und zum Tode verurteilt, kam aber im Zuge der sowjetischen Invasion 1939 in Polen frei und arbeitete während des

153 Hellbeck, Jochen: Die Stalingrad-Protokolle, S. 87-88.

154 Nacional'naja Akademia Nauk Belarusi, Istoričeskaja spravka, T. Gorbunov: http://nasb.gov.b y/rus/members/academicians/gorbunov.php (Stand: 31.07.2021).

155 Wikipedia, V. Malin: https://ru.wikipedia.org/wiki/Малин,_Владимир_Никифорович (Stand: 31.07.2021). Wikipedia, I. Krupenia: https://ru.wikipedia.org/wiki/Крупеня,_иван_А нуфриевич (Stand: 31.07.2021).

156 Spravočnik po istorii Kommunističeskoj partii Soevetskogo Sojuza 1891-19991, E. Uralova: w ww.knowbysight.info/UUU/17219.asp (Stand: 31.07.2021). 
Krieges als Sekretär des belarussischen Komsomol. ${ }^{157}$ Der bekannte belarussische Schriftsteller Michail Lyn'kov (Belarussisch: Michas' Lyn'koŭ) und Vasilij Zakurdaev (Belarussisch: Vasil' Zarkurdaeŭ), ein Leitungsmitglied der Partisanenbewegung, hatten als einzige Kommissionsmitglieder während des Bürgerkrieges in der Roten Armee gedient. ${ }^{158}$ Von 1938 bis 1948 war Ly'nkov Vorsitzender des belarussischen Schriftstellerverbandes und gab während des Krieges die Frontzeitung »Für ein sowjetisches Belarus« (Za Sovetskuju Belorus') heraus. Neben einem bislang unbekannten Mitglied wurde der Akademiker Ivan Kravčenko in die Kommission berufen. Vor dem Krieg hatte er am Minsker Pädagogischen Institut unterrichtet und war Autor maßgeblicher Werke zur Geschichte der sowjetischen Republik Belarus. ${ }^{159}$

Diese bunt gemischte Gruppe verband die Erfahrung in der parteipolitischen Arbeit. Darüber hinaus schienen die Mitglieder aufgrund ihrer spezifischen Fähigkeiten und Beziehungen ausgewählt worden zu sein. Es ist anzunehmen, dass Erfahrungen im Untergrund bzw. in der Armee ebenso wertvoll waren wie politische Beziehungen zu den obersten Parteikadern. Auffallend viele Mitglieder verfügten über journalistische bzw. schriftstellerische Fertigkeiten, die für die Aufbereitung der gesammelten Materialien zum Zweck der Publikation von großer Bedeutung waren.

In seinem Bericht, den der Vorsitzende Gorbunov im Januar 1943 über das erste halbe Jahr der Kommissionsarbeit verfasste, definiert er die Aufgaben des Ausschusses: „So viel Material wie möglich über die Teilnahme der BSSR im Großen Vaterländischen Krieg gegen den deutschen Faschismus sammeln, dieses sichern und mit der thematischen Auswertung beginnen, um es für zukünftige Publikationen aufzubereiten. ${ }^{160}$ Die Juristin, die Politiker, Wissenschaftler und Schriftsteller, die so privilegiert waren, dass sie aus der besetzten sowjetischen Republik Belarus evakuiert worden waren bzw. mit Unterstützung fliehen konnten, sollten nun von Moskau aus Materialien zum Kampf eines Landes sammeln, das es seit August 1941 in seiner Staatlichkeit nicht mehr gab. Der von der Partei erwartete Partisanenkampf und die Untergrundbewegung zum Widerstand gegen die deutschen Besatzungstruppen entstanden $\mathrm{zu}$ diesem Zeitpunkt gerade erst und das Leben der zurückgelassenen Zivilbevölkerung, insbesondere der großen jüdischen

157 Wikipedia, S. Prityckij: https://ru.wikipedia.org/wiki/Притыцкий,_Сергей_Осипович (Stand: 31.07.2021).

158 Wikipedia, M. Lyn'kov: https://ru.wikipedia.org/wiki/Лыньков,_Михаил_Тихонович (Stand: 31.07.2021). Wikipedia, V.ZZakurdaev: https://ru.wikipedia.org/wiki/Закурдаев,_Василий_Ив анович (Stand: 31.07.2021). 
Minderheit, war von dem täglichen Überlebenskampf gegen die deutschen Besatzer geprägt.

Theoretisch war die Sammelarbeit der Kommission durch die enge Abstimmung mit der Moskauer Zentrale von Isaak Minc gut koordiniert. Die Aufgaben wurden verteilt, Sekretäre, Fotoreporter, Stenografen und wissenschaftliche Mitarbeiterinnen und Mitarbeiter wurden bestimmt. ${ }^{161}$ Jedoch bestand neben der drängenden Frage nach der Art der zu sammelnden Materialien die Frage nach der praktischen Durchführung der Sammelarbeit: Wie sollten Informationen und Materialien im deutsch besetzten »Generalbezirk Weißruthenien « gesammelt werden ${ }^{162}$

Die meisten Objekte gelangten durch die einzige Frontlücke, durch das bereits genannte »Tor von Suraž«, in den Besitz der Kommission. Diese Verbindung in die besetzten Gebiete stellte eine wichtige Evakuationsroute dar und war für die Versorgung der Partisaninnen und Partisanen von großer Bedeutung. ${ }^{163}$ Politoffiziere und Komsomolarbeiter nutzten diese Route, um die Untergrund- bzw. Partisanenbewegung anzuleiten. Die Kommissionsmitglieder machten von diesem Zugang Gebrauch, um Informationsmaterial über die Besatzungsherrschaft zu sammeln. Nachdem die deutsche Armee diese Lücke im September 1942 geschlossen hatte, begleiteten die Sammlerinnen und Sammler nun die militärischen Transportflugzeuge, die regelmäßig zu den Partisaneneinheiten flogen. Die Kommissionsmitglieder wurden bereits auf der Landebahn von Kommandeuren und verwundeten Partisaninnen und Partisanen bedrängt, die ihre Erlebnisse berichten und Neuigkeiten aus der Hauptstadt erfahren wollten. Die Historiker interviewten sie und zeichneten ihre Erzählungen vor Ort auf. ${ }^{164}$ Die Begegnung mit den Kommissionsmitgliedern aus Moskau konnte für die unter der deutschen Besatzung lebenden Menschen von großer emotionaler Bedeutung gewesen sein. Der Kontakt war eine der wenigen Informationsquellen über den Kriegsverlauf für die Kommandeure, die im Untergrund von Meldungen, die über die regionalen Ereignisse hinausgingen, abgeschnitten waren. Gleichzeitig ermöglichte ihnen die Begegnung, vom eigenen Widerstandskampf zu berichten. Diese Berichterstattung konnte in Anbetracht des Kollaborationsverdachts, mit dem die Partei den unter deutscher

Voronkova, Irina: Sozdanie i sostavlenie Belorusskogo Cosudarstvennogo Muzeja istorii Velikoj Otečestvennoj vojny, Minsk 2001, S. 4.

162 Das »Reichskommissariat Ostland« entstand als Folge des Angriffs des Dritten Reichs auf die Sowjetunion im Juni 1941. Die vier deutsch besetzten »Generalbezirke« erstreckten sich über das Baltikum und Teile der heutigen Republik Belarus. Am 1. September 1941 wurden die Hälfte der belarussischen Kresy sowie die Gegend um Minsk zum »Ceneralkommissariat Weißruthenien«zusammengefasst, das unter der Leitung von Wilhelm Kube stand. Hoffmann, Joachim: Die Kriegführung aus Sicht der Sowjetunion, in: Boog, Horst (Hg.): Der Angriff auf die Sowjetunion, Frankfurt a.M. 1991, S. 848-964, hier S. 934 und für eine Karte siehe S. 928.

164 Voronkova, Irina: Sozdanie i sostavlenie Belorusskogo Gosudarstvennogo Muzeja, S. 5. 
Besatzung lebenden sowjetischen Menschen pauschal begegnete, überlebenswichtig sein. Für die Kommissionsmitglieder war das »Tor von Suraž« ein exklusiver Zugang zu den besetzten Gebieten. Für die Formierung des Kriegsgedenkens bedeuteten die Aufzeichnungen jedoch nur eine ausschnitthafte Dokumentation des belarussischen Widerstandes. Nur die Erlebnisse der Partisaninnen und Partisanen, nicht die der Zivilbevölkerung, die im Untergrund Widerstand leistete, wurden aufgezeichnet. Auch ist anzunehmen, dass in den Berichten nur parteitreue Augenzeuginnen und Augenzeugen auftauchten und die bürgerkriegsähnlichen Zustände, die zum Teil in den Partisanengebieten der sowjetischen belarussischen Republik herrschten, nicht dokumentiert wurden.

Es überrascht nicht, dass die über 2000 Materialien und Dokumente, über die die Kommission nach dem ersten halben Jahr ihrer Sammlungsarbeit verfügte, in erster Linie schriftlicher Art waren: Berichte, Briefe, Gesprächsaufzeichnungen, Untergrundzeitungen, Propagandamaterial der Partei, Flugblätter, Wandzeitungen der Partisanenverbände, Fotos, aber auch Propagandamaterial der Deutschen wie Plakate, Flugblätter und Zeitungen wie »Der neue Weg«, die von den Besatzern in verschiedenen Städten auf Belarussisch herausgegeben wurden. Neben diesen zweidimensionalen Materialien listete Gorbunov zusätzlich »39 Kleidungsstücke der Partisanen« auf, darunter Jacken, Mäntel, Hüte sowie Waffen, wie Gewehre, Pistolen und Handgranaten. ${ }^{165}$ Dass diese Alltagsgegenstände in die Hände der Kommission gelangten, zeigt die politische Priorität, die ihrer Arbeit zugesprochen wurde: Obwohl genau diese Gebrauchsgegenstände zum allernötigsten Bedarf der notleidenden Zivilbevölkerung und der schlecht ausgerüsteten Partisanenbewegung zählten, wurden sie nach Moskau geschafft, wo sie entweder im Archiv der Kommission oder, im Falle von Dubletten, im Parteiarchiv des ZK der KPdSU oder in der Ausstellung des GIM landeten. ${ }^{166}$

Vor dem Überfall der Wehrmacht auf die Sowjetunion hatte die militärische Führung die Bedeutung der Partisanenbewegung als gering eingeschätzt, da sie im Kriegsfall von Kämpfen auf fremdem Territorium ausgegangen war. Im zweiten Kriegsjahr, als sich große Gebiete der Sowjetunion unter deutscher Besatzung befanden, war der Partisanenkampf zu einem unerlässlichen Kriegsmittel geworden. Dennoch blieb die sowjetische Führung skeptisch gegenüber den irregulären und schwer zu kontrollierenden Verbänden im Feindesland. Informationen über ihren loyalen Kampf und die öffentliche Präsentation ihrer Tätigkeiten, beispielsweise im deutungsmächtigen Staatlichen Historischen Museum in Moskau, waren daher von großer Wichtigkeit. 


\section{Die Sonderausstellung "Belarus lebt, Belarus kämpft, Belarus war und wird sowjetisch sein"}

Die Initiative für eine Sonderausstellung im GIM kam von den Kommissionsmitgliedern selbst, die bereits die nötigen Absprachen mit der Ausstellungsabteilung des Museums getroffen hatten. Ende September 1942 hatte der Kommissionsleiter Timofej Gorbunov den Parteisekretär Pantelejmon Ponomarenko um Erlaubnis gebeten, im GIM drei Säle mit den gesammelten Objekten zu inszenieren. ${ }^{167}$ Bereits einen Monat später beauftragte Ponomarenko die Kommission, in Zusammenarbeit mit dem GIM eine Sonderausstellung mit dem Titel »Belarus lebt, Belarus kämpft, Belarus war und wird sowjetisch sein« einzurichten und ihm den Ausstellungsplan zur Prüfung vorzulegen. ${ }^{168}$ Kurze Zeit später kündigte die Parteizeitung »Sowjetisches Belarus« (Sovetskaja Belorus'), die während des Krieges in Orjol, Kazan und Moskau erschien, die Ausstellungseröffnung im GIM an. Der kurze Zeitungsartikel hob vor allem das Ausstellungskapitel über das öffentliche Leben hervor: "Besonders ausführlich werden die Aktivitäten der belarussischen Wissenschaftler, Schriftsteller, Kompositeure, Maler und Künstler gezeigt. « ${ }^{169}$ Im Herbst 1942, als die deutsche Besatzungsherrschaft unbesiegbar schien, waren Beweise des lebendigen öffentlichen belarussischen Lebens die wichtigste Nachricht für das sowjetische Hinterland. Auch die drei prägnanten Aussagen des Ausstellungstitels >Belarus lebt, kämpft und ist sowjetisch`folgten diesem Impetus.

167 NARB, f. 750p, op. 1, d. 44, I. 11.

168 NARB, f. 750p, op. 1, d. 44, I. 1. Diese Rhetorik des Sowjetpatriotismus übernahm nach der Wende bei Stalingrad auch der erste Sekretär der KP Litauen Antanas Sniečkus, als er im Juli 1943 in der »Pravda « verkündete: »Litauen war und wird wieder sowjetisch sein « (Litva byla i budet sovetskoj!). Zitiert nach Makhotina, Ekaterina: Erinnerungen an den Krieg, S. 66.

Ohne Autor: Belarus' žyve, belarus' zmagaecca, Vystaŭka ŭ Dzjaržaŭnym gistaryčnym muzei, in: Sovetskaja Belarus', 28. Oktober 1942, S. 4. Auf der gleichen Seite wurde die Beteiligung belarussischer Künstler an der Ausstellung »Großer Vaterländischer Krieg « in der Tret'jakovGalerie angekündigt. Vgl. Ohne Autor: Mastaki na vystaŭcy »Vjalikaja ajčynnaja vajna«. 
Abbildung 2: Plakat des Staatlichen Historischen Museums (GIM) mit der Ankündigung der Sonderausstellung »Belarus lebt, Belarus kämpft, Belarus war und wird sowjetisch sein«, Moskau Oktober 1942 @ BDMGVAV.

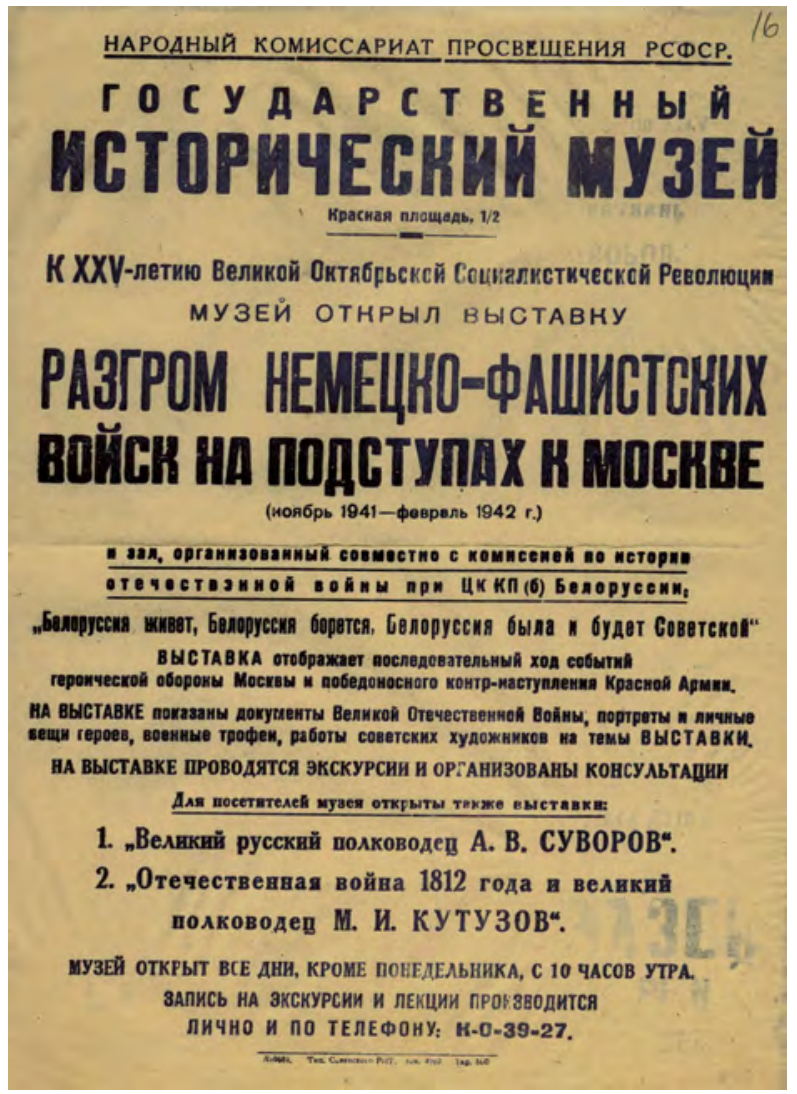

Zum 25. Jahrestag der Oktoberrevolution am 7. November 1942 hatte das GIM seine einjährige Sonderausstellung »Die Zerschlagung der deutschen Truppen vor Moskau « mit neuen Objekten bereichert und überarbeitet. Auf dem Ausstellungsplakat (Abb. 2) wurde die Sonderausstellung »Belarus lebt ...« (unter dem Titel der Dauerausstellung) wie folgt angekündigt: »Und der Saal, der gemeinsam mit der Kommission zur Geschichte des Großen Vaterländischen Krieges unter dem CK KP (b) Belarus organisiert wurde, [präsentiert A.H.] >Belarus lebt, Belarus kämpft, 
Belarus war und wird sowjetisch sein. « ${ }^{170}$ Die Sonderausstellung über den Widerstandskampf in der sowjetischen Bruderrepublik folgte also chronologisch auf die erfolgreichen Kämpfe der Roten Armee in Moskau. Im Anschluss an diese zwei Präsentationen, die sich direkt den Ereignissen des »Großen Vaterländischen Krieges« widmeten, konnten noch zwei weitere Sonderausstellungen besichtigt werden, die dem Leben des Generals Aleksandr Suvorov (1730-1800) und dem Krieg gegen Napoleon 1812 unter Führung von Michail Kutuzov (1745-1813) gewidmet waren. Diese zwei historischen Sonderausstellungen waren Konstanten des Ausstellungsprogramms im Krieg, die unabhängig von den kommemorativen Gegenwartsausstellungen historische Analogien von gewonnenen Kriegen und erfolgreichen militärischen Anführern zeigten.

Die Kommissionsunterlagen, unter anderem der Ausstellungsplan voller handschriftlicher Korrekturen und Ergänzungen, geben Einblick in die 313 Exponate der Ausstellung und lassen Rückschlüsse auf das Sammlungsprofil der Kommission zu. Für das erste der insgesamt fünf Ausstellungskapitel, das das Leben in der sowjetischen Republik vor dem Überfall der Wehrmacht darstellte, konnte die Kommission auf Dokumente aus den Parteiarchiven zurückgreifen. Während im Armeemuseum ein Jahr zuvor die Annexion der polnischen Gebiete im Rahmen des Geheimen Zusatzprotokolls von 1939 noch als "glückliche Wiedervereinigung der sowjetischen Völker« dargestellt wurde, war in dieser Ausstellung nun auf einem Tafeltext von der »Rettung des westlichen Belarus durch die Rote Armee vor den Deutschen « zu lesen. ${ }^{171}$ In ihrer Rhetorik versuchten man sich an dem gängigen Vorkriegsnarrativ zu orientieren und griff die Metapher von Stalins Gesetzen als schützende Sonne auf. Der erste Saal trug den Titel »Über unseren Städten und Dörfern schien die Sonne der stalinistischen Verfassung «. ${ }^{172}$ Hier wurden das Dekret über die territoriale Integrität der belarussischen SSR sowie Wappen der Republik und Zitate aus der Verfassung präsentiert. Daneben zeigten Fotos das Arbeits- und Freizeitleben der Bevölkerung, zentrale Plätze und Gebäude aus Minsk, Brest, Witebsk, Gomel' und Mahilëŭ sowie Aufnahmen aus dem BiałowieżaNationalpark. ${ }^{173}$ Diese zweidimensionalen Exponate wurden von drei Skulpturen des berühmten belarussischen Bildhauers Zair Azgur (Lenin und Stalin, Stalin im Sessel und die Büste der belarussischen Opernsängerin Larisa Aleksandroŭskaja)

BDMGVAV, N/D 28075.

NARB, f. 750p, op. 1, d. 44, I. 15-18, hier I. 15.

Der vierseitige Ausstellungsplan ohne Angabe des Autors enthält handschriftliche Streichungen und Ergänzungen in zwei Farben (schwarz und violett), die auf einen doppelten Korrekturvorgang hinweisen. An dieser Stelle hatte der Autor den Zusatz »stalinistische Sonne« vergessen. Dieser Zusatz wurde handschriftlich ergänzt.

NARB, f. 750p, op. 1, d. 44, I. 19-24, hier I. 19-20. 
und zehn Aquarellen des belarussischen Malers Uladzimir Kudrëvič ergänzt. Neben einem Foto von einem Umzug der Białystoker Textilarbeiter aus dem Jahr 1940 zeigte eine Vitrine traditionell bestickte Stoffe (Abb. 3). ${ }^{174}$

Abbildung 3: »Vitrine mit Stoffen « in der Sonderausstellung »Belarus lebt, Belarus kämpft, Belarus war und wird sowjetisch sein" (GIM, Saal 28), Moskau 3. November 1943, N.E. Bugel'ska ( GIM.

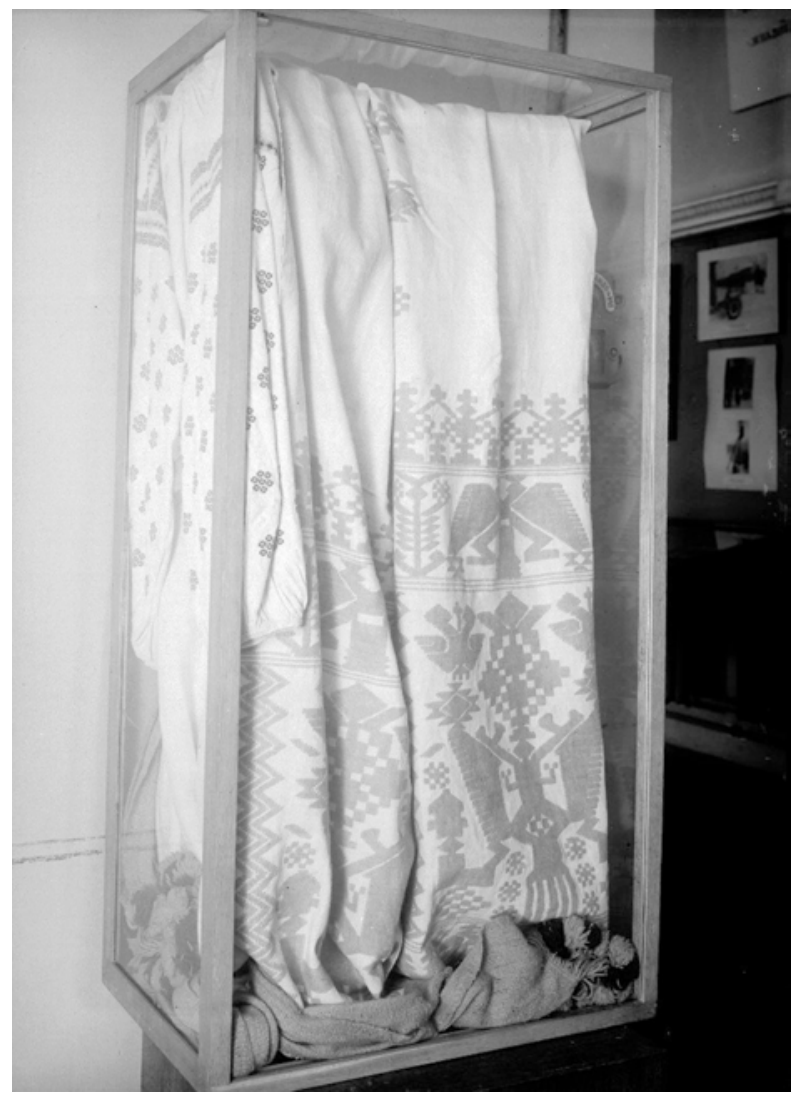

Das zweite Ausstellungskapitel mit dem Titel »Unter dem Stiefel der deutschfaschistischen Besatzer. Schwarze Nacht senkte sich über der belarussischen Erde« kontrastierte stark mit dem vorangegangenen. Hier griff die Kommission auf Dokumente und Fotos einer Sonderkommission zurück, die für die Erfassung der 
von der Wehrmacht verursachten Zerstörung verantwortlich war. Die ČGK, die insbesondere in den besetzten bzw. von der Roten Armee befreiten Gebieten arbeitete, stellte der Historikerkommission Abzüge von Aufnahmen zur Verfügung, die die Kriegsverbrechen der Wehrmacht dokumentierten. Neben Fotos von zerstörten Städten, der ermordeten Zivilbevölkerung und abgebrannten Dörfern waren in diesem Ausstellungskapitel deutsche Befehle und Anordnungen der deutschen Besatzungsherrschaft ausgestellt. ${ }^{175}$ Interessanterweise zeigten die Fotos und ihre Unterschriften Aufnahmen von der Verschickung der Zwangsarbeiterinnen und Zwangsarbeiter in das Deutsche Reich sowie Bilder aus Konzentrationsund Kriegsgefangenenlagern. Eine Vitrine stellte sogar die Aufzeichnungen eines belarussischen Bürgermeisters aus, der mit den deutschen Besatzern kollaboriert hatte. Dem Dokument waren folgende Erläuterungen beigefügt: »In seinen fehlerhaften Zeilen wird der Verräter erkennbar, der faschistische Lakai bemühte sich, die Hitleristen zufriedenzustellen und ergriff auf Befehl des Kommandanten alle Mittel, um die belarussische Bevölkerung auszurauben und die sowjetischen $\mathrm{Pa}$ trioten zu vernichten. ${ }^{176}$ Der Topos des dummen Verräters war fester Bestandteil der stalinistischen Feindpropaganda. Dieser eindeutige Hinweis auf die Zusammenarbeit zwischen den deutschen Besatzungstruppen und der einheimischen Bevölkerung bei der Ausbeutung und Vernichtung der belarussischen Bevölkerung (in erster Linie der jüdischen Minderheit) ist jedoch überraschend, weil diese Facette der Besatzungserfahrung aus der Erzählung vom »Großen Vaterländischen Krieg« in der Regel ausgeschlossen oder nur mit größter Vorsicht thematisiert wurde. ${ }^{177}$ Diese Ausnahme ist als ein Hinweis auf die kommemorative Dimension der Ausstellungen im Krieg zu lesen, die sich durch ihre große Nähe zu den Erfahrungen der Kriegsgeneration auszeichneten.

Das dritte Ausstellungskapitel unter dem Titel »Belarus lebt, Belarus kämpft« trug eindeutig die journalistische oder schriftstellerische Handschrift der Kommissionsmitglieder, die sich in der Auswahl und Inszenierung der Exponate zeigte. Neben Flugblättern, die das Agitationsbüro der Partei über dem besetzten Gebiet verteilen ließ, waren hier Exemplare der Untergrundpresse ausgestellt. ${ }^{178}$ Im Zentrum dieses Kapitels standen die belarussischen Schriftsteller, insbesondere der beliebte Dichter Janka Kupala (1882-1942), der wenige Monate vor der Ausstellungseröffnung in Moskau unter ungeklärten Umständen verstorben war. Eine Vitrine

175 Ebd. I. 20-21.

176 Ebd. I. 22.

177 Hier sind weitere Studien zur Entstehung der sowjetischen medialen Kriegsdarstellung wünschenswert. Einen Ansatz für einen Abgleich mit anderen deutsch besetzten Gebieten bietet E. Makhotinas Studie zu Litauen. Siehe insbesondere das Kapitel »Agitation und Gedenken während der deutschen Besatzung 1941-1944«, in: Makhotina, Ekaterina: Erinnerung an den Krieg, S. 54-72. 
zeigte Briefe und Telegramme der Anteilnahme aus der ganzen Sowjetunion. ${ }^{179}$ Auch Jakub Kolas (1882-1956), neben Janka Kupala der zweite Vertreter der literarischen "Belarussischen Wiedergeburt «, wurde mit der Präsentation eines seiner Gedichte gewürdigt. ${ }^{180}$ Der Kommissionsleiter Timofej Gorbunov nahm das Kapitel zum Anlass, ein Foto auszustellen, das ihn und den Vorsitzenden Ponomarenko im Kreis der Schriftsteller zeigte. ${ }^{181}$ Die Historiker hatten sich selbst als Bewahrer des kulturellen Erbes ihres Landes inszeniert. Den Abschluss dieses Kapitels bildeten Gemälde, Graphiken und Aquarelle, die die Kommission bei belarussischen Künstlern in Auftrag gegeben hatte. Diese sollten Werke erschaffen, die den Anspruch des Ausstellungsnarrativs "Belarus war und wird sowjetisch sein« erfüllen sollten. ${ }^{182}$

Das vierte Ausstellungskapitel war der Partisanenbewegung gewidmet. Neben vielen Fotos, die den Kampf und die Befreiung einzelner Dörfer dokumentierten, waren die sogenannten »Partisanen-Almanache (partizanskie al'manachy) ausgestellt. Diese handgezeichneten Chroniken gewährten einen unmittelbaren Eindruck vom Alltag der Widerstandsgruppen. ${ }^{183}$ Vitrinen präsentierten persönliche Gegenstände der Partisaninnen und Partisanen, darunter Geschenke des sowjetischen Volkes. ${ }^{184}$

Es werden Briefe aus der Roten Armee, von Verwandten und Bekannten sowie Telegramme aus Tbilissi, Taschkent, Ufa, Almaty, Kazan, Novosibirsk, Corkij (heute Nischnij Novgorod) und Tomsk genannt. Vgl.: NARB, f. 750p, op. 1, d. 44, I. 23. In der Ausstellung wurde das Gedicht »Bac'ka Minau« (Väterchen Minau) ausgestellt, das Jakub Kolas dem hochdekorierten Partisanenanführer Minau Šmirou gewidmet hatte. Foto mit der Unterschrift »Sekretär des CK der KP (b) B Genosse Ponomarenko P. K. und Corbunov unter belarussischen Schriftstellern, in: NARB, f. 750p, op. 1, d. 44, I. 22.

NARB, f. 750p, op. 1, d. 44, I. 23. Laut Irina Voronkova gelangten beinahe alle künstlerischen Arbeiten der Sonderausstellungen im GIM in die heutige Sammlung des Belarussischen Museums zur Ceschichte des Großen Vaterländischen Krieges, wo sie als »goldene Kollektion« gelten. Voronkova, Irina Ju.: Sozdanie i sostavlenie Belorusskogo Gosudarstvennogo Muzeja, S. 7. Ebd.

GIM: Nr. 109627, OPI GIM, F. NVA, Inventory 1f, Arch. unit 166/39385f, Nr. 109627, OPI GIM, F. NVA, Inventory 1f, Arch. unit 166/39389f. 
Abbildung 4: Vitrine »Persönliche Dinge der Partisanen von Belarus « in der Sonderausstellung »Belarus lebt, Belarus kämpft, Belarus war und wird sowjetisch sein« (GIM, Saal 28), Moskau 3. November 1943, N.E. Bugel'ska (c) GIM.

Abbildung 5: Vitrine »Geschenke für die Partisanen « in der Sonderausstellung »Belarus lebt, Belarus kämpft, Belarus war und wird sowjetisch sein« (GIM, Saal 28), Moskau 3. November 1943, N.E. Bugel'ska (C) GIM.
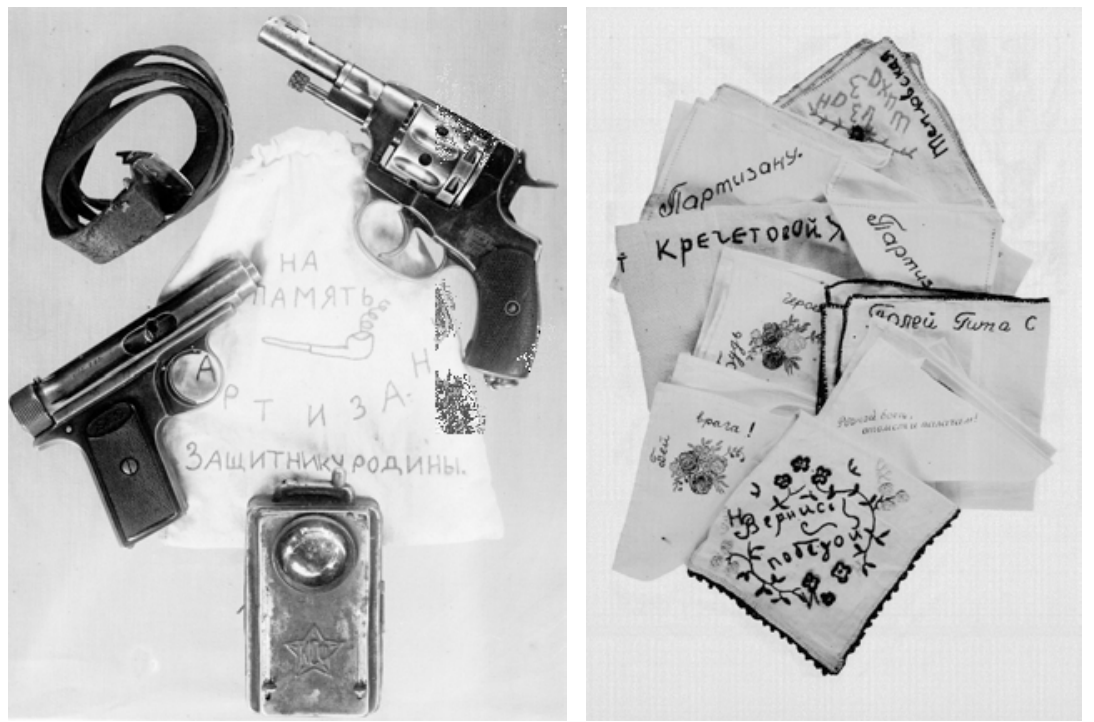

Die erste Vitrine (Abb. 4) zeigte zwei Pistolen, einen Gürtel und eine Taschenlampe, die um einen Beutel drapiert waren. Auf die Mitte des Beutels war eine rauchende Pfeife gestickt, ein Hinweis darauf, dass er für Tabak gedacht war. Um die Pfeife herum befand sich die Aufschrift »Zur Erinnerung an die Partisanen, Verteidiger der Heimat«. In der zweiten Vitrine (Abb. 5) lagen neun schneeweiße, handbestickte Taschentücher, liebevoll mit Rosen und Blumenranken verziert, die Ränder mit Borten besetzt, damit sie nicht ausfransten. Die Stickereien waren motivierende Aufrufe wie: »Sei ein Held«, »Schlag den Feind!«, »Heimatlicher Kämpfer, räche die Henker!«, »Komm mit dem Sieg zurück«, Für Partisanen«, und »von T. Krečetova«, »Aus Šichazany, von Teplovskaja«. Da in der Regel jegliche Angaben zur Provenienz der Ausstellungsobjekte fehlten, kann nur vermutet werden, wer diese Taschentücher bestickt hatte. Auf dem Foto sehen die Taschentücher wie auch der Tabaksbeutel unbenutzt aus. Offensichtlich hatten sie die Partisaneneinheiten nie erreicht - sie waren wohl mehr von symbolischen als praktischen Nutzen. Das Vertrauen in den Widerstand, der Rückhalt der Bevölkerung war gewissermaßen 
in die Tücher eingestickt worden. Die Geschlossenheit zwischen dem Volk und den Kämpferinnen und Kämpfern hinter der Front sollte so für das Moskauer Publikum unmissverständlich werden.

Und etwas lässt sich doch über die Provenienz der Taschentücher herausfinden, denn zwei der neun Taschentuch-Stickerinnen nannten ihre Namen und ihre Herkunft: Eine T. Krečetova und eine Frau Teplovskaja aus Šichazany, einem Dorf in der Republik Tschuwaschien, 600 Kilometer östlich von Moskau. Wie diese Taschentücher nach Moskau kamen, ist unbekannt - möglicherweise hatten die Stickerinnen durch die Kommission von den Heldentaten der Partisaninnen und Partisanen gehört und wollten, gemäß der politischen Kampagne »Alles für die Front«, mit ihren Geschenken zum Sieg beitragen. Die fünfte und letzte Abteilung schloss den Kreis und stellte den Kampf der Roten Armee bei der Befreiung der besetzten Gebiete ins Zentrum der Inszenierung. ${ }^{185}$

Die Ausstellungsstücke zeigten das breite Sammlungsspektrum der Kommission und ihr Netzwerk, das sie mit zusätzlichen Exponaten versorgte. Es war ihr gelungen, eine reichhaltige Ausstellung zu konzipieren, die eine teleologische Erzählung von der sowjetischen Republik Belarus zeigte: Vor dem Krieg habe die "stalinistische Sonne über Belarus geschienen, das sich momentan in einer "schwarzen Nacht « befinde, aber dennoch »lebe« und bald von der Roten Armee befreit werden würde. Auf den zweiten Blick zeigt sich, dass diese Darstellung nicht frei von Widerständen und Feinden war, die es zu überwinden galt (Kollaboration, Kriegsgefangenschaft, Zwangsarbeit). Interessanterweise schien dabei ein stark regionaler Fokus zu helfen. Die Historiker, Schriftsteller und Journalisten der Kommission brachten mit ihren gesammelten Objekten eine spezifisch belarussische Komponente in die Ausstellung, die dank der Darstellung von Folklore (traditionell gewebte Tücher) und bekannter Künstler (Z. Azgur, L. Aleksandroŭskaja, J. Kupala, J. Kolas) über den Partisanenkampf die spezifische Kriegserfahrung der sowjetischen Republik Belarus präsentierte. ${ }^{186}$

185 NARB, f. 750p, op. 1, d. 44, I. 25. Zur Frage, ob belarussische Soldatinnen und Soldaten an den Feldzügen teilnahmen, bleibt der Ausstellungsplan unspezifisch. Generell wurde die heterogene ethnische Zusammensetzung der Roten Armee in den hier untersuchten Ausstellungen nicht thematisiert.

Für die Ausstellungsanalyse, die an dieser Stelle nicht vertieft werden kann, sind im NARB weitere aufschlussreiche Quellen überliefert: Zitate und Texte der Ausstellung in: NARB, $f$. 750p, op. 1, d. 44, I. 32-36, Objektbeschriftungen: NARB, f. 750p, op. 1, d. 44, I. 37-48; Ausschnitte aus einem Führungstext der Ausstellung: NARB, f. 750p, op. 1, d. 44, I. 49-56; großformatige Spruchbänder, Losungen und Ausstellungsplakate, die in der Ausstellung hingen: NARB, f. 750p, op. 1, d. 44, I. 57-105. Ähnliche Materialien (Plakate, Spruchbänder, Fotos der GIM-Ausstellung) befinden sich zusätzlich in: NARB, f. 750p, op. 1, d. 45, I. 1-60 und in: NARB, f. 750p, op. 1, d. 46, I. 1-9. 


\section{Die Sammel- und Dokumentationsarbeit der Kommission}

Die Veröffentlichung des von der Historikerkommission gesammelten Materials, zum Beispiel im Rahmen der beschriebenen Ausstellung, war nach dem Sammeln die zweite und ebenso wichtige Aufgabe der Kommission. Aus den gesammelten Materialien und Zeitzeugeninterviews stellten sie Texte und Broschüren zusammen, die sie an verschiedene öffentliche Einrichtungen (Bibliotheken, Zeitungsredaktionen, Radiostationen) schickten. Umfangreiche Aufsätze mit Titeln wie »Die Deutschen in Belarus« informierten über die Kriegsverbrechen und Zerstörungen sowie über eine angebliche wirtschaftliche Re-etablierung des Großgrundbesitztums und dem Verlust der belarussischen Kultur »unter dem Joch der Faschisten ${ }^{187}$ Diese Texte sollten eine möglichst umfassende Verbreitung der Informationen in der sowjetischen Bevölkerung gewährleisten: Ein großer Teil der Materialien wurde vom Dozenten-Büro der KP Belarus für Vorträge benutzt, anschauliches Material wie Fotos und Flugblätter wurden den Moskauer Museen zur Verfügung gestellt und eine Reihe von Texten wurde an die Zeitungen und Journale geschickt. ${ }^{188}$ Die Relevanz dieser Texte schlug sich auch im Budget der Kommission nieder: Bemerkenswerterweise waren nach den Lohnzahlungen die Autorenhonorare für die Aufsätze, die Auswertung der Interviews und die Fotos der größte Kostenfaktor - wohingegen der Kostenpunkt »Reisen der Mitarbeiter an die Front bzw. in das Hinterland des Feindes « der kleinste war. ${ }^{189}$ Diese Budgetierung hing vermutlich mit den beschränkten Möglichkeiten der Kommissionsmitglieder zusammen. Nachdem die Frontlücke im Herbst 1942 von der Wehrmacht geschlossen worden war, war die Kommission auf die wenigen Transport- und Versorgungsflüge angewiesen, um in die Partisanengebiete zu gelangen. Vorstellbar ist auch, dass die zivilen Mitglieder der Kommission diese Reisen aufgrund der damit verbundenen Lebensgefahr zu vermeiden suchten. Zusammen betrachtet jedenfalls zeigen Adressaten und Kostenstruktur den Stellenwert der Öffentlichkeitsarbeit in der Kommission.

Die Augenzeugenberichte in den Medien und die Objekte in den Ausstellungen suggerierte dem Publikum eine glaubhafte Berichterstattung aus einer Kriegsregion, über die sonst wenig Informationen verfügbar waren. Nachrichten über den sowjetischen Widerstand waren im Fall der besetzten Republik Belarus, in dem sich die deutsche Herrschaft stetig festigte und Gerüchte von Kollaboration kursierten, von besonders großer Wichtigkeit. Auch bestand die Intention, die Bevölkerung in

187 NARB, f. 750p, Op. 1, d. 4, I. 1-8, hier I. 5.

188 Ebd. I. 6-7.

189 Pro Quartal bekam die Kommission 37.400 Rubel zugesprochen. Lohnkosten: 20.400 R, Honorare: 11.600 R, Dienstreisen: 1.100 R. (Haushaltskosten: 6.600 R, Bücher: 6.800 R, andere Ausgaben, Aufbau der Ausstellung usw.: 7.400 R), vgl. NARB, f. 750p, Op. 1, d. 4, I. 8. 
den besetzten Gebieten durch Berichte aus Moskau zu erreichen, um ihre Kampfmoral zu stärken: »The thought that Soviet power was still alive and could return must have bolstered partisans and threatened those who had cooperated or might cooperate with the occupiers. ${ }^{190}$

Gorbunovs Bericht wäre im Sinne der sozialistischen Praxis der >Kritik und Selbstkritik unvollständig gewesen, hätte er nicht im letzten Abschnitt auf die Schwachstellen (nedostatki) der Kommissionsarbeit hingewiesen. Neben praktischen Problemen der Lagerung bezeichnete der Kommissionsleiter die unzureichenden Kontakte zu den Partisaneneinheiten im Hinterland als Hindernis und verpflichtete seine Angestellten, in Zukunft mehr Dienstreisen in die frontnahen Gebiete zu unternehmen. ${ }^{191}$

Jedoch war die systematische und umfassende Sammlung von Objekten zum Krieg in der sowjetischen Republik Belarus auch ein Jahr später nicht möglich. In seiner Sitzung im März 1943 beriet das ZK der KP Belarus über den »Zustand der Kommissionsarbeit «. ${ }^{192}$ Es wurde festgehalten, dass die Kommission nicht alle Möglichkeiten zur Vermehrung der Kriegsmaterialien wahrgenommen habe, und dass die Suche ausgeweitet und vertieft werden müsse. Es wurde beschlossen, mehr Mitarbeitende zu den kämpfenden Einheiten, den evakuierten Betrieben und zu den Parteieinheiten der Regionen der besetzten Gebiete zu schicken. Des Weiteren sollten Subkommissionen zu den im Untergrund agierenden Parteikomitees der Gebiete Witebsk, Minsk, Vilejka, Polessk und Mahilëv gegründet werden, die ihrerseits die Suche nach Materialien und Dokumenten zum »Großen Vaterländischen Krieg « verfolgen sollten. ${ }^{193}$ Doch diese Parteikomitees im Untergrund existierten nur auf dem Papier, da auch hier zu diesem Zeitpunkt kein Kontakt zur Kommission bestand.

Der Bericht spiegelt die Ansprüche an die Kommission, die in der Realität unmöglich umzusetzen waren. Auch im Frühjahr 1943, als sich mit dem Kampf um Stalingrad der Krieg endgültig zu Gunsten der Sowjetunion gewendet hatte, konnte in den genannten Gebieten unmöglich eine Suche stattfinden, da die Parteieinheiten in den besetzten Städten weiterhin im Untergrund agierten und nur sporadische Kontakte zur Führung im Moskauer Exil hatten.

Zusätzlich zu dem Beschluss der verstärkten Sammlungsarbeit gründete der erste Sekretär der KP Belarus in dieser Parteisitzung eine weitere Kommission, in der er sich selbst zum Vorstand erklärte. Pantelejmon Ponomarenko, der zugleich einer der zwei Leiter der Partisanenbewegung war, befehligte das belarussische

Bernstein, Seth: Raised under Stalin, Young Communists and the Defense of Socialism, Ithaca 2017, S. 194. 
Pendant der ČGK, die nach der erwarteten Befreiung durch die Rote Armee in Belarus die verursachten Schäden der nationalsozialistischen Besatzung dokumentieren sollte. ${ }^{194}$

Die Gründung der Kommissionen durch das Zentralkomitee der Belarussischen Partei und die Besetzung dieser Ausschüsse mit Mitgliedern aus den eigenen Reihen zeigen, dass die Arbeit der Kommissionen als ein Mittel zur Stärkung des Widerstandes bzw. des Kampfes um die sowjetische Republik Belarus angesehen wurde. Die Organisation der sowjetischen Partisanenbewegung und die Verbreitung von Informationen über diesen Kampf hatten in der Parteiarbeit oberste Priorität. Ein Kommissionsmitglied erinnerte sich, dass insbesondere die praktische Hilfe Ponomarenkos, des obersten Kommandanten der Partisanenbewegung, die Kommissionsarbeit unterstützt habe. ${ }^{195}$

\section{Die Museumsgründung im Krieg}

Ein halbes Jahr später, im September 1943, begann die Operation »Bagration«, die zur Befreiung der sowjetischen Republik Belarus führen sollte. ${ }^{196}$ Ende des Monats tagte das ZK der belarussischen Partei in Moskau und beschloss, sofort nach der Befreiung von Minsk ein Museum zu gründen. ${ }^{197}$ Über die Hälfte der Sitzungsteilnehmenden waren Mitglieder der Historikerkommission, und es ist anzunehmen, dass die Idee einer Museumsgründung stark von ihnen initiiert worden ist. Auch der erste Direktor des zukünftigen Museums, der während dieser Sitzung ernannt wurde, war ein Kommissionsmitglied: Der Journalist Vasilij Dem’janovič Parfimovič, der das literarische Pseudonym Stal'nov (Belarussisch: Stal'noŭ) nutzte, hatte vor dem Krieg als Korrespondent für verschiedene Zeitungen im Fernen Osten und auf der Krim gearbeitet - zuletzt für die belarussische Zeitung »Stern« in der Stadt Orša, von der er aus nach Moskau evakuiert worden war. ${ }^{198}$

194 NARB, f. 4p, op. 3, d. 1249, I. 82-92. Auch diese Kommissionsgründung war eine Reaktion auf die Cründung der übergeordneten »Außerordentlichen Kommission, ČCK« in Moskau (November 1942). Der belarussischen Untersuchungskommission schien größte politische Relevanz zugesprochen worden zu sein, denn sie wurde mit der Parteielite besetzt, und der ersten Kommission wurden zwei Mitglieder abgezogen: Der Sekretär für Propaganda Timofej Corbunov und der im Untergrund erprobte Leiter des belarussischen Komsomol Sergej Prityckij.

195 Stal'nov, Vasilj: Letopis' neumirajuščego podviga, Zvjazda, S. 4, 22.10.1974 (Übersetzung aus dem Belarussischen von Aleksandr Pustavitau).

196 Zur »Operation Bagration« siehe: Beevor, Antony: The Second World War, New York 2012, S. 586-601.

197 NARB, f. 4p, op. 3, d. 1251, I. 57-59.

198 Voronkova, Irina: Sozdanie i sostavlenie: Sozdanie i sostavlenie Belorusskogo Cosudarstvennogo Muzeja, S. 4. 
Das Protokoll Nr. 188 zeigt, dass zu diesem Zeitpunkt ein anderer als der heutige Name (»Museum der Geschichte des Vaterländischen Krieges«) im Gespräch gewesen war: »Museum zur Geschichte des Kampfes des belarussischen Volkes mit den deutsch-faschistischen Besatzern im Großen Vaterländischen Krieg“ (Muzej po istorii bor'by belorusskogo naroda s nemecko-fašistskimi okkupantami v Velikoj Otečestvennoj vojny). ${ }^{199}$ In diesem Titel hat der heutige Kriegsmythos von der Einheit des Volkes mit den Partisaninnen und Partisanen seinen Ursprung. Gleichzeitig wird der spezifisch belarussische Kampf im »Großen Vaterländischen Krieg« betont. Die Gleichsetzung von Volk und Widerstand implizierte, dass jeder und jede gegen die Deutschen gekämpft hatte, und schloss jegliche Ambivalenz in der Besatzungserfahrung aus. Das Sammlungsprofil, das im Gründungsprotokoll des Museums festgelegt wurde, belegt den ausschließlichen Fokus auf den Partisanenkampf.

Pantelejmon Ponomarenko bestimmte die Arbeitsschritte, die bis zur Museumseröffnung zu erfolgen hatten:

»Die grundlegende Arbeit, die das Museum in der nächsten Zeit durchführen wird, besteht in der Sammlung aller Materialien, die den Kampf des belarussischen Volkes charakterisieren. Bei der Suche muss die Aufmerksamkeit auf folgende [Materialien A.H.] gelegt werden:

a) Beispiele von Partisanenwaffen und alle Arten der militärischen Spionagetechnik der Partisanen. Darunter: Granaten, Pistolen, Gewehre, Maschinengewehre, sanitäre Ausrüstung usw.; von den Partisaneneinheiten selbst gefertigte [Waffen A.H.].

b) Dokumente, Materialien und Trophäen, die im Zusammenhang mit den großen Operationen der Partisaneneinheiten stehen, mit den Sprengungen der Eisenbahnbrücken, der Inbetriebnahme der entgleisten feindlichen Wagen, der Vernichtung bedeutender deutsch-faschistischer Persönlichkeiten.

c) Porträts, Skulpturen herausragender Persönlichkeiten der Partisanenbewegung und Fotografien der Kommandeure, Kommissare und Anführer der Partisaneneinheiten, zudem Fotografien von ihrer militärischen Tätigkeit und dem Leben und Alltag der Partisanen und Partisaninnen (partizan i partizanok).

d) Dokumente, Plakate, Flugblätter, Zeitungen, Journale, Bilder, Broschüren, Bücher und Fotos über die Partisanenbewegung, über die herausragenden Operationen und Persönlichkeiten der Partisanenbewegung.

e) Spezifische Gegenstände der Hauswirtschaft der Partisanen.

f) Die technische Ausrüstung für die Untergrundpresse der Partisanen, Serien von Cebietszeitungen sowie städtischen und regionalen Zeitungen, Serien von Flugblättern und Ankündigungen.

g) Beispiele von Partisanen-Trophäen, die in den Kämpfen erbeutet wurden. 
h) Angaben über Piloten, die sich im Partisanenkampf ausgezeichnet haben und Materialien, die die Unterstützung der Partisanenbewegung durch die Regierungsorgane und den Stabs der Partisanenbewegung beweisen.

i) Dokumente, Fotografien und Materialien, die die Gräueltaten der deutschen Besatzer auf dem belarussischen Territorium zeigen. ${ }^{200}$

Acht der neun Objektkategorien spiegelten Pantelejmon Ponomarenkos Streben nach einer Verewigung des von ihm geleiteten Partisanenkampfes. Bereits im zweiten Punkt (b) forderte er die Sammlung von Objekten, die jene Dimension des Partisanenkampfes darstellten, die er als sein persönliches Vermächtnis betrachtete. Ponomarenko, den der belarussische Historiker Emanuil Ioffe in seiner Biografie »eiserner Stalinist « nannte, forderte die Musealisierung seiner Person und seines Verhaltens im Krieg ein, indem er Dokumente über seine Führungsrolle im Partisanenkampf verlangte. ${ }^{201}$ Der letzte und einzige Punkt, der nicht in direktem Zusammenhang mit dem Partisanenkampf steht, sondern Exponate über die von den Deutschen verübten Kriegsverbrechen vorsieht, zeigt das zweite Standbein der staatlich initiierten Erinnerung: Das Narrativ vom belarussischen Volk als Opfer deutscher Kriegsverbrechen. Diese Dimension des Kriegserlebnisses war jener Handlungsspielraum, den die späteren Ausstellungsmacherinnen und Ausstellungsmacher für die Darstellung ihres eigenen Kriegserlebnisses nutzen konnten.

Ein weiterer Hinweis auf die erinnerungspolitisch gewollte Gleichsetzung von Volk und Partisaninnen bzw. Partisanen war die Ankündigung Ponomarenkos, dass das neue Museum im Gebäude des ehemaligen Staatlichen Historischen Museums eröffnet werden sollte. ${ }^{202}$ Das Historische Museum in Minsk galt vor dem Krieg als das wichtigstes Museum der sowjetischen belarussischen Republik und war für seine einzigartigen Sammlungen berühmt. ${ }^{203}$ Während der deutschen Besatzung wurde das Museum geplündert und die Museumsexponate durch den Einsatzstab von Reichsleiter Alfred Rosenberg in das bayrische Schloss Höchstädt gebracht. ${ }^{204}$ Eine Neueröffnung des Historischen Museums bzw. politische Unterstützung des Hauses nach der Befreiung war nicht vorgesehen. ${ }^{205}$ Der Tausch der Museen vom Staatlichen Historischen Museum zum Staatlichen Museum der Geschichte des Partisanenkampfs ist ein Hinweis auf die Prioritäten der Museumspolitik

\footnotetext{
200 Ebd. I. 57-58.

201 loffe, Emmanuil: Pantelejmon Ponomarenko, železnyj' stalinist, Minsk 2015.

202 NARB, f. 4p, op. 3, d. 1251 , I. 58.

203 Ohne Autor: Istorija Muzeja, offzielle Homepage des Nationalen Historischen Museums der Republik Belarus: http://histmuseum.by/ru/museum/museum-history/ (Stand: 31.07.2021).

204 Ebd.

205 Anlässlich des 20-jährigen Jubiläums der Befreiung von Minsk wurde das Staatliche Historische Museum am 7. November 1964 wiedereröffnet. Vgl. ebd.
} 
in der befreiten belarussischen Republik. Ein neuer Gründungsmythos sollte geschaffen werden, der den Partisanenkampf zur allumfassenden Kriegserfahrung überformte und die »Partisanenrepublik Belarus« begründete. Als im Oktober 1947 die Beutestücke des deutschen Kunstraubes an die UdSSR zurückgegeben wurde, beanspruchte das >Partisanenmuseum $<$ die Objekte des ehemaligen Historischen Museums, was die Hierarchie unter den belarussischen Museen bestätigte und die geplante Wiedereröffnung des Geschichtsmuseums erneut verzögerte. ${ }^{206}$

Die Gründung des Museums durch das ZK und der damit verbundene Appell $\mathrm{zu}$ einer verstärkten Materialiensuche führte zu einer engeren Zusammenarbeit zwischen den Kommandeuren der Partisaneneinheiten, Kommissionsmitgliedern und der Partei. Unter Vermittlung der beiden Leiter der Partisanenbewegung Pantelejmon Ponomarenko und Pëtr Kalinin wurden zwei Monate später aus Moskau "streng geheime« Funksprüche an die Kommandierenden der Partisaneneinheiten und Verbände geschickt (Abb 6), in denen sie aufgefordert wurden, Dokumente, »die das Leben und die Tätigkeiten der Partisanen charakterisieren«, zu sammeln und dem zukünftigen Museum zur Verfügung zu stellen. ${ }^{207}$

Abbildung 6: Funkspruch an Žurejko, Kommandeur der Partisaneneinheiten, Moskau 18. November 1943 @ BDGMVAV.

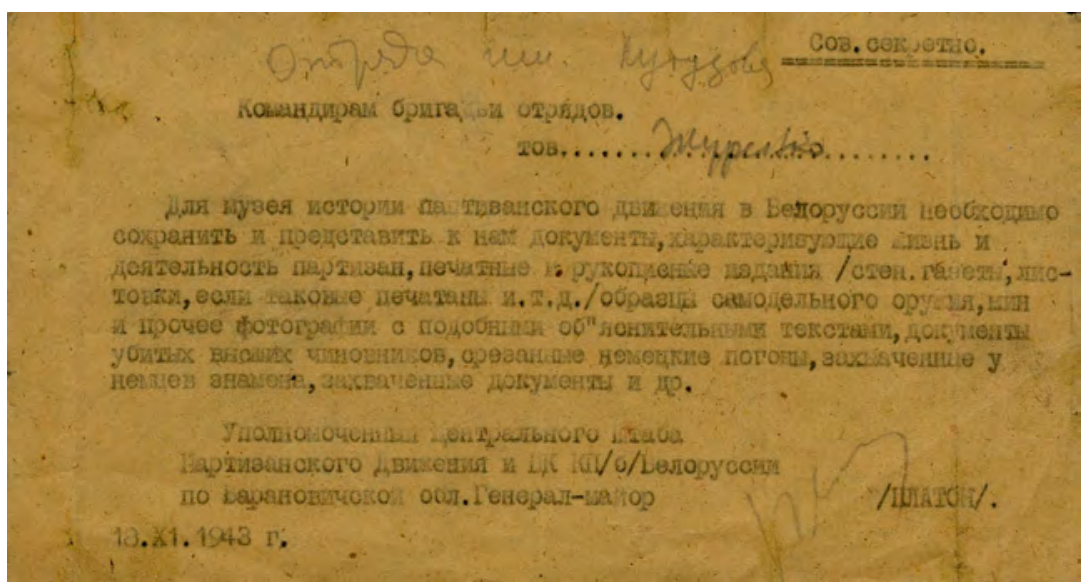

Die Partisaninnen und Partisanen sollten die Fotografien, Dokumente der getöteten deutschen Beamten, die abgeschnittenen Schulterstücke, die Fahnen usw.

206 Ebd.

207 BDMCVAV, KP 45363/8, d-4453, sowie in: Belaruski dzjaržaŭny muzej gistoryi vjalikaŭ ajčynnaŭ vajny (Hg.): Belaruski dzjaržaŭny muzej gistoryi vjalikaŭ ajčynnaŭ vajny, Minsk 2015, S. 13. 
für den Gebrauch als zukünftige Museumsexponate mit ausführlichen, erklärenden Texten zur Provenienz der Objekte versehen. Diese Funksprüche führten zu geteilten Reaktionen. Laut den Erinnerungen des Partisanenführers Pëtr Loveckij lösten sie bei den kämpfenden Einheiten »einen Sturm der Entrüstung« aus: »Sind die in Moskau verrückt geworden? Was für ein Museum? Sie sollten uns lieber Munition schicken!« Ein anderer Kommissar erwiderte: »Jungs, wir hatten Unrecht! Wenn es um die Gründung eines Museums geht, dann ist die Befreiung nah «, und Loveckij antwortete: "Nun wirst du die deutschen Orden und Schulterstücke nicht mehr ins Lagerfeuer werfen. ${ }^{208}$

Diese Reaktionen spiegeln die Ungleichzeitigkeit und Diskrepanz zwischen den kämpfenden Partisaninnen und Partisanen und ihren politischen Anführern in Moskau, die die Materialien der Gegenwart als Exponate für zukünftige Generationen in den Museumsvitrinen verewigen wollten. Darüber hinaus zeigt es, den hohen Stellenwert den das Museum als kulturelle Errungenschaft des Friedens genoss. Der Funkspruch ist in einem weiteren Punkt aufschlussreich: Sie sollten für ein Museum sammeln, das in diesem Dokument den Namen »Museum der Geschichte der Partisanenbewegung in Belarus «trägt. ${ }^{209}$ Wie im Gründungsprotokoll des Museums gingen die Akteure in der Planungsphase von einem Museum aus, das sich auf die lokale Kriegserfahrung stützen würde. Jedoch ging der hier angeführte Titel in seiner thematischen Zuspitzung noch einen Schritt weiter: Während im September noch von einer Darstellung des Kampfes des Volkes gesprochen wurde, stand hier nun ausschließlich der Partisanenkampf im Fokus. Ob der Titel bewusst gewählt wurde, um die Partisanenführer zur Kooperation zu bewegen, indem man ihnen eine museale Würdigung in Aussicht stellte, kann nicht beantwortet werden. Auf jeden Fall wurden sie durch die Aufmerksamkeit von höchster Stelle in ihrem Kampf bestärkt. ${ }^{210}$

Retrospektiv betrachtet wurde mit der Museumsgründung bereits während des Krieges der Grundstein für die Entstehung eines neuen nationalen Mythos gelegt. Der Partisanenkampf wurde zum maßgeblichen Symbol des Widerstands, der nach

208 Aus den Erinnerungen von Pëtr Loveckij. Dieser war während des Krieges stellvertretender Leiter des Komsomol und einer der ersten Mitarbeiter und späterer Direktor des Museums der Ceschichte des Croßen Vaterländischen Krieges, zitiert nach: Voronkova, Irina: Sozdanie i sostavlenie Belorusskogo Cosudarstvennogo Muzeja S. 11.

209 »Muzej istorii partizanskogo dviženija v Belorussii«. BDMGVAV [Belarussisches Staatliches Museum der Ceschichte des Croßen Vaterländischen Krieges] Inv. No. KP 45363/8, d-4453.

210 In einem weiteren überlieferten Funkspruch forderte Ponomarenko die Partisanen der Pinsker Einheit auf, ihre Waffen für das zukünftige Museum aufzubewahren. Er verlieh seiner Aufforderung Cewicht, indem er auf das persönliche Interesse von Kliment Vorošilovs, des Befehlshabers der Leningrader Front, hinwies. Vgl. NARB, f. 4117, op. 1, d. 2, I. 60. 
Kriegsende zum Befreiungskampf des belarussischen Volkes umgedeutet wurde. ${ }^{211}$ Dies schuf die Voraussetzung dafür, dass die pro-sowjetischen Partisaninnen und Partisanen als einzige Bevölkerungsgruppe mit unversehrter Reputation aus dem Krieg hervorgingen, während andere Untergrundgruppen, die Widerstand geleistet hatten, in der Nachkriegszeit mit dem Vorwurf der Kollaboration verfolgt wurden.

Die Historikerkommission hatte mit ihrer Sammlung und Sonderausstellung das Fundament für das neue Museum in der befreiten Hauptstadt gelegt. Die Minsker muzejščiki, die die Arbeit der Kommission fortführten, orientierten sich an den Sammlungsschwerpunkten und Inszenierungsstrategien der Historiker im Krieg.

\section{Die Sammelarbeit nach der Befreiung}

Nach der Eroberung von Brest am 28. Juli 1944, als die Befreiung der belarussischen Sowjetrepublik durch die Rote Armee abgeschlossen war, konnten auch die Minsker muzejščiki »auf den heißen Spuren der Ereignisse« Objekte sammeln. Zwischen Herbst 1944 und Frühjahr 1945 organisierte das Museum mit der Unterstützung Ponomarenkos vier Expeditionen an die Front, zwei zu den kämpfenden Einheiten nach Polen und, etwas später, zwei nach Berlin.

Dabei wuchs vor allem die »Partisanen-Kollektion« zur umfassendsten Sammlung des Museumsbestandes heran. Bis heute ehrt das Museum den hochdekorierten Partisanenführer Pëtr Nikolaevič Gončarov (1920-2008) für seine Sammlungsarbeit, die den Grundstock der Partisanenobjekte bildet. ${ }^{212}$ Gončarov, ein gebürtiger Russe, trat mit 22 Jahren am 1. Mai 1942 den Partisanenverbänden bei und stieg schnell zum Kommandeur der Minsker Brigade »Belarus'« auf (Abb. 7). ${ }^{213}$ In seiner "Militärischen und politischen Charakteristik« (eine Art sowjetisches Führungszeugnis) wird er als »widerstandsfähiger, ausdauernder und willensstarker Anführer« bezeichnet, der die »Massen« zum »Kampf« mobilisieren konnte. Er genoss "große Autorität« unter den anderen Partisanenführern und hatte sich im Kampf als »mutig, entschlossen, hartnäckig« erwiesen. Auf seiner »Rechnung« (̌̌čet) standen 730 getötete, 557 verwundete und 40 gefangene deutsche Soldaten und Offi-

211 Marples, David: Die sozialistische Sowjetrepublik Weißrussland, 1945-1991, in: Beyrau, Dietrich/Lindner, Rainer (Hg.): Handbuch der Geschichte Weißrusslands, Göttingen, 2001, S. 166.

212 Am 3. Dezember 2016 veranstaltete das Museum zur Geschichte des Großen Vaterländischen Krieges ein Gedenkkonzert zu Ehren des »Frontovik« und »Museumsveteranen« P. N. Gončarov. Vgl.: www.warmuseum.by/index.php/component/k2/item/662-концерт-в-честьронтовика--ветерана-музея-пн-гончарова (Stand: 31.07.2021).

213 Partizanskaja letopis', Belorusskogo telegrafnogo agenstva/Belorusskogo godudarstvennogo muzeja istorii velikoj otečestvennoj vojny, https://letopis.belta.by/05 (Stand: 31.07.2021). 
ziere sowie zahlreiche Sabotageakte. ${ }^{214}$ Seine Vorgesetzten bezeichneten ihn als "politisch entwickelt « und »moralisch standhaft $«$.

Abbildung 7: Leitungsstab der Partisanen Brigade »Belarus'«. In der Mitte stehend Pëtr Nikolaevič Gončarov, Minsker Gebiet Datum unbekannt, Fotograf/Fotografin unbekannt (c) BDMGVAV.

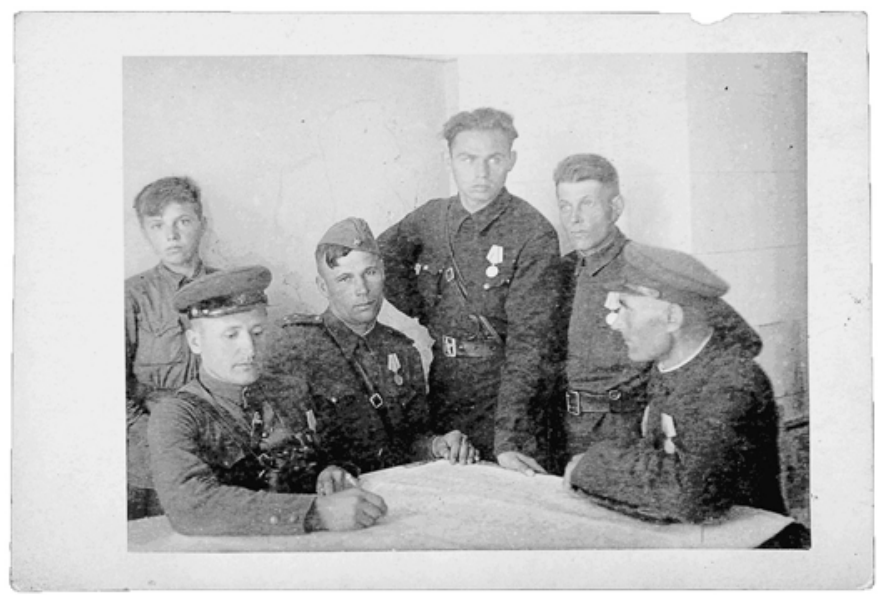

Sein Durchsetzungswille, der ihm im Partisanenkampf Respekt und Lob eingebracht hatte, half Gončarov auch bei seiner Sammlungsarbeit. Er erinnert sich an die Anfänge seiner Arbeit im Museum:

»Wir vereinbarten, dass wir zuerst eine Ausstellung über die »Waffen der Partisanen« einrichten würden. Aber woher sollten wir die Exponate nehmen? Die Partisaneneinheiten wurden in Lošyca [Parkanlage in Minsk, A.H.] entwaffnet. Ich, der ich zum Leiter der Partisanen-Abteilung bestimmt worden war, bin zum stellvertretenden Partisanenführer gegangen ... Und bekam Zutritt. Aber wie sollte ich alle diese Waffen nach Minsk transportieren? Ich begann in der Stadt nach einem Lastwagen zu suchen. Ich gestehe [kajusja]: Ich habe den Chauffeur zu dieser illegalen Fahrt überredet. Aber was sollte ich tun? Ich nahm Geld aus meinem Feldrucksack. Ja ja, kurz zuvor hatte ich meinen Sold bekommen. Fast die Hälfte des Soldes für das Jahr 1941, den ganzen Sold für 1942 und 1943 und die Hälfte des Jahres 1944. Fast der ganze Rucksack war voller Geld. So habe ich die ersten großen Summen für die Bezahlung des Transportes der Gewehre, Maschinengewehre, der

214 Komandir Brigady »Belorus'«/Kommissar Brigady »Belorus'« (ohne Datum): Boevaja i političeskaja charakteristika, in: BDMCVAV, KP 77852. 
selbstgebastelten Minen, der Kanonen, der Granatwerfer, die in den Waldwerkstätten repariert wurden und der Trophäen von Lošyca ins Museum bezahlt. « ${ }^{215}$

Diese Episode illustriert, dass der Beginn der musealen Sammlungsarbeit des Minsker Museums nicht wie im Moskauer Fall in den Händen von erfahrenen Kuratorinnen und Kuratoren mit einflussreichen Beziehungen zum Verteidigungsministerium und zur Roten Armee lag, sondern in der Alltagsgeschichte von Museumslaien, die die deutsche Besatzung überlebt hatten. Als Ponomarenko im September 1944 das Museum besuchte, um sich vor der Ausstellungseröffnung einen Eindruck vom Zustand der Museumssammlung zu machen, war er aber nicht zufrieden mit der Arbeit der Angestellten, die er zuvor zu muzejščiki befördert hatte. Sie hätten zu wenige Exponate gesammelt, außerdem fehle es der Kollektion an Objekten der militärischen Ausrüstung. ${ }^{216}$ Er nutzte seine Beziehungen zur 1. Belarussischen Front, die sich im September 1944 westlich der Grenze auf dem Vormarsch nach Warschau befand, und schickte Pëtr Gončarov, um entsprechende Exponate zu sammeln. ${ }^{217}$ Der Kommandostab unterstützte den ehemaligen Partisanenführer tatkräftig und stellte ihm 15 Soldaten als Begleitschutz und ein Auto zur Verfügung. Bis nach Warschau folgte die »Brigade« der vorrückenden Roten Armee sauf den heißen Spuren der Ereignisse und sammelte in acht polnischen Städten Materialien, die mit mehreren Eisenbahnwaggons zurück nach Minsk gebracht wurden. ${ }^{218}$ Entgegen den Erwartungen enthielt der Inhalt dieser Waggons jedoch kaum militärische Objekte, sondern alltägliches Gebrauchsmaterial, das im zerstörten Minsk schwer zu finden war. Gončarov brachte von der Front diverse Möbel und Einrichtungsgegenstände, Bretter und Nägel, Vorhänge und Farben sowie Leisten für Bilderrahmen, Kreide und Lappen mit. ${ }^{219}$ Diese überraschenden Gegenstände lassen darauf schließen, dass Gončarov im September 1944 nicht mit einem konkreten Sammlungsprofil entsandt worden war, sondern selbst entschied, was gesammelt wurde. Dabei ließ er jene Dinge einpacken, die ihm am notwendigsten erschienen. Nach dem Krieg erzählte der Kurator: »Die Suche nach Exponaten hatte kein System, man nahm, was man konnte. Wir brachten in erster Linie Dinge, die der deutschen Armee gehört hatten und auch Möbel ins

215 Gončarov, Pëtr, zitiert in: Hužaloŭski, Aljaksandr: Gistorija muzejnaj spravy belarusi, Minsk 2012, S. 222. Für die Übersetzung danke ich Elena Metel'skaja.

216 Voronkova, Irina: Sozdanie i sostavlenie Belorusskogo Gosudarstvennogo Muzeja, S. 26.

217 BDGMVAV, kp 69104, d. 11511.

218 I. Vorokova nennt die Städte Biała Podlaska, Terespol, Meseritz, Siedlece, Minsk, Mazowiecki, Sokołów Podlaski, Gmina Małkinia Górna, Praga (Vorort von Warschau). Vgl. ebd.

219 Neben diesen Gebrauchsgegenständen brachte Gončarov einige erbeutete Waffen, Fotografien und eine Karte, auf der deutsche Besatzungsverbände die Partisaneneinheiten verortet hatten, mit. Ebd. S. 26-27. 
Museum. ${ }^{220}$ Es ist anzunehmen, dass es den muzejščiki nur dank dieser Ausbeute der >wissenschaftlichen Expedition möglich war, innerhalb der extrem kurzen Frist zwei vollständig eingerichtete Sonderausstellungen $\mathrm{zu}$ inszenieren. ${ }^{221}$

Als Gončarov eineinhalb Jahre später auf eigenen Wunsch aus dem Museum entlassen wurde, schrieb ihm der Direktor Vasilij Stal'nov ein Arbeitszeugnis (Charakteristika), das nicht positiver hätte ausfallen können. Er betonte insbesondere die "große Arbeit«, die Gončarov beim Sammeln von Exponaten für die größte Abteilung des Museums geleistet hätte und seine »unmittelbare und äußerst aktive Teilnahme« an der Vorbereitung für die Ausstellung über die Partisanenwaffen. Für diese "ausgezeichnete und selbstlose Arbeit (otličnaja i samootveržennaja rabota) erhielt er eine Prämie und die Medaille für »Ehrenhafte Arbeit im Großen Vaterländischen Krieg«. Der Museumsdirektor schloss seinen Bericht mit folgender Beurteilung:

»Cenosse Gončarov ist diszipliniert und hat viel dafür getan, diese Disziplin unter den Arbeitern des Museumskollektivs zu verbreiten. Er ist politisch gebildet und beherrscht [vyderžan]. Er arbeitet viel an sich selbst [rabotaet nad soboj] und erhöht systematisch sein Wissen und fördert es, damit er die Arbeit an der Ceschichte des Großen Vaterländischen Krieges besser organisieren kann. Er hat keine Verwarnungen. ${ }^{222}$

Die Eigeninitiative des ehemaligen Partisanen, mit der sich Gončarov weder an Erwartungen noch an Regeln hielt, hatte sich gelohnt. Obwohl er Gesetze missachtete, Leute bestach und sogar den Befehl des Ersten Sekretärs Ponomarenko umdeutete, indem er Möbel anstelle von Trophäen sammelte, wurde er für seine Arbeit hoch ausgezeichnet. Dabei zeigt sich, dass im Museum mit zweierlei Maß gemessen wurde. Während andere Museumsmitarbeitende für kleinere Disziplinarverstöße (z.B. Verletzung der Aufsichtspflicht) regelmäßig gerügt, verwarnt und bestraft wurden, wurde Gončarov für sein vorbildhaftes Verhalten ausgezeichnet. Diese Vorzugsbehandlung ist ein Hinweis auf die herausgehobene Stellung, die die ehemaligen Partisanen und seltener, Partisaninnen, in der belarussischen Nachkriegszeit genossen.

220 Orel, Daria: Kak popolnjajutsja fondy muzeja istorii Velikoj Otečestvennoj vojny, i počemu posetiteli vidjat liš' $2 \%$ ot nych, 23. Juni 2017, in: Minsk News: https://minsknews.by/kak-po polnyayutsya-fondyi-muzeya-istorii-velikoy-otechestvennoy-voynyi-i-pochemu-posetiteli-vid yat-lish-2-ot-nih/ (Stand: 31.07.2021).

221 Im Frühjahr 1945 unternahmen die Minsker Museumsangestellten zwei weitere »Dienstreisen«zur 1. Belarussischen Front, die sie im Februar nach Lodz und im Mai nach Berlin führten. Auch hier wurden neben potentiellen Museumsexponaten Einrichtungs- und Cebrauchsgegenstände (Möbel, Wanduhren, Rollläden und Radios) für das Museum gesammelt. Vgl. Voronkova, Irina: Sozdanie i sostavlenie, S. 27. 
Im Herbst 1944, als immer mehr geflüchtete Menschen in die befreite Sowjetrepublik Belarus zurückkehrten, füllten sich die Lagerräume des jungen Museums mit Objekten. Der Museumsdirektor Vasilij Stal'nov, der neben diesem Posten seine Anstellung als Kommissionssekretär behielt, machte sich seine Arbeitserfahrung und Kontakte zu Nutze und schickte Anfang August 13 Mitarbeitende für »wissenschaftliche Expeditionen« in die von der Roten Armee befreiten Gebiete Witebsk, Mahilëv und Minsk, um Materialien und Exponate für zukünftige Ausstellungen zu sammeln. ${ }^{223}$ Mal im Namen der Kommission, mal als Museumsdirektor warb Stal'nov bei Privatpersonen, ehemaligen Partisanenführern und regionalen Parteivorsitzenden für zukünftige Ausstellungsobjekte. Er schrieb zahlreiche Briefe an Hinterbliebene von ausgezeichneten Helden und an bekannte Augenzeugen selbst und bat sie, der Museumssammlung persönliche Gegenstände zu überlassen. ${ }^{224}$ Dabei bediente auch er sich des bewährten Arguments, dass die Erinnerungsstücke jetzt bewahrt und gesammelt werden müssten, damit sie nicht vergessen oder verloren gingen. Er appellierte an das »sozialistische und patriotische Bewusstsein" dass sie »verpflichtet«, die Objekte zu übergeben. Bei älteren oder kranken Adressaten lockte er mit Lohn und Honorar und drängte zur Eile. ${ }^{225}$ Einen ehemaligen Kommandanten der Partisanenbrigade versuchte er mit dem Argument zu überzeugen, dass der Kampf seiner Brigade und ihre Heldentaten nur dann bekannt werden würden, wenn er alle relevanten Materialien dem Museum übergebe. Darüber hinaus bat er ihn, die Geschichte seiner Partisanenbewegung aufzuschreiben. Falls er Hilfe bräuchte, stünde ihm das Museum zur Verfügung - er solle einfach mit dem Wichtigsten beginnen. ${ }^{226}$

Für aufsehenerregende Ausstellungsobjekte konnte sich Museumsdirektor Stal'nov auf seinen mächtigen Fürsprecher Ponomarenko verlassen. Dieser hatte eine konkrete Vorstellung von den Inszenierungen in der zukünftigen Ausstellung: Er schrieb die Partisanenführer an und forderte sie beispielsweise auf, dem Museum die vollständige Einrichtung ihrer »Waffen-Werkstatt« für eine Rekonstruktion derselben zur Verfügung zu stellen. ${ }^{227}$

223 NARB, f. 1246, op. 1, d. 3, I. 3. Von diesen Dienstreisen existieren handschriftliche Berichte im Museumsarchiv. VgI. BDMGVAV, op. 5, d. 24, I. 1-13.

Für die Briefe, die im Herbst 1944 (vor Ausstellungseröffnung) verschickt wurden, vgl. exemplarisch: NARB, f. 1246, op. 3, d. 5, I. 1; 8; 11; 20; 25.

Stal'nov stellte einer Privatperson Lohn und Honorar in Aussicht, wenn sie dem Museum ein Paket mit Fotografien zur Verfügung stellte. Vgl. NARB, f. 1246, op. 1, d. 5, I. 1. Den Sekretär des Drogičinsker Kreises ermahnte er, dem Museum schnellstmöglich Tagebücher, Fotos, Flugblätter, und weitere Materialien zuzustellen, die die Partisanenbewegung und die Kriegsverbrechen der deutschen Besatzungsbehörden dokumentierten. NARB, f. 1246, op. 1, d. 5, I. 5 .

226 NARB, f. 1246, op. 1, d. 5, I. 8.

227 NARB, F. 4117, O. 1, D. 2, I. 60. P. Ponomarenko schrieb Vasilij Korž mit seinem Kampfnamen »Korž Komarov« [Mücke] an. Interessanterweise bedankt er sich in seinem Brief auch im Na- 
Dem Museumsdirektor standen also finanzielle Mittel und weitreichende Kontakte zur Verfügung, um dem Museum einen Grundstock an Exponaten zu sichern. Einen Eindruck von der Heterogenität der rund 550 Objekte zur Partisanenbewegung, die im September 1944 auf einen Schlag in die Museumssammlungen eingingen, gibt die Liste, die der Museumsdirektor zur Genehmigung vorlegte. Unter den Objekten befanden sich beispielsweise: 50 Paar »Partisanen-Ski«, eine von den Deutschen erbeutete Schreibmaschine, 20 Maschinengewehre, Äxte, Sägen, 10 Salzstreuer und 5 Badeanzüge. ${ }^{228}$ Ende September, kurz vor der Eröffnung des Museums, zählte die Minsker Sammlung zum »Großen Vaterländischen Krieg« bereits über 10.000 Exponate. $^{229}$

men von Kliment Vorošilov. Möglicherweise brauchte selbst der Partisanenführer die Unterstützung des Marschalls, um die Partisanen von der Abgabe ihrer Waffen zu überzeugen.

228 NARB, f. 1246, op. 1, d. 5, I. 17.

229 Voronkova, Irina: Sozdanie i sostavlenie Belorusskogo Gosudarstvennogo Muzeja, S. 15. 


\section{Krieg und kraevedenie. Die Sammlung des Tscheljabinsker Museums an der Heimatfront}

Auch wenn die Menschen östlich der Front, im sowjetischen Hinterland, nicht wie in Moskau von deutschen Bombenangriffen bedroht wurden oder wie in Minsk unter den Grausamkeiten der feindlichen Besatzungsherrschaft litten, so trafen die Folgen des Krieges die Bevölkerung an der sogenannten Heimatfront ebenfalls mit aller Härte.

Die mittelgroße Industriestadt Tscheljabinsk, die zugleich die Hauptstadt des gleichnamigen Gebietes ist, liegt $1.700 \mathrm{~km}$ und rund 2,5 Flugstunden östlich von Moskau. Sie wurde während des Krieges unter anderem für ihre Panzerproduktion berühmt, die ihr den Namen »Tankograd« (Panzerstadt) einbrachte. ${ }^{230}$ Neben der Umstellung der Fabriken auf Waffenproduktion, der in dem Abnutzungskrieg größte Bedeutung zukam, war das Stadtbild während des Krieges von evakuierten Fabriken, Kommissariaten und anderen administrativen Einrichtungen geprägt. Diese waren nach Kriegsausbruch mitsamt den Arbeitern und ihren Familien von frontnahen Städten im Westen der Sowjetunion hinter den Ural evakuiert worden. Tscheljabinsk musste mehrere 100.000 Flüchtlinge unterbringen, während gleichzeitig die Fabriken ihre Produktion von zivilen Gütern und Nahrungsmitteln auf Munition, Laster und Panzer umstellten. Die Stadt, die seit den 1930er Jahren mit enormem Wohnungsmangel und Versorgungsproblemen zu kämpfen hatte, war nun gezwungen, eine unverhältnismäßig große Anzahl evakuierter Familien und Industriebetriebe aus Leningrad, Charkow und Moskau aufzunehmen. Nur die äußerst strikte Verteilung der raren Güter verhinderte eine Eskalation der Versorgungssituation, die fast in eine humanitäre Katastrophe gemündet wäre. ${ }^{231} \mathrm{Um}$ das Dilemma der Regierung, Armee und Zivilbevölkerung nicht gleichwertig mit Nahrung versorgen zu können, zu verdecken, waren die statistischen Behörden des Hinterlandes dazu aufgefordert, die Todesursache »Hunger« in ihren Statistiken über die Sterblichkeit zu verbergen. Das führte dazu, dass in der Forschung die Hungertoten des belagerten Leningrads oder der besetzten Gebiete viel bekann-

230 Laut Lennart Samuelson wurde dieser Name von dem amerikanischen Korrespondenten und Autor William Henry Chamberlin (1897-1969) bei einem Besuch der Stadt in den 1940ern eingeführt. Vgl. Samuelson, Lennart: Tankograd, The Formation of a Soviet Company Town, Cheliabinsk 1917-2000, Basingstoke 2011, S. 6.

Insgesamt wurden 700 Betriebe (davon 200 Industriebetriebe) mit den Arbeitern und ihren Familien nach Tscheljabinsk evakuiert. Hinzu kamen bis zum Frühling 1942427.700 Flüchtlinge aus anderen Teilen der Sowjetunion in die Stadt und ins Tscheljabinsker Cebiet. Vgl. Samuelson: Tankograd, Evakuation and Conversion of Industrie, S. 220-226. 
ter sind als die Folgen der Hungersnot im unbesetzten Hinterland. ${ }^{232}$ Hier, an der »Heimatfront«, lebten und arbeiteten die Menschen beinahe vier Jahre unter unerträglichen Entbehrungen. Sie versuchten Kälte, Dreck, Erschöpfung, Krankheiten und Hungersnöte auszuhalten, die so akut waren, dass sie viele das Leben kosteten. Und trotzdem produzierten die Arbeiterinnen und Arbeiter, so schwach, unterernährt und krank sie waren, jene Waffen, Fahrzeuge, Flugzeuge und $\mathrm{Mu}$ nition, die nötig waren, um die Wehrmacht zu besiegen. ${ }^{233}$ Historikerinnen und Historiker, die nach Erklärungen jenseits von Zwang und Totalitarismus suchen, stehen vor dem Rätsel, was die Motivationen der Menschen für diese großen Opfer waren. ${ }^{234}$ Mikrostudien wie die vorliegende geben Teilantworten auf die Frage, wie ein entbehrungsreiches und gleichzeitig sinnerfülltes Überleben im Krieg unter den harten Bedingungen einer Industriestadt an der »Heimatfront« möglich war.

Durch ihre rüstungsproduzierende Industrie erhielt die Stadt einen höheren politischen Stellenwert, der sich nicht zuletzt darin ausdrückte, dass Tscheljabinsk im August 1943 der »Status einer Republik-Stadt« verliehen wurde. Das implizierte neue staatliche Subventionen, die die Partei nutzte, um das städtische Kulturleben $\mathrm{zu}$ unterstützen und es, laut einer Direktive, mindestens auf den Stand der Hauptstadt $z u$ heben. ${ }^{235}$

Auch die Museen des Süd-Urals waren von drastischen finanziellen Kürzungen, dem Ausfall von Mitarbeitenden durch Arbeits- und Armeerekrutierungen und von der Umwidmung ihrer Häuser als Lagerhäuser und Spitäler betroffen. Das größte Tscheljabinsker Museum wurde im Sprachgebrauch der Zeit »konserviert « (zakonservirovan) und musste seine Ausstellung Ende Oktober 1941 schließen, um Platz für die von der Front evakuierten Archive des sowjetischen Geheimdienstes (NKVD) zu machen. ${ }^{236}$

232 Filtzer, Donald/Coldman, Wendy Z.: Introduction, The Politics of Food and War, in: dies. (Hg.): Hunger and War, Food Provisioning in the Soviet Union During World War II, Indiana 2015, S. 1-43, hier S. 41-42.

233 Filtzer, Donald: Starvation Mortality in the Soviet Home-Front Industrial Regions during World War II, in: Ders./Goldmann, Wendy (Hg.): Hunger and War, S. 323.

234 Diese Frage wurde zuletzt ausgiebig in dem Sammelband »The People's War « behandelt. Vgl. Thurston, Robert W./Bonwetsch, Bernd (Hg.): The People's War, Responses to World War II in the Soviet Union, Chicago 2000. Ebd. S. 224-226.

236 Ungefähr 100 Museen im Hinterland (davon 29 Gebietsmuseen, d.h. Museen in den Hauptstädten des jeweiligen Cebietes) wurden temporär geschlossen und ihre Gebäude evakuierten Betrieben übergeben. Vgl. Kaulen, Marija: Muzejnoe delo Rossii, S. 156. 


\section{Kraevedenie - oder die Mensch-Natur-Beziehung im Museum}

Das Tscheljabinsker Museum gehört bis heute zur Gattung der kraevedčeskie muzei (regionalwissenschaftliche Museen), die interessanterweise im Krieg eine institutionelle Aufwertung erfuhren. Sie stellten den größten Anteil der Museen im Verbund des Narkompros, und die Behörde beauftragte diese Museen, als Beitrag zur Verteidigung im »Großen Vaterländischen Krieg« strategische lokale Ressourcen zu erschließen, medizinische Heilkräuter und essbare Pflanzen zu sammeln sowie die Geschichte ihrer Region zu erforschen. ${ }^{237}$

Kraevedenie lässt sich am besten als »Regionalwissenschaft« übersetzen (kraj: Region, vedenie: Wissenschaft). Die Ursprünge dieser heterogenen Bewegung liegen in den pädagogischen Reformen des ausgehenden Zarenreiches als die Schulklassen durch Exkursionen mit ihrer Umwelt vertraut gemacht werden sollten. In der jungen Sowjetunion formierte sich die kraevedenie als ein synthetisches Untersuchungsfeld, dass die jeweilige Region in ihrer Gesamtheit darstellte und dabei anthropologische, historische und naturwissenschaftliche Aspekte berücksichtigte. Ein »Zentralbüro für Kraevedenie« wurde als Unterabteilung des Narkompros eingerichtet und die Vertreterinnen und Vertreter der Bewegung (kraevedy) wurden beauftragt, wertvolle Dokumente und Artefakte vor den Zerstörungen des Bürgerkrieges zu retten. ${ }^{238}$ Die regionalwissenschaftlichen Museen widmeten sich als Sammlungs- und Forschungszentren den ethnologischen und naturwissenschaftlichen Phänomenen ihrer Regionen. Da sich ihr Selbstverständnis durch die persönliche Identifizierung der kraevedy mit ihrem regionalen Forschungsgegenstand auszeichnete, wurde die kraevedenie in der Forschung als »identity discipline« beschrieben. ${ }^{239}$ Dieser individuelle Bezug konnte dazu führen, dass sich das wissen-

Ebd. S. 156.

238 Die fragmentarische Historiographie spiegelt die Schwierigkeiten bei der Definition der russischen Variante der Regionalwissenschaften. In der Regel bezieht sich die Forschung zu kraevedenie als Standardwerk auf: Johnson, Emily D.: How St. Petersburg learned to study itself, The Russian Idea of Kraevedenie, Pennsylvania 2006. Jedoch liegt der Fokus dieser Studie weniger auf der kulturwissenschaftlichen Bewegung, sondern vielmehr auf der Entstehung des Mythos der Zarenstadt St. Petersburg. Der breite interdisziplinäre Ansatz der Bewegung, der über das 20. Jahrhundert bis heute von jeder Ceneration neu bestimmt wurde, ist nur eine der Herausforderungen für eine Studie zur Geschichte der kraevedenie, die bislang ein Forschungsdesiderat darstellt. Dabei sollte jedoch nicht nur die spezifisch russische Ausrichtung berücksichtigt werden, sondern die Bewegung als Bestandteil eines universalen Ansatzes der Moderne betrachtet werden, der das Lokale im Nationalen zu bestimmen versuchte. Johnson, Emily: How St Petersburg learned to study itself, S. 6. 
schaftliche Interesse der Regionalwissenschaftlerinnen und Regionalwissenschaftler mit lokalem Aktionismus verband. ${ }^{240}$

Nach einer Blüte der kraevedenie in den 1920er Jahre, die rückblickend als »Goldenes Jahrzehnt « beschrieben wurde, geriet die Bewegung aufgrund ihres stark lokalen Bezuges in Verdacht, regionalen Separatismus zu begünstigen. ${ }^{241}$ Ende der 1920er Jahre, im Zuge der Zentralisierung, wurden die kraevedy in den Säuberungen der akademischen Zirkel massiv repressiert, und ihre regionalbezogene Interdisziplinarität wurde zugunsten einer Propaganda von staatlichen Planzielen unter Kontrolle gebracht. Bereits 1930, im Zuge des »Ersten Allrussischen Museumskongresses« war die Unabhängigkeit der kraevedy massiv eingeschränkt worden: Die Museen wurden unter strikte staatliche Kontrolle gestellt, die von nun an die inhaltliche Ausrichtung ihrer Arbeit bestimmte. Die Ausstellungsinhalte und Ziele wurden grundlegend reformiert: Die klassischen Themen des regionalwissenschaftlichen Museums, die Abteilung mit den Mineralien sowie der Flora und Fauna der Region, die Archäologie, Ur- und Frühgeschichte sowie die ethnographisch-folkloristischen Ausstellungskapitel und die historische Abteilung mussten dem Themenschwerpunkt »Sozialistischer Aufbau« weichen, der den größten Teil der Ausstellungsfläche einnehmen sollte. Was von der sowjetischen Museologie als "Bolschewistische kraevedenie« bezeichnet wurde, bezeichnet die russische Forschungsliteratur heute als »Vernichtung der kraevedenie«. ${ }^{242}$ Für die regionalwissenschaftlichen Museen bedeutete das fortan, Geschichte und Natur ausschließlich als Material zu zeigen, das durch den Willen der Menschen und ihre Schaffenskraft verändert werden konnte und dadurch die gesellschaftlichen Beziehungen verbesserte. Aus den naturwissenschaftlichen und regionalwissenschaftlichen Bildungseinrichtungen sollten Propagandazentren der wirtschaftlichen und technischen Errungenschaften des sowjetischen Systems werden. ${ }^{243}$ Mitte der 1930er Jahre wurde ihre Anwendung in den regionalwissenschaftlichen Museen dem Konzept des Dialektischen Materialismus unterworfen und in den Repressionen von 1937-1938 wurde die Bewegung erneut gesäubert. ${ }^{244}$

Im Juni 1942, ein Jahr nach dem Überfall der Wehrmacht auf die Sowjetunion, wandte sich der Volkskommissar für Bildung Vladimir Potëmkin an die Direktoren

240 Mel'nikova, Ekaterina: „Sbližalis' narody kraia, predstavitelem kotorogo javljajus' ja«: Kraevedčeskoe dviženie 1920-1930-ch godov i sovetskaja natsional'naja politika, in: Ab Imperio, No. 1, 2012, S. 209-40.

241 Šmidt, Sigurd: Kraevedenie i dokumental'nye pamjatniki, Tver 1992.

242 Šmidt, Sigurd, zitiert nach: Antipin, Nikolaj: Čeljabinskij kraevedčeskij muzej, S. 27.

243 Gavrilova, Sof'ja: Sovetskie kraevedčeskie muzei, 20.10.2017, in: Artgid: https://artguide.com /posts/1340\#disqus_thread (Stand: 31.07.2021).

244 Zur Repression der kraevedenie, der betroffenen Museumsmitarbeitenden und zum Ausstellungsumbau im Tscheljabinsker Museum vgl. Antipin, Nikolaj: Čeljabinskij kraevedčeskij muzej, 1913-1957, Čeljabinsk 2011, S. 27-30. 
der regionalwissenschaftlichen Museen und nannte einzelne Häuser, die die neue Ausrichtung ihrer Arbeit für die militärische Verteidigung der Sowjetunion vorbildlich vollzogen hätten. ${ }^{245}$ Diese sechs namentlich genannten Museen im sowjetischen Hinterland hätten lokale Ressourcen wie beispielsweise Quarzsand für die Herstellung von Glas, feuerfesten Ton, Baumaterialien und Heilkräuter erschlossen. Im gleichen Atemzug betonte Potëmkin, dass viele regionalwissenschaftliche Museen dieser Aufforderung noch nicht nachgekommen seien und forderte von den Direktoren, ihr Personal aufzustocken, die regionalwissenschaftliche Arbeit in den Schulen, Kolchosen und Bibliotheken zu koordinieren, die Suche nach örtlichen Ressourcen und Materialien zum »Großen Vaterländischen Krieg« zu verstärken und mit Vorträgen sowie Wanderausstellungen das Wissen über die Geschichte der Region und die Bedeutung ihrer Ressourcen zu verbreiten. ${ }^{246}$

\section{Ivan Gorochov - Ein »eigen-sinniger « Museumsdirektor?}

Der Tscheljabinsker Museumsdirektor Ivan Gorochov wurde 1884 in Kurgan (ca. $250 \mathrm{~km}$ östlich von Tscheljabinsk) geboren und besuchte das Priesterseminar in Tobolsk, einer Stadt östlich des Uralgebirges. Anschließend studierte er Naturwissenschaften an den Universitäten in Kazan und in St. Petersburg. 1914 wurde er als Lehrer für Naturwissenschaften und Geografie nach Nischni Tagil geschickt, von wo aus er ein Jahr später nach Tscheljabinsk kam. ${ }^{247}$ Gorochov interessierte sich seit seiner Jugend stark für die Geologie des Süd-Urals und spezialisierte sich früh auf die Ausgrabungen in der Region. ${ }^{248}$

245 Potemkin, Vladimir: O meroprijatijach po razvitiju kraevedčeskoj raboty v dni vojny, Prikaz narodnogo komissara prosveščenija RSFSR, Nr. 392, 22. Juni 1942, in: NIIKMR (Hg.): Rabota politiko-prosvetitel'nych učreždenij v uslovijach voennogo vremeni, S. 12-14.

246 Ebd. S. 13.

247 Antipin, Nikolaj: Ivan Gorochov i ego muzej, in: Gorochovskie čtenija, Materialy pervoj regional'noj muzejnoj konferencii, Čeljabinsk 2010, S. 6.

248 In seiner Autobiografie, die I. Gorochov 1963 verfasste, betont er, dass seine geistliche Ausbildung der Wille seines Vaters gewesen sei und er nach Abschluss des Priesterseminars »nicht zu den Popen (nopy) gegangen sei«. Vgl. Gorochov, Ivan: Kratkaja avtobiografija osnovatelja i pervogo direktora Čeljabinskogo oblastnogo kraevedčeskogo muzeja I. G. Gorochova, 17. September 1963, in: GIMJUU Staatliches Historisches Museum des Süd-Urals], alte Signatur: ČOKM [Regionalwissenschaftliches Museum des Tscheljabinsker Gebietes], A-1794-a. Pr-131, zitiert nach: Antipin, Nikolaj: Ivan Gavrilovič Gorochov, 125-letiju so dnja roždenija osnovatelja muzeja posvjaščaetsja, Čeljabinsk 2009. S. 6-10, hier S. 6. An anderer Stelle betont er, dass er nach Abschluss des Priesterseminars den »starken Wunsch« (tverdoe želanie) nach einer Ausbildung im naturwissenschaftlichen Bereich verspürt habe. Vgl: OGAČO [Vereinigtes Staatliches Archiv des Tscheljabinsker Gebietes], f. R-627, op. 1, d. 103, I. 7. Dass sich eine geistliche Ausbildung und ein naturwissenschaftliches Studium nicht ausschließen mussten, sondern im Gegenteil sich gegenseitig befruchten konnten, zeigt die Biografie des bekannten Priesters und Mathematikers Pavel Florenskij, der sich auch aufgrund seiner Lebensdaten 
Abbildung 8: Die kraevedy Ivan Gorochov (unten links), Michail Merkur'ev und Ivan Demidov auf Propspektion im Tscheljabinsker Gebiet 10. Juli 1926, Fotografin/Fotograf unbekannt ( O OGAČO.

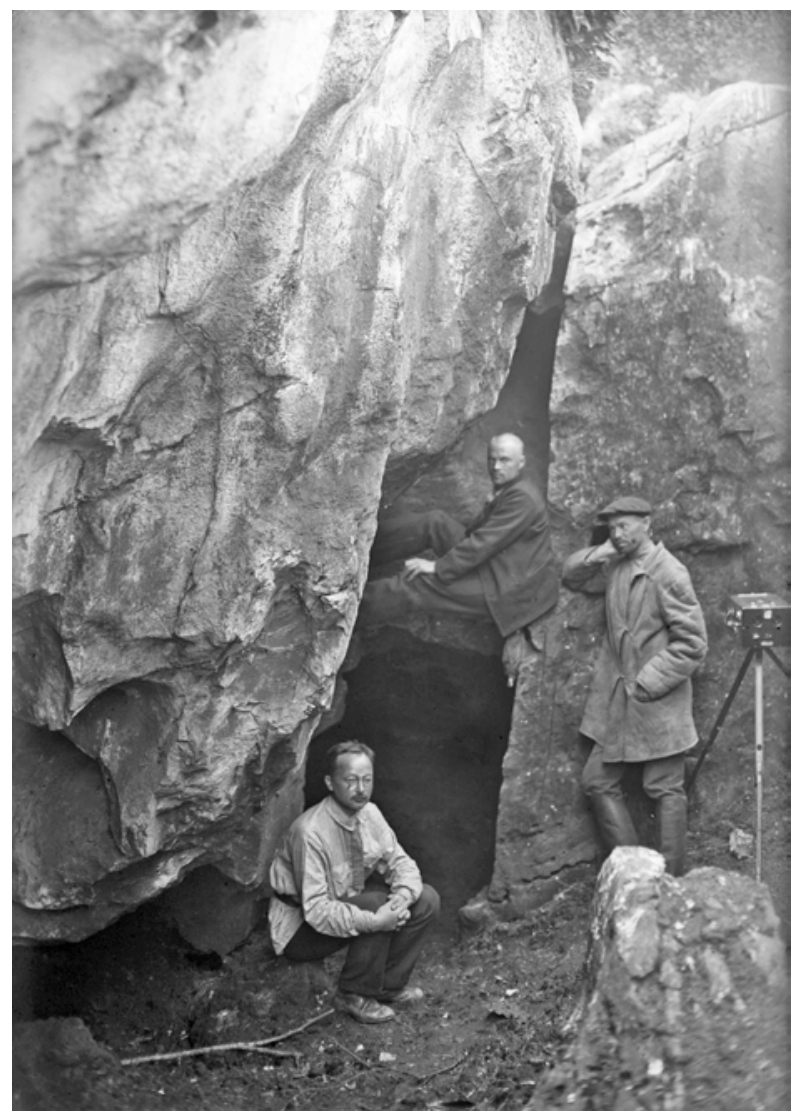

Dieses Engagement führte 1918 zur Gründung der »Tscheljabinsker Gesellschaft zum Studium der Region « (Čeljabinskoe obščestvo izučenija mestnogo kraja), die Gorochov bis zu ihrer Auflösung 1931 leitete. 1919, im Zuge der sowjetischen Machtetablierung im Süd-Ural, beauftragte der Revolutionsrat Ivan Gorochov damit, in

(1882-1937) für einen weiterführenden Vergleich mit I. Gorochov anbietet. Für eine Übersetzung und Einordnung der zentralen Texte von P. Florenskij vgl. Mierau, Sieglinde und Fritz (Hg.): An den Wasserscheiden des Denkens, Ein Pawel Florenski Lesebuch, Berlin 1991. 
Tscheljabinsk ein regionalwissenschaftliches Museum zu gründen. ${ }^{249}$ Am 1. Juli 1923 eröffnete das Museum als regionales Forschungszentrum, das archäologische und geologische Expeditionen in die Region organisierte (Abb. 8). ${ }^{250}$ Neben seinen Ausstellungssälen verfügte das Museum über eine Bibliothek, ein Fotostudio sowie ein mineralogisches und chemisches Labor und ein biologisches Studienzimmer. Über Vorträge, Ausstellungen, Exkursionen und Publikationen verfolgten die $\mathrm{Mu}$ seumsmitarbeitenden ihre primäre Aufgabe, die sie in der Verbreitung der Lehre von der Natur und Umwelt der Tscheljabinsker Region sahen. ${ }^{251}$

Die Quellengrundlage für die Betrachtung der agency des Tscheljabinsker Museumskollektivs während der Kriegs- und Nachkriegsjahre sind die sogenannten »Berichte über die Arbeit des Museums« (Otčet o rabote muzeja). Jedes Jahr im Herbst schickte das Moskauer Museumsinstitut einen Brief an alle Direktoren der regionalwissenschaftlichen Museen in der Sowjetunion. Der Aufforderung, einen Bericht über die vergangene Arbeit und einen Plan über die Arbeit des Museums im kommenden Jahr einzureichen, war ein »exemplarisches Schema« (typovaja schema) beigelegt, an dem sich die Direktoren beim Verfassen ihres Berichtes zu orientieren hatten. ${ }^{252}$ Diese Empfehlung bestand aus einem verbindlichen und einem erwünschten Teil. Während jeder Bericht grundsätzliche Aussagen über den $\mathrm{Zu}$ stand des Gebäudes, das Personal, die Ausstellungsarbeit, den Museumsrat, die wissenschaftliche Forschungstätigkeit, die Sammlung und die Bildungs- und Vermittlungsarbeit treffen musste, gab der Brief den Museumsdirektoren zusätzliche Hinweise, was sie beim Verfassen des jeweiligen Briefes besonders zu berücksichtigen hätten.

In der Vorstrukturiertheit des Berichts zeigt sich bereits eine grundsätzliche Eigenschaft dieser Quelle: Der Schreibende bediente in der Regel das Genre der Berichterstattung. Die Museumsdirektoren wussten, was ihre Vorgesetzten hören wollten. Sie konnten die Rhetorik ihres Textes entsprechend ausrichten und gezielt über die Erfolge oder die Missstände des Museums berichten. Es wäre aber zu kurz gegriffen, in den otčety nur ein pflichtgetreues Ausfüllen und Abarbeiten vorgegebener Themen zu sehen. Die Berichte, die in der Regel zwischen 15 und 30 Seiten lang sein konnten, vermitteln einen (möglicherweise unerwartet) lebendigen Eindruck von der Museumsarbeit. Die geforderten Angaben über Budget, Infrastruktur oder Personal ließen immer auch Raum, neben der Präsentation erfolgreich geleisteter Arbeit Beschwerden oder besondere Anliegen anzubringen. Der Bericht über

249 Gorochov, Ivan: Dopolnenija k avtobiografii I. G. Gorochova, zitiert in: Antipin, Nikolaj: Ivan Gavrilovič Gorochov, 125-letiju so dnja roždenija osnovatelja muzeja posvjaščaetsja, Čeljabinsk 2009, S. 14-22, hier S. 18. 
die inhaltliche Arbeit des Museums erlaubte es beispielsweise, eigene Interessen zu platzieren, und die Angaben zur Besucherbetreuung, wie zum Beispiel Zitate aus dem Gästebuch, eigneten sich ideal, um die geleistete Museumsarbeit von $\mathrm{Au}$ ßenstehenden (positiv) bewerten zu lassen. Vor diesem Hintergrund verbirgt sich hinter dem Arbeitsbericht mehr als nur ein reiner Tätigkeitsbericht. Diese formalisierte Quelle ist ein Kommunikationsmedium, das einen überraschend individuell geprägten Argumentationstext enthält, der Auskunft über die gewünschte Außenwahrnehmung des berichtenden Museumsdirektors gibt. Die Berichte mussten in dreifacher Ausfertigung getippt werden: Ein Exemplar blieb im hauseigenen Museumsarchiv, zwei Exemplare wurden dem Tscheljabinsker »Gebietskomitee für kulturelle Aufklärungsarbeit «(Oblkul'tpros) übergeben, das nach erfolgter Prüfung des Berichtes eine Kopie an das zentrale Museumsinstitut in Moskau schickte. Dieses wiederum sandte eine Beurteilung (ocenka) zurück an die Museumsdirektoren.

Die inhaltliche Analyse der Arbeitsberichte gewährt einen Einblick in den individuell geprägten Umgang des Museumsdirektors mit den Vorgaben der Behörde. Während er manche Anforderungen erfüllte, ignorierte er andere. Wenn es ihm günstig erschien, ergänzte er die gewünschten Angaben mit detailreichen Auskünften über seine eigenen Interessen, wie zum Beispiel Forschungsberichte über Ausgrabungen, nach denen die Berichtsvorlage nicht gefragt hatte. Auch die Forderungen des Museumsinstitutes im Krieg setzte Gorochov auf seine eigene Weise um. Während die muzejščiki an der Front und im besetzten Gebiet Kriegsrelikte und Trophäen sammelten, befolgte der Tscheljabinsker Museumsdirektor Ivan Gorochov den Auftrag des Narkompros und konzentrierte seine Sammlungsarbeit auf mineralische und pflanzliche Rohstoffe, die er dem Museumsinstitut als strategisch wichtige Ressourcen und Arzneimittel präsentierte. Während ihm diese Arbeit als sinnvoll erschien und sie darüber hinaus in Einklang mit seinem Verständnis von kraevedenie stand, vernachlässigte er den Befehl, Objekte und Materialien zu sammeln, die den Beitrag des Tscheljabinsker Gebietes zum »Großen Vaterländischen Krieg« bezeugten. Dabei wären diese militärischen Objekte für den Museumsdirektor in »Tankograd« leicht zugänglich gewesen; womöglich leichter als die Erforschung von Bodenschätzen unter Kriegsbedingungen, wenn Geld und Materialien für aufwendige Exkursionen fehlten. Die zahlreichen Fabriken der Rüstungsstadt produzierten reichhaltiges Anschauungsmaterial, das den Beitrag des Gebietes zum Kampf im »Großen Vaterländischen Krieg« spiegelte. Gorochov hätte Plakate, Fotos und Auszeichnungen der besten Arbeiter dokumentieren können und Modelle, Prototypen oder Beispiele einzelner Panzer, Artillerie oder Schusswaffen sammeln können. Ungeachtet dessen sammelte Gorochov Steine, Mineralien und Pflanzen, die in der Hungersnot der Kriegsjahre den Mangel an Nahrungsmitteln kompensieren sollten oder in den überfüllten Spitälern des Tscheljabinsker Gebietes und an der Front als Heilkräuter zur Versorgung von Verwundeten dienten. 
Für die Deutung dieser Beobachtungen bietet es sich an, auf zwei wissenschaftliche Konzepte aus der Forschung zur Alltagsgeschichte in der DDR zurückzugreifen. Von der Frage ausgehend, mit welchen Formen und Praktiken Menschen Herrschaftsformen interpretierten und sich aneigneten, entwickelte Alf Lüdtke Mitte der 1980er Jahre das geschichtswissenschaftliche Konzept der Kategorie »Eigensinn « und setzte es in Beziehung zu seinem Verständnis von »Herrschaft als soziale Praxis«. ${ }^{253}$ Thomas Lindenberger, der diese Konzepte aufgriff und weiterentwickelte, betonte das Erkenntnispotential, das in der unscharfen Mehrdeutigkeit des Begriffes »Eigen-Sinn« zur Erforschung von polyvalenten Deutungen von Handlungen historischer Akteure liege. Entgegen einem potentiellen Missverständnis ist »eigen-sinniges« Verhalten eben nicht mit »Widerstand « gleichzusetzen, sondern zeichnet sich durch einen nicht explizit negativen Bezug auf das Herrschaftsverhältnis aus: ")Eigen-Sinn kann in Widerstand gegen Vereinnahmungen und Aktivierungsversuche >von oben $<$ münden [...], ist jedoch auch in der gezielten Nutzung und damit Reproduktion herrschaftskonformer Handlungsweisen zu beobachten, indem diese für >eigen-sinnige Individuen einen andern - und sei es nur zusätzlichen >Sinn $<$ beinhalten als den der offiziellen Ideologie. ${ }^{254}$

Die empirische Analyse der Sammlungsarbeit des Tscheljabinsker Museumsdirektors im Krieg zeigt ein solches Agieren, das situativ zwischen Aneignung und Umdeutung des Herrschaftsdiskurs changierte. Mit seinem inkonsistenten Handeln verfolgte Gorochov diverse Eigeninteressen. ${ }^{255}$ Thomas Lindenberger hat

Lüdtke, Alf: Eigen-Sinn, Fabrikalltag, Arbeitererfahrung und Politik vom Kaiserreich bis in den Faschismus, Hamburg 1993; Ders.: Geschichte und Eigensinn, in: Berliner Geschichtswerkstatt (Hg.): Alltagskultur, Subjektivität und Ceschichte, Zur Theorie und Praxis von Alltagsgeschichte, Münster 1994, S. 139-153; Ders.: (Hg.): Herrschaft als soziale Praxis, Historische und sozialanthropologische Studien, Göttingen 1991, insbes. Einleitung, S. 9-63.

254 Lindenberger, Thomas: Die Diktatur der Grenzen, Zur Einleitung, in: ders.: (Hg.): Herrschaft und Eigen-Sinn, Studien zur Gesellschaftsgeschichte der DDR, Köln/Weimar/Wien 1999, S. 13-44, hier S. 29. T. Lindenberger plädierte dafür, das Konzept des »Eigen-Sinns«, dass sich für den Kontext der DDR-Vergangenheit als erkenntnisreich bewährt hat, auf weitere kommunistische Diktaturen zu übertragen. Das Tscheljabinsker Fallbeispiel im (Spät-)Stalinismus trägt zu diesem transnationalen Apell bei. Die Befunde ergänzen hier die Forschung, die »eigen-sinniges «Verhalten nur in einer poststalinistischen Gesellschaft für möglich hielt. Vgl.: Behrends, Jan: Entfernte Verwandte, Stalinismusforschung und DDR-Geschichte, in: Gieseke, Jens (Hg.): Staatssicherheit und Gesellschaft, Studien zum Herrschaftsalltag in der DDR, Göttingen 2007, S. 48-75. In seinem etwas starren Verständnis von Identität ist die stalinistische Gesellschaft von revolutionären Subjekten geprägt, die ein neues sowjetisches Ich formen wollten. Erst nach dem Tod Stalins sei eine relative Privatsphäre entstanden, die es den Menschen erlaubte, sich »eigen-sinnig« an die Herrschaft anzupassen.

Lindenberger, Thomas: Eigen-Sinn, Herrschaft und kein Widerstand, in DocupediaZeitgeschichte, Begriffe Methoden und Debatten: https://docupedia.de/zg/Lindenberger_ei gensinn_v1_de_2014 (Stand: 31.07.2021). 
darauf hingewiesen, dass »eigen-sinnig« handelnde Akteure $\mathrm{zu}$ »Machtsubjekten« wurden, die nicht losgelöst von der ihr vorstehenden Herrschaft betrachtet werden können. ${ }^{256}$ Hier liegt der zweite analytische Vorteil des Konzeptes: „Eigen-Sinn« ist kein Gegenstück zur Herrschaft, sondern vielmehr Ausdruck der Interaktion von Einzelnen mit dem Staat. Damit ist Ivan Gorochov Teil der elitären Bildungsschicht der muzejščiki im Stalinismus, die innerhalb der staatlichen Diskurse individuelle Ausdrucksformen fanden.

\section{Kriegsausbruch und Museumsschließung}

Zu Beginn des Jahres 1941 hatte der Museumsdirektor Ivan Gorochov allen Grund, optimistisch zu sein - das regionalwissenschaftliche Museum sollte endlich einen Neubau erhalten, um zusätzlich zu den Themen »Natur und Umwelt« eine historische Abteilung mit einem Schwerpunkt zum »sozialistischen Aufbau« einzurichten. Die sakrale Architektur der »Heiligen Dreifaltigkeitskirche« (Svjato-Troickaja cerkov'), in der das Museum im Zuge der stalinistischen Kulturrevolution von 1929 untergebracht worden war, war für Museumszwecke gänzlich ungeeignet (Abb. 9). ${ }^{257}$ Von den rund $800 \mathrm{~m}^{2}$ des Gebäudes konnte nur knapp die Hälfte des Kirchenschiffs als Ausstellungsfläche dienen. Die Bespielung dieser verhältnismäßig kleinen Fläche wurde von dem hohen Innenraum (bis zu 17 m Raumhöhe), den Säulenbögen, den drei Kapellen und den schlechten Lichtverhältnissen zusätzlich erschwert. $^{258}$

256 Lindenberger, Thomas: SED-Herrschaft als soziale Praxis, Herrschaft und »Eigen-Sinn«: Problemstellung und Begriffe, in: Gieseke, Jens (Hg.): Staatssicherheit und Gesellschaft, Studien zum Herrschaftsalltag in der DDR, Cöttingen 2007, S. 23-47, hier S. 32.

257 Für eine chronologische Geschichte des Tscheljabinsker regionalwissenschaftlichen Museums vgl. Antipin, Nikolaj: Čeljabinskij kraevedčeskij muzej, S. 146-158. Zur stalinistischen Kulturrevolution von 1929 vgl. Fitzpatrick, Sheila (Hg.): Cultural Revolution in Russia, 19181931, 4. Aufl., Indiana 1990. Die Praxis, regionalwissenschaftliche Museen in einer ehemaligen Kirche oder einem Kloster unterzubringen, war in der Sowjetunion weit verbreitet: »One of the reasons why museums occupy these buildings is because, after the Revolution of 1917, the Soviet Covernment usually did not have enough funds to construct new museums buildings, and it was quite reasonable to use those which had been nationalized, among them - churches, cathedrals, private villas, tsars' palaces, et cetera. Vgl. Mikhailova, Anna: Spatial Evolution of a Museum Building, S. 29.

258 Antipin, Nikolaj: Ivan Gavrilovič Gorochov, S. 21. 
Abbildung 9: Die »Heilige Dreifaltigkeitskirche«, in der sich von 1929 bis 1989 das Tscheljabinsker regionalwissenschaftliche $\mathrm{Mu}$ seum befand, Tscheljabinsk Jahr unbekannt, Fotografin/Fotograf unbekannt (C) OGAČO.

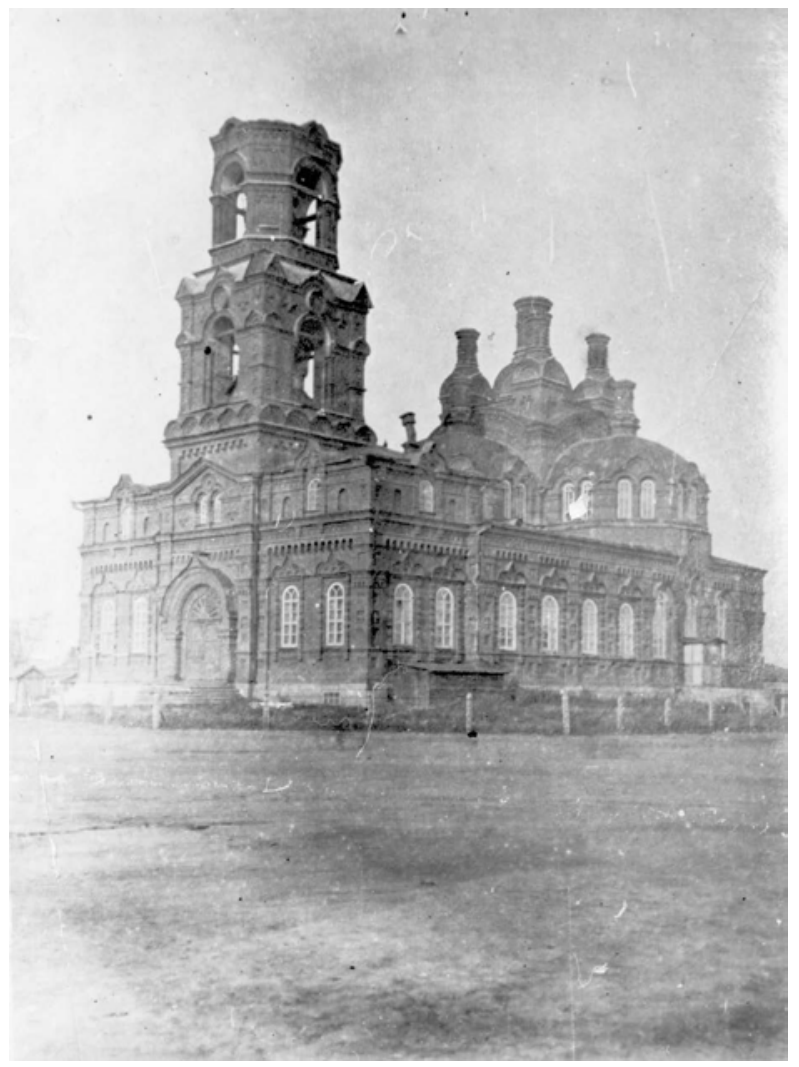

Es gab weder Lagerräume für die Sammlungen noch Arbeitszimmer für die Mitarbeitenden. Der Direktor, seine Frau und der Museumswächter bewohnten zwei kleine Zimmer im Vorraum der ehemaligen Kirche, die kaum zu heizen wa- 
ren. ${ }^{259}$ Der Kriegsausbruch im Juni 1941 verschob die langerwarteten Neubaupläne auf unbestimmte Zeit.

Auch in Tscheljabinsk, fern von der Front, reagierte die Kuratorinnen und $\mathrm{Ku}$ ratoren auf die Forderung des Museumsinstitutes nach Sonderausstellungen zur siegreichen militärischen Vergangenheit des Landes und errichteten in der Fußgängerzone eine kleine Sonderausstellung zum Thema des »Vaterländischen Krieges« von 1812. Gorochov beauftragte einen Schuldirektor damit, einen Ausstellungsplan zum Thema »Der Kampf der Völker der UdSSR gegen den deutschen Faschismus « zu erstellen, da die Stelle des Museumshistorikers vakant war. ${ }^{260}$ Bei der Versammlung von Museumsdirektoren des Tscheljabinsker Gebietes im Sommer 1941 musste Gorochov jedoch eingestehen, dass diese Ausstellung bislang nicht verwirklicht worden war. Er versprach, diesen »Fehler auszubessern « und sogleich mit dem Sammeln von örtlichen Materialien zum »Großen Vaterländischen Krieg« $\mathrm{zu}$ beginnen (er nennt »Trophäen, Reliquien, Dokumente, Briefe und Materialien über Landsmänner [im Krieg A.H.] «) und eine entsprechende Ausstellung zu erstellen. ${ }^{261}$ Diese Ankündigung blieb jedoch ein Lippenbekenntnis - anstelle von klassischen Kriegsausstellungen errichtete Gorochov im September 1941 gemeinsam mit dem Roten Kreuz Sonderausstellungen zum Thema »Die sanitäre Verteidigung « und informierte die Tscheljabinsker Bevölkerung über Infektionskrankheiten, Erste Hilfe bei Verwundeten sowie Bluttransfusionen und Blutspenden. ${ }^{262}$

Obwohl dem Direktor bewusst war, dass von seinem Museum die geistige Mobilisierung der Bevölkerung durch Ausstellungen über den heroischen Kampf der Roten Armee gefordert wurde, schien er Ausstellungen zu bevorzugen, die einen praktischen Nutzen für die Menschen in der Region hatten. Trotz der großen Entfernung von der Front herrschte auch in Tscheljabinsk Angst vor deutschen Luftangriffen, und die vielen evakuierten Verwundeten und Geflüchteten bestätigten die Angst vor den Kriegsereignissen im Westen des Landes. Gorochovs naturmedizinisches Engagement hing vermutlich auch mit der hohen Sterblichkeit zusammen, die im Herbst 1941 das sowjetische Hinterland und insbesondere die Industriestädte im Süd-Ural erfasste. Donald Filtzer, der die demographischen Auswirkungen der kriegsbedingten Hungersnot im Ural untersuchte, stellte fest, dass insbesondere Kleinkinder sowie Ältere und schwache Menschen einer auffällig hohen Sterberate zum Opfer fielen. Die Gründe für die Sterblichkeit sieht er in den Folgen des

259 Ebd. S. 21. Auch nach Kriegsende beklagte sich Ivan Gorochov regelmäßig über die kalten Temperaturen, die trotz der behelfsmäßigen Reparatur der Dampfheizung im Winter nicht über 3 Grad Celsius stiegen, und erinnerte die Kulturbehörde des Tscheljabinsker Cebietes an ihr Versprechen, dem Museum ein zweckmäßigeres Gebäude zur Verfügung zu stellen. Vgl.: OGAČO, f. R-627, op. 3, d. 398, I. 11-26, hier I. 26. 
Schocks, den die Evakuation auslöste und in den zwei großen Epidemien Typhus und Masern, die 1941 ausbrachen und sich mit der Flucht aus dem Westen in den Osten der Sowjetunion ausbreiteten. ${ }^{263}$

Ende Oktober 1941 erhielt Gorochov von der örtlichen Parteibehörde völlig unerwartet den Befehl, sein Museum »einzupacken « (svernut') - innerhalb von drei Tagen sollte die große Sammlung in den Keller geräumt werden, um Platz für die Archive des evakuierten Geheimdienstes (NKVD) zu machen. ${ }^{264}$ Dieser Befehl zeigt die staatliche Priorisierung der Kommissariate - obwohl das Narkompros den $\mathrm{Mu}$ seen größte propagandistische Bedeutung zugesprochen hatte und das regionalwissenschaftliche Museum das einzige Museum in der Stadt war, das die geistige Mobilisierung im Krieg hätte übernehmen können, musste es dennoch von einem auf den anderen Tag seine Ausstellungen abbauen und Platz für die Archivbestände des Kommissariats machen.

Die folgenden drei Kriegsjahre befand sich der Museumsdirektor in einem unauflöslichen Dilemma. Jedes Jahr erhielt er vom Moskauer Museumsinstitut den Befehl, Ausstellungen zum »Großen Vaterländischen Krieg« zu organisieren - obwohl er jedoch weder Zugang zu seiner Sammlung noch zu seinem Museum hatte. Der Moskauer Befehl zielte an der Realität vor Ort vorbei. Die Tscheljabinsker Gebietsverwaltung kürzte dem Museum, das nicht offiziell geschlossen war, zum Jahresende 1941 massiv die Mittel. Von den vormals 22 Angestellten blieben dem Direktor nur noch eine Botanikerin, eine Bibliothekarin und eine Reinigungskraft. Um die Sammlungen, die im Museumskeller keinen Platz mehr hatten, zu retten, brachte der Museumsdirektor die zoologische Sammlung in einer Schule unter und zog mit seiner Frau, der Bibliothek, der Mineralien-, Herbarien- und Insektensammlung in die zwei Zimmer der ehemaligen Ak-Moschee um. ${ }^{265}$

\section{Kraevedenie an der Heimatfront}

Das Dilemma verschärfte sich, als Ivan Gorochov im Juli 1942 die Leitung der regionalwissenschaftlichen Organisationen im ganzen Tscheljabinsker Gebiet übertragen wurde. ${ }^{266}$ In den »Maßnahmen über die kraevedenie-Arbeit in den Kriegstagen« der städtischen Bildungsbehörde wurde an erster Stelle die Bedeutung der örtlichen Ressourcen für die Fabriken und Betriebe und damit für die Verteidigung

1942 erreichte die Kindersterblichkeit ihren Höhepunkt. In den urbanen Zentren stieg sie von 206 Toten pro 1000 Geburten im Jahr 1940 auf 345/1000 Geburten im Jahr 1942. Vgl. Filtzer, Donald: Starvation, hier S. 269. 
des Landes genannt. Ivan Gorochov wurde beauftragt, in Museen, Schulen, Kulturhäusern und Bibliotheken die Suche und Erforschung von örtlichen Rohstoffen Erze, Torf, Baumaterialien sowie Ess- und Heilpflanzen - zu organisieren. Die Suche nach Materialien zur Geschichte des »Großen Vaterländischen Krieges«, die in Moskau und bei der belarussischen Historikerkommission höchste Priorität hatte, wurde hier nur in einem Nebensatz am Ende erwähnt. Um die Suche in den drei Bereichen zu organisieren, wurde Gorochov dazu aufgefordert, einen sogenannten »kraevedenie-Rat « zu gründen, der mit den bestqualifizierten Geografen, Biologen und Historikern besetzt werden sollte. Für die praktische Such- und Sammelarbeit sollten Schulklassen und Kindergärten mobilisiert werden. Der Abteilungsleiter der örtlichen Bildungsbehörde befahl Gorochov innerhalb einer Woche einen Plan vorzulegen, der die Organisation dieser Arbeit beschrieb und dessen Ausführung von den Behörden täglich beurteilt werden würde. ${ }^{267}$

Die staatliche Unterstützung der Suche nach Ess- und Heilpflanzen muss im Kontext der politischen Kampagne zur Förderung lokaler Lebensmittelressourcen und subsidiärer Landwirtschaft gesehen werden. Die deutsche Besetzung der lebensmittelproduzierenden Regionen in der westlichen Sowjetunion, insbesondere in der Ukraine, hatte die Problematik der Nahrungsmittelversorgung eskalieren lassen. Im Frühjahr 1942 war es unmöglich geworden, die Rote Armee und die Zivilbevölkerung im Hinterland ausreichend zu versorgen und die Behörden versuchten die unzureichenden Lebensmittelrationen über eine Förderung lokaler Initiativen zu ergänzen. ${ }^{268}$ Der hier beschriebene Rückgriff auf die kraevedy lässt sich mit dem allgemeinen Mangel an medizinischem Fachpersonal im Hinterland erklären. Die gut ausgebildeten regionalen Ärztinnen und Ärzte waren entweder an die Front mobilisiert worden oder verpflichtet, in den Militärspitälern der Gebiete zu arbeiten. $^{269}$

Im September 1942 besuchte der Tscheljabinsker Museumsdirektor den Vortrag »Über die Arbeit der Museen im Krieg« von Manevskij, dem Leiter des Moskauer Museumsinstitutes. ${ }^{270}$ Der Vortrag, der die Bedeutung der Museen im Krieg be-

267 Ebd.

268 Goldman, Wendy: Not by Bread alone, Food, Workers and the State, in: dies./Filtzer, Donald (Hg.): Hunger and War, Food Provisioning in the Soviet Union During World War II, Indiana 2015, S. 44-97, hier S. 74-75.

269 Donald Filtzer erwähnt, dass die Stadt Tscheljabinsk hier von dem aus Kiew evakuierten Personal der Medizinischen Institute profitierte, dass 40-60 Prozent der Ärzte in der Stadt stellte. In den kleineren Industriestädten des Cebietes musste die Versorgung der Bevölkerung wegen des Mangels an Ärztinnen und Ärzten von Sanitäterinnen und Sanitätern übernommen werden. Vgl. Filtzer, Donald: Starvation Mortality, S. 283, Fußnote 33. Vor diesem Hintergrund wurde dem Regionalwissenschaftler I. Gorochov die Verantwortung über das ganze Tscheljabinsker Gebiet übertragen. 
tonte, schien Gorochov in seinem Leitungsauftrag zu bestätigen. Einige Tage später verfasste der Direktor einen Bericht über die »Arbeit der [Tscheljabinsker A.H.] regionalwissenschaftlichen Museen im Krieg«. Darin schildert Gorochov empört, dass von den neun Museen des Tscheljabinsker Gebietes lediglich sein eigenes und ein kleines Museum in der benachbarten Stadt Miass die Kürzungen bzw. die Beschlagnahmung ihrer Gebäude durch die staatlichen Behörden überlebt hätten. Er beklagte, dass sie jedoch kaum noch arbeiten könnten und dass der große Verlust an Kollegen, die ihre Arbeit »beherrschten und liebten«, sich »zweifellos stark auf die Museumsarbeit des ganzen Tscheljabinsker Gebietes « auswirken würde. ${ }^{271}$ Hier deutet sich die Rhetorik an, die Gorochovs weitere Korrespondenz mit dem Museumsinstitut prägen sollte: Er stellte die Moskauer Befehle und Anordnungen den realen Gegebenheiten vor Ort gegenüber und versuchte auf diese Weise, auf die bestehenden Missstände aufmerksam zu machen. So hätte die städtische Parteizentrale entgegen ihrer Ankündigung die für Ausstellungen notwendigen Räumlichkeiten nicht freigegeben und er könne deswegen die gewünschten Ausstellungen nicht inszenieren. Gleichzeitig schienen dem Direktor die Gefährdung seiner Stelle und die Möglichkeit, dass er sein Museum nicht zurückerhalten würde, bewusst gewesen zu sein. Nach dieser Beschwerde übte er sich in Selbstkritik und nannte die bislang nicht erfolgte Ausstellungsarbeit zu Themen des »Großen Vaterländischen Kriegs« ein »schwerwiegendes Versäumnis (ser'eznoe upuščenie) und einen »Fehler, den das Museum in kürzester Frist ausbessern « werde. ${ }^{272}$ Der Bericht zeigt das Lavieren Gorochovs zwischen Anklage und Kooperationsbereitschaft, mit dem er versuchte, sein Museum durch den Krieg zu retten.

Gorochov musste aktiv bleiben, sonst wären ihm vermutlich die spärlichen Mittel auch noch gestrichen und sein Museum nicht nur auf Zeit, sondern für immer geschlossen worden. Ausstellungen konnte der Direktor nur in Form von Sonderbzw. Wanderausstellungen in fremden Räumlichkeiten organisieren. Das Thema war gesetzt, das Museumsinstitut forderte Ausstellungen zum »Großen Vaterländischen Krieg«. Jedoch waren die Kriegsausstellungen nur ein Teil des behördlichen Auftrags, und es scheint, als habe Gorochov aus der Not eine Tugend gemacht und stattdessen die naturwissenschaftliche Arbeit in den Vordergrund gestellt. Der Jahresbericht von 1942 thematisierte neben den Hinweisen auf die schlechten Lagerungsbedingungen der Sammlung im Keller, die fehlende Ausstellungsfläche und das fehlende Personal, die "wissenschaftlichen Arbeit « des Museums. ${ }^{273}$ Die Schwerpunkte dieser Tätigkeit lagen in der Erforschung der pflanzlichen und mineralischen Rohstoffe der Region. Gorochov betonte seine Expertise, die in seinem 
spezifischen Mensch-Natur-Verständnis lag. Dabei waren insbesondere das Sammeln und die Erforschung von Heilkräutern geeignete Argumente für die Relevanz dieser naturwissenschaftlichen Arbeit im Krieg. Gorochov beschrieb, wie das $\mathrm{Mu}-$ seum in Zusammenarbeit mit der Apothekenvereinigung nach »wildwachsenden Heilkräutern für die Bedürfnisse der Front und des Hinterlandes« gesucht habe. Bevor die gesammelten lokalen Pflanzen zu Medikamenten verarbeitet wurden, klassifizierten und dokumentieren die kraevedy unter Gorochov die Heilpflanzen. Im Bericht zählt er Leinkraut, Herzgespann, Kamille und Blauen Natternknopf, die seine Museumsmitarbeitenden getrocknet, gepresst und zur Anschauung in Herbarien eingefügt hatten. ${ }^{274}$ Die großzügigen Schaukästen trugen den Titel »Wildwachsende vitaminreiche Rohstoffe«. Sie wurden in Serie gefertigt und dienten den muzejščiki zur Dokumentation bei öffentlichen Vorträgen (Abb. 10). ${ }^{275}$

Abbildung 10: Herbarium »Wildwachsende vitaminreiche Rohstoffe« in der Sonderausstellung »Die Rolle Tscheljabinsks im Großen Vaterländischen Krieg«, Tscheljabinsk 1946-1949, Fotografin/Fotograf unbekannt (C) OGAČO.

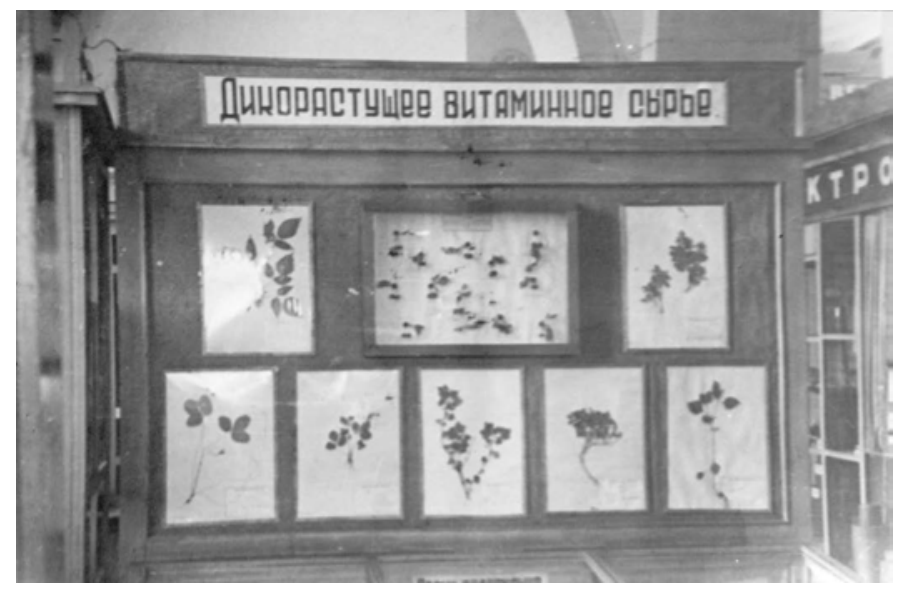

Eine Bestätigung für die Relevanz dieser Arbeit waren die vielen Anfragen, die Privatpersonen, wissenschaftliche Einrichtungen und städtische Betriebe an das Museum richteten. Gegenüber dem Museumsinstitut führte Gorochov eine ausführliche Beschreibung dieser Beratungstätigkeit seines Museums an: 20 verschiedene Institutionen, von der Moskauer Akademie der Wissenschaften bis zum 
Tscheljabinsker Pädagogischen Institut, hätten nach dem Vorkommen bestimmter Heil- und Esspflanzen und Mineralien gefragt. Gorochov betonte, dass gerade diese Beratungstätigkeit die »weit bekannte Autorität des Museums « beweise. ${ }^{276}$

Dem Museumsdirektor war wohl trotz aller wissenschaftlichen Kontakte bewusst, dass seine einseitige Ausrichtung der Museumsarbeit die Missgunst des Museumsinstitutes provozieren konnte. Um einem derartigen Vorwurf vorzubeugen, zitierte er aus einem Schreiben des Narkompros:

»In einer der Broschüren des NKP RSFSR [...] aus dem Jahr 1942 wird davon gesprochen, dass s die Rote Armee Bedarf an einer Reihe von Materialien haben wird und Auskünfte darüber verlangt. Die regionalwissenschaftlichen Museen sind verpflichtet zu wissen, wo sich diese Materialien befinden, damit sie erschöpfende Auskünfte darüber geben können.く

Dieses angeführte Zitat ist die Genehmigung der Arbeit, die das Tscheljabinsker Cebietsmuseum schon seit einer Reihe von Jahren durchführt [...]. $^{277}$

Gorochov konfrontierte das Museumsinstitut mit den eigenen Anweisungen, um seine naturwissenschaftliche Forschungstätigkeit zu legitimieren. Die Erforschung von Mineralien für ihren Einsatz in der Rüstungsindustrie mag für ihn gleichbedeutend gewesen sein mit der Aufklärung über Pflanzen, die als Ersatznahrung und Heilmittel verwendet werden können. Für Gorochov war die Beratung der Tscheljabinsker Bevölkerung ein selbstverständlicher Bestandteil der sogenannten "Propaganda der kraevedenie«. Rhetorisch ließ sie sich ideal mit den wirtschaftlichen Zielen der Kriegszeit verbinden. Beispielsweise, wenn er einen Vortrag im Tscheljabinsker Radio über Pflanzen als Ersatznahrung hielt und betonte, dass die gesammelten Arzneipflanzen gleichzeitig einen »bedeutenden Teil zur Volkswirtschaft« beitrugen. ${ }^{278}$

Wie reagierte das Moskauer Museumsinstitut auf diese Verknüpfung lokaler Ressourcen mit den übergeordneten politischen Zielen? Tatsächlich griff Institutsvorsteher Manevskij das rhetorische Argument der naturwissenschaftlichen Arbeit "für die Bedürfnisse der Volkswirtschaft und der Verteidigung des Landes« auf. ${ }^{279}$ Gleichzeitig ermahnte er den Museumsdirektor eindringlich, den »schwachen Bereich« des Museums, den er in der mageren Sammlung von Objekten mit "militärischem Verteidigungscharakter«sah, zu stärken und unverzüglich mit dieser Sammelarbeit zu beginnen. In Manevskijs Verständnis von kraevedenie hatten Militaria, als von Menschen gefertigte Produkte des regionalen Rohstoffreichtums, 
mehr Platz in der Ausstellung verdient als die von Gorochov bevorzugte naturwissenschaftliche Darstellung der Exploration und Dokumentation der regionalen Reichtümer.

Theoretisch wäre Gorochov bei der Suche nach Militaria nicht auf sich allein gestellt gewesen. Im Museumsarchiv ist eine Einladung von der »Gebietskommission zur Suche nach Materialien zum Großen Vaterländischen Krieg « überliefert. $^{280}$ Auch Gorochovs Argument, keine historisch ausgebildeten Mitarbeiter im Haus zu haben, wurde hinfällig, als ihm eine Kollegin aus dem Moskauer Revolutionsmuseum geschickt wurde, die nun das Sammeln der Exponate und die Ausstellungen zum »Großen Vaterländischen Krieg« übernehmen sollte. ${ }^{281}$ Jedoch berichtet Gorochov in seinem Rechenschaftsbericht für das Jahr 1943, dass die Kuratorin Tatjana Akinidova, die von der städtischen Bildungsbehörde nach kurzer Zeit für ihre Zwecke abgezogen wurde, kaum Materialien zum Krieg gesammelt habe und inzwischen nach Moskau zurückgekehrt sei. Den geforderten Ausstellungsplan zur Geschichte des »Großen Vaterländischen Krieges« habe sie auch nach mehrmaligen Nachfragen nicht eingereicht. Daraus zog Gorochov gegenüber dem Museumsinstitut den Schluss, dass die schlechten Arbeitsbedingungen und die niedrigen Löhne Bedingungen darstellten, unter denen erfahrene und gut ausgebildete Kollegen nicht arbeiten würden.

Die Ermahnung hatte dennoch Wirkung gezeigt. Im Arbeitsplan stand nun die »Suche nach Materialien zur Geschichte des Großen Vaterländischen Krieges« als dritte Kategorie neben der Suche nach mineralogischen und pflanzlichen Rohstoffen. Gorochov betonte die enge Zusammenarbeit mit der Gebietskommission zur Geschichte des »Großen Vaterländischen Kriegs«, die es ermöglicht hätte, Illustrationsmaterial zum Krieg zu sammeln. Darüber hinaus habe man eine Sammelanleitung an alle Kultureinrichtungen geschickt, die dem Museum Exponate zur Verfügung stellen sollten. In Anbetracht der Rüstungsproduktion, die die ganze Stadt dominierte, nahm sich das Argument der fehlenden Exponate allmählich etwas fragwürdig aus. Auch wenn Gorochov im Vergleich zu den Moskauer oder Minsker muzejščiki nicht an die Front fahren konnte, um Kriegsrelikte zu sammeln, so wäre es für ihn ein Leichtes gewesen, den Beitrag des Hinterlandes zur militärischen Verteidigung des Landes anhand der Panzer- und Waffenproduktion in seiner Stadt auszustellen.

Doch Gorochov betrachtete diesen Beitrag differenzierter. Er berichtete von seiner erfolgreichen Sammlungstätigkeit in den naturwissenschaftlichen Bereichen. Als Beleg für den Nutzen dieser Arbeit führte er jene zahlreichen Anfragen an, die das Museum erreichten. Neben den berühmten Forschungsinstitutionen, die eine wissenschaftliche Expertise verlangten, stärkte Gorochov sein Argument,

280 OGAČO, f. R-627, op. 3. d. 395, I. 73.

281 Ebd. I. 5-9. 
indem er Einzelpersonen nannte, die mit praktischen Alltagssorgen an das $\mathrm{Mu}$ seum herangetreten waren. Ihre Bitten um Rat zeugt von dem Mangel, den die Tscheljabinsker Bevölkerung im Krieg litt: Wie kann aus Pflanzen Tinte gewonnen werden? Kann man verfaulte Kartoffeln noch für die Gewinnung von Stärke verwenden? Wie lassen sich Streichhölzer selbst herstellen, und mit welcher Asche sollte Seife gekocht werden? Gleichzeitig sind die Anfragen ein Beleg dafür, dass die Tscheljabinsker Bevölkerung in dem geschlossenen Museum eine Anlaufstelle für ihre Alltagssorgen sahen und in den kraevedy Expertinnen und Experten für das Überleben in der Hungersnot an der Heimatfront des Krieges fanden. ${ }^{282}$

1943, als die Hungersnot im Ural ihren Höhepunkt erreichte, verstärkte Gorochov sein Hilfs- und Beratungsangebot nochmals. Im Vergleich zu anderen Regionen des Hinterlandes hatte der Ural die höchste Sterberate. Der lebensbedrohliche Nahrungsmittelmangel, der zu Krankheit und Tod führte, wurde durch das harte Klima und die unbeheizten Schlafräume und Produktionshallen der Fabriken, wo der Großteil der Stadtbevölkerung arbeitete, noch verschärft. Die Menschen mussten lange und kräftezehrende Distanzen zu Fuß überwinden, und die lokale Lebensmittelversorgung war aufgrund der vernachlässigten Landwirtschaft der Region extrem eingeschränkt. Hinzu kam die Arbeitslast von täglich 11-12 Stunden in den Rüstungsfabriken (ohne Ruhetage), die körperlich kaum zu bewältigen war. $^{283}$

In dieser angespannten Lage erreichten den Museumsdirektor Mahnungen des Moskauer Museumsinstitut, die auf die Erfüllung des politischen Bildungsauftrages drängten. Die immer noch nicht verwirklichte Ausstellung zum »Großen Vaterländischen Krieg« wurde in der Jahresbeurteilung als Beweis für die »schlecht entwickelte Arbeit« des Museums genannt. ${ }^{284}$ Die Museologen verstärkten den Druck, indem sie nach Objekten für die "Staatliche Liste« (gosudarstvennij učet) fragten. Das Tscheljabinsker Museum sollte erinnerungswürdige Objekte aus wertvollen Metallen und Objekte aus der archäologischen Sammlung auswählen, diese mit einer detaillierten Beschreibung versehen und nach Moskau schicken. ${ }^{285}$ Ohne Zugang zu seinen Sammlungen konnte der Direktor diesem Auftrag jedoch unmöglich nachkommen. Als Sammlungsleiter betrachtete er es als seine Pflicht, den Zustand der eingelagerten Objekte im Kirchenkeller regelmässig zu begutachten. Jedoch brauchte er eine offizielle Erlaubnis, um sein Museum zu besichtigen. Die

Ebd. I. 5-9.

Während laut der Statistik im Jahr 1940 3,5 Prozent der Personen an Hunger starben, ließen sich 1943 32.,3 Prozent der Todesfälle auf Mangelernährung zurückzuführen. Da keine Zahlen für die ländliche Bevölkerung erhoben wurden, gelten diese Angaben nur für die Stadt Tscheljabinsk. Vgl. Filtzer, Donald: Starvation Mortality, hier S. 271-274. 
Angestellten des NKVD gewährten ihm, wie er berichtete, nur mit "großem Unwillen« (bol'šoj neochotoj) Zugang. Gorochov musste feststellen, dass der Grund für dieses Verweigerung in der illegalen Bereicherung der Gäste lag: Sie hatten die Siegel an den Türen aufgebrochen, Vitrinen geöffnet und Gegenstände aus dem Museumseigentum entwendet. ${ }^{286}$

Unterstützung für sein spezifisches Mensch-Natur Verständnis fand Gorochov in verwandten Wissenschaftsbereichen. Im März 1944 wurde die erste »Geografische Gesellschaft des Tscheljabinsker Gebietes « gegründet und Gorochov präsentierte sich im Arbeitsbericht als Geburtshelfer dieser Institution: Da das Museum als eines der ersten die Relevanz der Erforschung von Ressourcen erkannt hätte, fiele ihm dank seiner großen Expertise und Erfahrung folgerichtig die Aufgabe zu, die junge Gesellschaft zu unterstützen, damit eine Symbiose entstünde, von der beide Institutionen profitieren könnten. ${ }^{287}$

Im Jahresbericht verknüpfte Gorochov seine Begeisterung für diese neue Kooperation mit einer Beschwerde über den »stark vernachlässigten Zustand «, in dem sich das Museum nach der Abreise des Geheimdienstes im August 1944 befände. Die Museumsexponate (historische Möbel, technische Geräte etc.) hätten aufgrund der Benutzung durch die Archivarinnen und Archivare große Schäden davongetragen hätten. Die Schilderungen sollten seinen Wünschen Nachdruck verleihen: Er beschrieb die Renovation des Gebäudes als oberste Priorität im Arbeitsplan und bat das Innenministerium, die Kosten zu übernehmen. ${ }^{288}$

Das Moskauer Museumsinstitut zeigte sich jedoch weder beeindruckt von der Beschwerde über das unrühmliche Verhalten der Angestellten des Innenministeriums noch honorierten die Verantwortlichen Gorochovs Unterstützung für die Geografische Gesellschaft. Diesmal ließen sie auch das Argument nicht gelten, dass der Direktor nicht über Ausstellungsfläche verfügte und forderten explizit Wanderausstellungen und die Suche nach Objekten zum Thema des »Großen Vaterländischen Krieges ${ }^{2}{ }^{289}$

Im Jahr des Sieges beschloss die Stadt das Gebäude erneut als regionalwissenschaftliches Museum zu nutzen. Als die Renovierungsarbeiten begannen, kündigte der Direktor die Planung der gewünschten Ausstellung mit dem Titel »Die Rolle Tscheljabinsks im Großen Vaterländischen Krieg« an. ${ }^{290}$ Im Zentrum seines Berichtes stand jedoch die »Erste Geografische Konferenz«, die im März 1945 in der Stadt stattfand und an der das Museum mit Vorträgen und Wanderausstellungen zum Thema »Nützliche Ausgrabungen im Tscheljabinsker Gebiet« und »Die Rolle

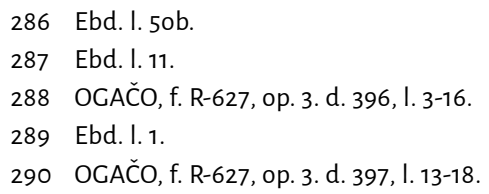


der kraevedy in der Geografischen Gesellschaft « teilnahm. Diesmal antwortete das Moskauer Institut auffallend direkt: »Der größte Fehler in der Arbeit des Museums im Jahre 1945 ist seine einseitige Ausrichtung; die ganze Museumsarbeit wurde auf die Erforschung der natürlichen Reichtümer der Region gerichtet.« Das Museumsinstitut forderte eine regionalwissenschaftliche Arbeit, die alle Bereiche in Betracht ziehen und sich insbesondere in einer Ausstellung zum »Großen Vaterländischen Krieg « niederschlagen sollte. ${ }^{291}$

Am Ende des Krieges verfügte das Tscheljabinsker Museum über eine lokalspezifische Sammlung mit natürlichen Ressourcen, die zentral für die Kriegserfahrung der Menschen im Süd-Ural waren. Das metallene Potential der Berge präsentierte die Voraussetzungen und den Vorzug der Region als Rüstungszentrum der Sowjetunion, die Tscheljabinsk zu Tankograd machte. Die gepressten Heilkräuter und essbaren Pflanzen in den Herbarien verwiesen auf die Maßnahmen, die die kraevedy ergriffen hatten, um der Hungersnot und der hohen Sterblichkeit entgegenzuwirken.

Die Grundlage für die möglicherweise überraschende Steine- und Kräutersammlung Gorochovs war seine Vorstellung von einer reziproken Beziehung zwischen den Menschen und der sie umgebenden Natur. Diese Geisteshaltung, die Respekt und Bewahrung gegenüber den natürlichen Ressourcen ausdrückt, scheint der unter Stalin dominierenden Vorstellung der Unterwerfung der Natur durch den omnipotenten neuen sowjetischen Menschen entgegenzustehen. ${ }^{292}$ Mit seiner Auffassung einer engen Verflechtung und Wechselbeziehung zwischen menschlicher Handlungsmacht und den naturgegebenen Bedingungen befand sich Ivan Gorochov jedoch weder in Opposition noch in Isolation $\mathrm{zu}$ den vorherrschenden Narrativen. Im Gegenteil, Forschungsansätze zeigen, dass der sowjetische und insbesondere der stalinistische Zugang zur Beziehung zwischen Mensch und Natur sehr viel komplexer war. Vertreterinnen und Vertreter der Umweltwissenschaften

Ebd. I. 1.

Die Forschung zur russischen Umweltgeschichte geht von der Vorstellung der erheblichen Konsequenzen aus, die die gewaltsamen Transformationsprozesse (Erschließungs- und Infrastrukturprozesse, der GuLag und der Krieg gegen die Bauernschaft) auf die Natur hatten. Dieser rücksichtslose Umgang gegenüber Menschen und Natur wird dabei jedoch nicht als russisch-sowjetischer Sonderweg beschrieben, sondern in einen internationalen Kontext des 20. Jahrhunderts gestellt, in welchem die Unterwerfung der Natur letztlich immer die Oberhand über die Vorsicht der Naturschützenden behielt. Unter Stalin jedoch habe dieser beinahe ausschließlich utilitaristisch geprägte Zugang aggressive und dominante Züge angenommen, die Umweltschutzprogramme verhinderten, da »Nature itself, in many ways, came to be viewed as an enemy to be subjugated to the positive forces of the Communist Party to reshape it in a socialist fashion«. Vgl. Josephson, Paul R. u.a.: An Environmental History of Russia, New York 2013. 
erkannten die Funktionsweise von Ökosystemen durchaus an - ohne die menschlichen Interessen den Bedürfnissen der Natur unterzuordnen. Museumssammlungen, und insbesondere diejenigen eines Museums der kraevedenie, zielen auf die Exploration, Dokumentation, Klassifizierung und Sammlung von regionalen Ressourcen zu Forschungs- und Anschauungszwecken. Auf der methodischen Ebene ist dieser Ansatz der Tscheljabinsker muzejščiki mit dem Aktivismus für den Aufbau von sogenannten zapovedniki (Naturschutzgebieten) verbunden. Auch hier musste ein Bewusstsein für die Endlichkeit von Ressourcen geschaffen werden, um ihre Bewahrung zu fördern. ${ }^{293}$ Der Geologe und Museumsdirektor war Teil einer Elite von nationalen und internationalen Wissenschaftlerinnen und Wissenschaftlern, die vom Einfluss der unbelebten Natur (wie zum Beispiel Mineralien) auf die Gestaltungskraft von Menschen überzeugt waren. ${ }^{294}$

Das »eigen-sinnige« Verhalten des Museumsdirektors war sowohl von individuellen und emotionalen als auch von rationalen Interessen geprägt. Dabei wurde er von seinem beruflichen Ethos einer vorstalinistischen Vorstellung von kraevedenie geleitet. Die Darstellung einer spezifischen Mensch-Natur-Beziehung im regionalgeschichtlichen Museum war sein persönliches, biografisch geprägtes und berufliches Ziel, während das Bemühen um materielle Mittel (eigenes Gebäude, mehr und besser bezahlte Planstellen) sachlichen und praktischen Motiven folgte. Dieses Verständnis schlug sich auch in der Ausstellung »Die Rolle Tscheljabinsks im Großen Vaterländischen Krieg« nieder, die Gorochov und sein Team im April 1946 im wiedereröffneten Museum zeigte.

293 In seiner wegweisenden Studie über den frühen sowjetischen Naturschutz zeigte Douglas Weiner anhand der Naturschutzgebiete, dass die Bolschewiki die Natur nicht in erster Linie unterwerfen, sondern schützen wollten. Vgl. Weiner, Douglas: Models of Nature, Ecology, Conservation, and Cultural Revolution in Soviet Russia, Bloomington, 2000 (2. Aufl.). Auch Stephen Brain bezeichnete unter dem Stichwort »Stalinist Environmentalism« die Praktik des gleichzeitigen Schützens und Ausbeutens des sowjetischen Waldbestandes. Vgl. Brain, Stephen: Song of the Forest, Russian Forestry and Stalinist Environmentalism, Pittsburgh 2011. Andy Bruno fasste diese scheinbaren Widersprüche zusammen und sprach von einem »hostile and at the same time holistic approach«, der sowohl zur Verbesserung der Cesellschaft als auch zum Wohl der Natur diente. Vgl. Bruno, Andy: The Nature of Soviet Power, An Artic Environmental History, Cambridge 2016, S. 11-12.

294 Frey, Felix/Hasselmann, Anne: Stones at War, The Chelyabinsk War Exhibition of 1946 and Soviet Environmental Thought, in: Environmental History, 26 (3) Juli 2021, S. 533-554. 


\section{Kapitelfazit}

Die Kriegserfahrungen der muzejščiki in Moskau, Minsk und Tscheljabinsk waren maßgeblich von ihrem Aufenthaltsort geprägt. Dementspechend waren auch die Sammlungsstrategien der Museumsmitarbeitenden ortsabhängig. Nur in Moskau konnte sich die Methode des "sammeln auf den heißen Spuren der Ereignisse« entwickeln. Hier hatten die muzejščiki im Gegensatz zu Minsk und Tscheljabinsk bereits ab Winter 1941/42 die Möglichkeit, an die Front zu fahren und potentielle Exponate zu sammeln.

Die Arbeitspraxis, die im Moskauer GIM ihren Ursprung hatte, läutete einen grundlegenden Wandel in der Arbeitsweise der muzejščiki ein, der für die museumshistorische Perspektive relevant ist. Das Vakuum, das die verspäteten und widersprüchlichen Instruktionen des Museumsinstitutes auslösten, schuf Platz für Initiative und innovative Arbeitsweisen der muzejščiki. Das historische Bewusstsein, das die Museumsmitarbeitenden qua ihres Berufes besaßen, führte zu der Erkenntnis, materielle Zeugen der Gegenwart bewahren zu müssen. Das Leben im Krieg beschleunigte die Zeit und schob Gegenwart, Zukunft und Vergangenheit wie in einem Kaleidoskop zusammen. Deswegen besaßen Objekte der Gegenwart, die am nächsten Tag bereits historisch sein konnten, eine lebendige Aussagekraft und wurden in den Worten des Historikers Nikolaj Korobkov zu »Bruchstücken der Wirklichkeit«. Die bereits historische Gegenwart einzufangen, das Erlebnis ohne spätere Verzerrungen und Verfälschungen zeigen zu können, darin lag der Anspruch der muzejščiki an ihre Sammlungsarbeit im Krieg. Die dokumentarische Arbeit führte zu einer Aufwertung von schriftlichen und mündlichen Quellen sowie Fotografien, die laut der Kuratorin Anna Zaks in ihrem Umfang einen Platz in der Sammlung einnahmen, den sie nie zuvor gehabt hatten. ${ }^{295}$ Dieses grundsätzlich andere Quellenverständnis das die Methode des »Sammelns auf den heißen Spuren der Ereignisse« hervorbrachte, führte zu neuen Quellengattungen wie Zeitzeugeninterviews.

Interessanterweise entwickelte sich das Sammlungsprofil entlang des Kriegsverlaufs. Die Auswahl der zukünftigen Materialien folgte chronologisch den Ereignissen an der Front und wurde, wie der Krieg selbst, immer umfassender. Es war sozusagen der Krieg, der die Sammlung hervorbrachte, und ein dynamisches Sammlungskonzept wurde deckungsgleich mit der Quellenauswahl. Diese spontane und ergebnisoffene Einstellung zur Sammlungsarbeit war eine grundsätzlich neue Erfahrung für die muzejščiki, die bislang im Voraus verfassten Plänen und thematischen Objektkategorien gefolgt waren. Rückblickend beschreiben die Mos- 
kauer muzejščiki diese Erfahrung als eine Bereicherung, von der ihre weitere Arbeit in hohem Maß profitiert habe. ${ }^{296}$

Die Erfahrung der Schlacht um Moskau löste den Impuls zum Sammeln von Dingen aus, die diese Erlebnisse fixierten. Das Sammlungsprofil zu den Ereignissen rund um die erste gewonnene Schlacht des Krieges wurde zur Vorlage für alle weiteren Kollektionen zu den relevanten Episoden des Deutsch-Sowjetischen Krieges und zur Grundlage der Sammlung »Großer Vaterländischer Krieg«.

Im besetzten Minsk war eine Sammelarbeit, wie sie von den Moskauer muzejščiki durchgeführt wurde, undenkbar. Die Minsker Museen waren geplündert und ihre Gebäude zerstört oder für Zwecke der Besatzungsbehörden entfremdet worden. Der überraschende Überfall und unerwartet schnelle Vorstoß der »Heeresgruppe Mitte hatte eine Evakuation der belarussischen Bevölkerung und Betriebe unmöglich gemacht. Um das Überleben zu sichern, mobilisierte das Zentralkomitee in Moskau den Widerstand des Volkes gegen die Besatzer. Ein geeignetes Mittel schien dem Ersten Sekretär Pantelejmon Ponomarenko die Arbeit der Historikerkommissionen zu sein, die im ganzen Land nach Materialien suchten, um den Krieg zu dokumentieren. Die Mitglieder der belarussischen Historikerkommission schien der gleiche Impetus wie die Moskauer muzejščiki anzutreiben, und sie bemühten sich, Objekte zu sammeln, die die Kriegserfahrung ihres Landes möglichst umfassend abbildeten. Dies führte zu einer Sammlung, die neben dem Widerstand auch das Leid der besetzten Bevölkerung dokumentierte.

Der Krieg verstärkte das Bewusstsein um die Vergänglichkeit der Dinge und verlieh der Bewahrungsfunktion der muzejščiki politische Relevanz und Dringlichkeit. Die Sorge vor der unwiederbringlichen Zerstörung der eigenen Kultur muss die Kommission in besonders großem Ausmaß ergriffen haben. Sie führte dazu, dass sie neben Objekten mit direktem Kriegs- bzw. Besatzungsbezug Materialien zu Kultur, Tradition und Geschichte sammelte. Die Objekte der Ausstellung »Belarus lebt, Belarus kämpft ...« im GIM zeigen die individuelle Prägung ihrer Sammler, die als Schriftsteller und Journalisten ein eigenes Bewusstsein für die Spezifik ihrer Region hatten. Trotz der im Vergleich sehr viel schwierigeren Sammlungsbedingungen in dem besetzten Land, führte die Kommissionsarbeit $\mathrm{zu}$ einer musealen Kriegskollektion. Als sich im Sommer 1943 die Befreiung der sowjetischen Republik durch die Rote Armee abzeichnete, beschloss Ponomarenko die Überführung der Kommissionssammlung in die Gründung eines neuen Museums. Auch wenn es Ponomarenko in erster Linie um eine Musealisierung des von ihm geleiteten Partisanenkampfes ging und die von der Kommission gesammelten Zeugen des Leides, des Holocausts, der Kollaboration und dem Kulturleben nur Begleitmaterialien waren, so hatte er doch den historischen Wert dieser Kriegssammlung erkannt. Die 
Qualität lag, ähnlich wie in der Moskauer Museumssammlung, in der Aktualität und der damit verbundenen eindringlichen Aussagekraft.

An der Tscheljabinsker Heimatfront bestimmte das Profil des Museums die Sammlung im Krieg. Das Narkompros stellte einen anders gewichteten Sammlungsauftrag an die regionalwissenschaftlichen Museen des Hinterlandes. Die Aufforderung, lokale Ressourcen, Heilkräuter und nahrungsergänzende Pflanzen zu sammeln, traf auf das spezifische Mensch-Natur-Verständnis des Tscheljabinsker Museumsdirektors. So entstand im Süd-Ural eine Kriegssammlung eigener Art, die aber ebenso wie in Moskau und Minsk das Kriegserlebnis der lokalen Bevölkerung spiegelte. Die gesammelten Mineralien standen für das Potential der Region als metallverarbeitende Waffenschmiede und die Heilkräuter und essbaren Pflanzen für die Hungersnot und die hohe Sterblichkeit, die das Tscheljabinsker Gebiet im »Großen Vaterländischen Krieg« traf.

In der Kommunikation zwischen dem kraeved Gorochov und dem Moskauer Museumsinstitut ist die Diskrepanz zwischen der Schwerpunktsetzung des Regionalwissenschaftlers und dem Anspruch der Museologinnen und Museologen auf eine >klassische< Museumssammlung zum »Großen Vaterländischen Krieg« fassbar. Der Umgang mit dieser Spannung lässt sich anhand der Konzepte »EigenSinn« und »Herrschaft als soziale Praxis« greifen. Zur Erklärung des auf den ersten Blick rätselhaft erscheinenden Verhaltens des Museumsdirektors hat sich das Zusammendenken dieser zwei Ansätze bewährt. Der Vorteil »eigen-sinniges« Verhalten nicht als Widerstand zu betrachten, sondern als Möglichkeit der Akteure, den Herrschaftsvorgaben (zusätzlichen) Sinn zu verleihen, konnte für das Handeln Ivan Gorochovs fruchtbar gemacht werden. Am Beispiel des Museumsdirektors zeigt sich die dem Konzept inhärente Auffassung eines polyvalenten Verhaltens: In bestimmten Situationen reproduzierte er herrschaftskonforme Handlungsweisen, in anderen stellte er die Herrschaft in Frage. Diese Sichtweise bewahrt uns davor, den »Eigen-Sinn « der Herrschaft gegenüberzustellen. So kann eine romantisierende Analyse der Akteure »von unten«, die überall »eigen-sinniges «Verhalten feststellt und dies zum Beleg für allgemeinen Widerstand und Regimeferne verklärt, vermieden werden.

Während Ivan Gorochovs Sammlungstätigkeit einerseits den Anforderungen des Narkompros entsprach, entzog er sich ihnen gleichzeitig und unterlief durch eigenmächtiges Handeln den Herrschaftsanspruch der Behörden. Dieses Lavieren erlaubte $\mathrm{ihm}$, verschiedene »eigen-sinnige« Motivationen und Zielsetzungen zu verfolgen, die nur zum Teil eine Schnittmenge mit den Erwartungen des $\mathrm{Mu}-$ seumsinstitutes aufwiesen. Neben der Priorität, sein Museum und die Sammlung vor der endgültigen Beschlagnahmung durch die Behörden zu retten, versuchte der Direktor, seine Vorstellungen einer reziproken Natur-Mensch-Beziehung in der Erforschung der Geologie und der Pflanzenwelt des Süd-Urals umzusetzen. 
Es scheint, als hätten die Folgen des Krieges, die Beschlagnahmung seines Gebäudes und die Hungersnot im Tscheljabinsker Gebiet Ivan Gorochov Argumente in die Hände gespielt, um deutlich weniger ideologisch geprägte (Kriegs-)Ausstellungen einzurichten und dafür, wie zur Gründungszeit des Museums, als regionales Forschungszentrum die Flora bzw. die Mineralien und Fossilien des Süd-Urals erforschen und diese Erkenntnisse vermitteln zu können. Indem Gorochov diese Arbeit als ökonomische und gleichzeitig strategische Hilfe für Front und Hinterland deklarierte, gelang es ihm, eine Kriegssammlung anzulegen, die von dem anders gewichteten Verständnis der kraevedenie geprägt war. Am Ende des Krieges hatte Gorochov nicht nur die Wiedereröffnung seines Museums erreicht, sondern auch eine für die Region spezifische Kriegskollektion angelegt. Das Museum verfügte über Herbarien, die die Heilkraft und den Vitamingenhalt von Pflanzen und Kräutern erläuterten, und über eine Sammlung von Mineralien, deren Erforschung militärstrategische Vorteile versprach. Mit dem Fokus auf die Wirkkraft der natürlichen Ressourcen des Tscheljabinsker Gebietes hatte der Museumsdirektor materielle Erinnerungen an eine Kriegsepisode bewahrt, die in der Regel von der Akzentuierung ihrer heldenhaften Verarbeitung zu Waffen durch die sowjetischen Arbeiterinnen und Arbeiter verdrängt wurde.

Unter dem Prisma der Sammeltätigkeit wurden verschiedene relevante Aspekte der Museumsarbeit im Krieg deutlich. Unabhängig vom Standort der $\mathrm{Mu}$ seen zeigten sich Leerstellen und Widersprüche zwischen den Anordnungen des Museumsinstitutes und der Kriegsrealität. Während in Moskau trotz anhaltender Bombardierung eine »antifaschistische Ausstellung « errichtet wurde, formulierte die belarussische Historikerkommission einen Sammelauftrag, der in einem vom Feind besetzten Land unmöglich ausgeführt werden konnte. In Tscheljabinsk beanspruchte das Kommissariat für Inneres die einzige Institution, die durch Ausstellungen zur geistigen Mobilisierung im Hinterland hätte beitragen können. Diese Diskrepanzen zwischen offiziellen Forderungen und realer sowjetischer Lebenswelt wurden durch den Ausnahmezustand des Krieges verstärkt und eröffneten den muzejščiki Handlungsfreiräumen zur Selbstermächtigung. Als Beispiel für diese neuen Sagbarkeitsräume und als Argument für das durch den Krieg erstarkte historische Bewusstsein stehen ihre Rhetorik und ihre Arbeitspraxis, mit der sie die Behörden von den eigenen Vorstellungen und Zielen $\mathrm{zu}$ überzeugen versuchten. Vorrevolutionäre Arbeitsweisen wurden als vorbildhafte Handlungsanweisungen präsentiert. Die muzejščiki konfrontierten das Narkompros und die GlavPURKKA mit ihrer eigenen Unzulänglichkeit, ja betonten diese, um staatliche Unterstützung für ihr Handeln zu erhalten. Diese Verhaltensweise zeugt von mutiger Klarheit in Zeiten knapper Ressourcen. Der Direktor des Leningrader Artilleriemuseums zitierte als Beleg sogar den schlechten Ausbildungsstand der Roten Armee, dem nur mit einer anschaulichen Museumssammlung zu den Kriegsereignissen abgeholfen werden könnte. Das Museumsinstitut wiederum reagierte mit Verspätung auf 
die Forderungen der muzejščiki und veröffentlichte oberflächliche Handbücher zum Sammeln von Materialien zum »Großen Vaterländischen Krieg«.

Die im Krieg entwickelte Arbeitsmethode des Sammelns von Objekten, die die Gegenwart spiegeln, wirkte sich auf die Entwicklung des sowjetische Museumswesen aus. Aus der Retrospektive kommen die Moskauer Museumsarbeitenden zu dem Schluss, dass die Erfahrung der Arbeitsweisen im Krieg zu Innovationen ihrer museologischen Praxis geführt hätten. Der neue Typus von Gegenwartsausstellungen erforderte eine neue Sammlungstechnik. Das Sammeln von Exponaten der Gegenwart hatte die wissenschaftlichen Methoden der sowjetischen Museologie vorangetrieben. Im Gegensatz zur Sammlungstätigkeit in der Vorkriegszeit, als die Exponate zur vorrevolutionären Geschichte Russlands vereinzelt und in der Regel zufällig in den Museumsbestand gelangten, erforderte das Sammeln von Objekten zum gegenwärtigen Krieg ein Bewusstsein für Systematik schon bei der Auswahl. $^{297}$

Heute werden die im Krieg entstandenen Kollektionen »Goldene Sammlungen« genannt und zu den wertvollsten der drei Häuser gezählt. Im Museum der Vereinigten Streitkräfte der Russländischen Föderation in Moskau werden beispielsweise bis heute die deutschen Verdienstkreuze für die Eroberung Moskaus gemeinsam mit der »Fahne des Sieges« als zentrale Inszenierung im sogenannten »Saal des Sieges « ausgestellt. ${ }^{298}$ Die belarussischen »Partisanen-Almanache« gelten als besondere Rarität der musealen Kriegsexponate, die als Minsker Aushängeschild bei internationalen Fachtagungen präsentiert werden. ${ }^{299}$ Die Herbarien aus dem Tscheljabinsker Museum, die an die Hungersnot der Bevölkerung im Süd-Ural erinnern, sind allerdings nicht überliefert. Offenbar wurde ihnen kein herausragender Erinnerungswert zugesprochen. Die Mineralien hingegen nehmen nach wie vor einen prominenten Platz im Tscheljabinsker Historischen Museum ein.

297 Levykin, Konstantin: Vvedenie, S. 3-7.

298 Vgl. Saal Nr. 18, in: www.cmaf.ru/ekspo/inside/129 (Stand: 31.07.2021).

299 Vgl. Vortrag von Galina Skorinko, Sammlungsleiterin des Minsker Museum der Ceschichte des Großen Vaterländischen Krieges »Kollekcija partizanskich rukopisnych žurnalov Belorusskogo gosudarstvennogo muzeja istorii Velikoj Otečestvennoj vojny« an der Konferenz »Meždunarodnoj naučno-praktičeskoj konferencii, posvjaščennoj 70-letiju Velikoj Pobedy, Muzejnye i archivnye kollekcii ob istorii Velikoj Otečestvennoj vojny 1941-1945 im Museum der Vereinigten Streitkräfte der Russländischen Föderation, Moskau, 26. Mai 2015. 
